QL

713.2

. $\mathrm{H} 46$

1900

KELL

\title{
ERNST HENTSCHEL
}

\section{DIE MEERESSAUGETIERE}







\section{DieMeeresfängeliere Von DrL.Hent/chel}

QL

713.2

. $\mathrm{H} 46$

1900

KELL

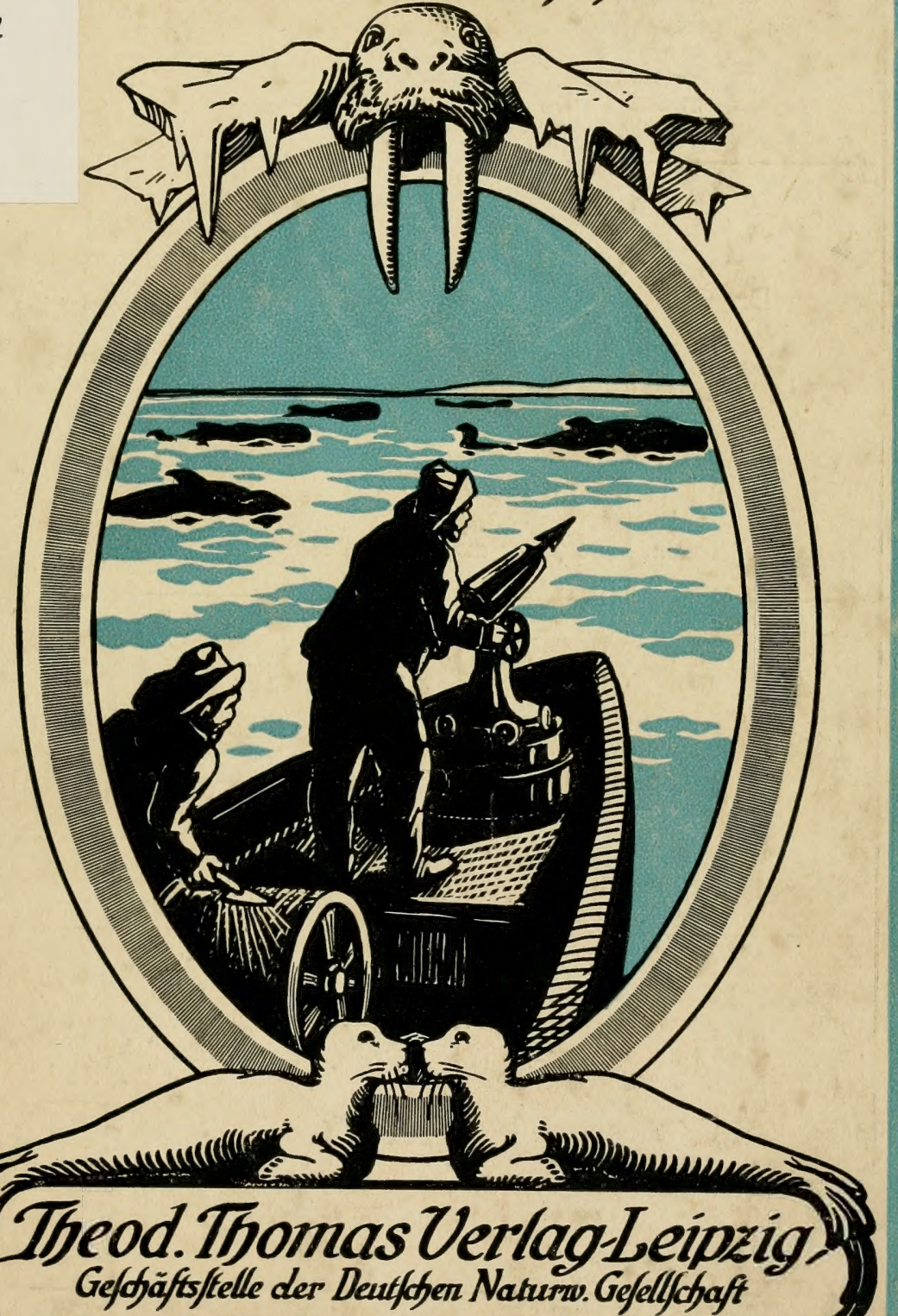




\section{0)Moal 12 II o1}

\section{Ratur}
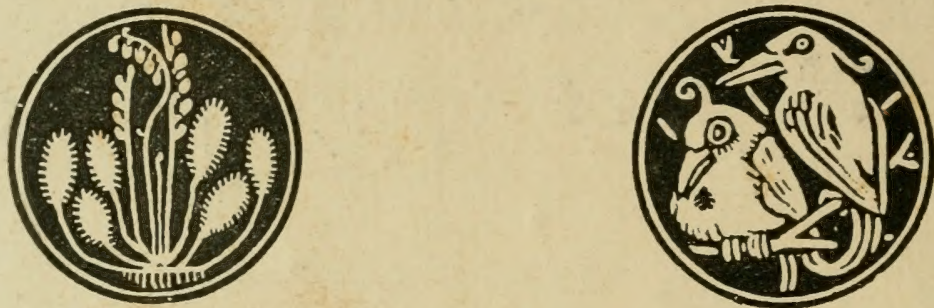

Salbmonatsfdrift für alle Paturfreunde

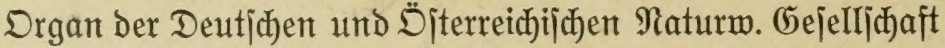
Serausgeber: Dr. Ileinty. $\quad$ Begründer: $\mathfrak{A}$. 5. Frranté.

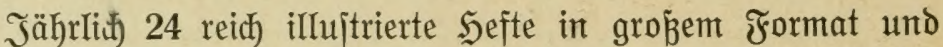
5 mertvolle mit vielen interejianten Bildern gejchmücte $\mathfrak{B}$ üc)er hervorragender naturw. Echriftiteller.

\section{Sierteljährlið mur 1 Marf 50 Pjennige.}

Die Büder werden auf $\mathfrak{B u r i d}$ gebunden geliefert gegen 3uzahlung von 40 Pfentig für jeden Einband.

\section{Jeder Arboment Der , $\mathfrak{A}$ atur"}

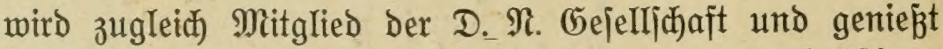

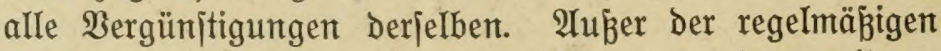
3ahlung obigen Betrages erwadjen ifm feine weiteren Berpflidftungen.

Áusführlide Pro|pefte bitte zu verlangen Bejtellungen Dura) jede Bu(b)andung

Theod. Ifomas Berlag in Leipzig 


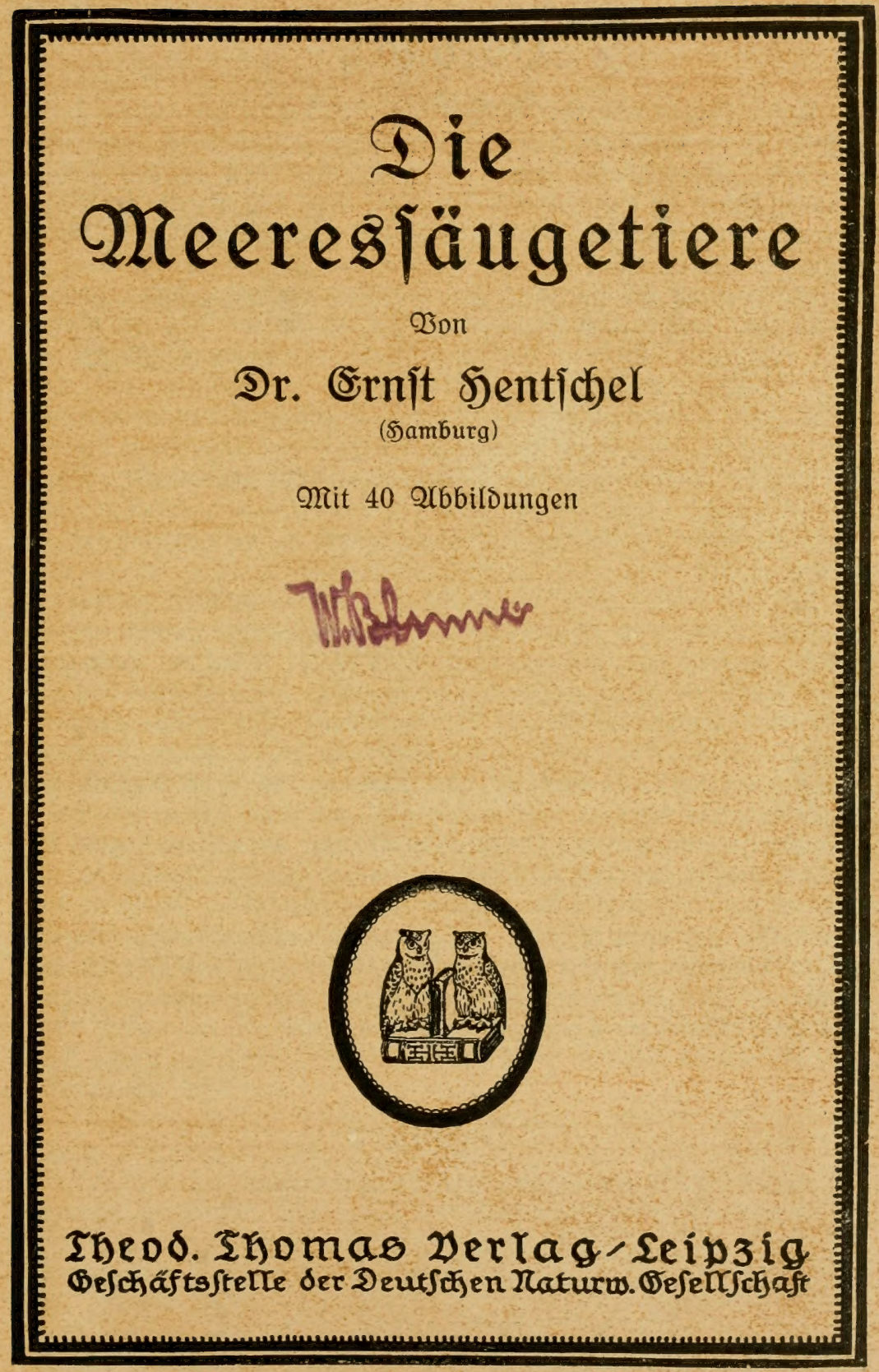




\section{Dormort.}

Unjer Wiffen won den Säugern der See hat in den leģten Jaḩr=

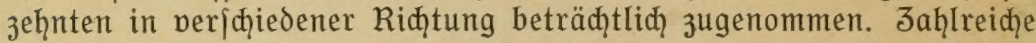
ozeanifḩe Expeditionen, fowie die forjhungsreijen in den polar= gebieten ḩaben die Kenntnis der Arten und iḩrer Lebensmeife gefördert. Das neue Aufblühen des Walfifd̨fangs ḩat reiḑe đelegenḩeit 3 u Beob= adthtungen am lebenden wie am toten एiere geboten. (Es hat aud zu einer genaueren Bekanntjḩaft mit ber Walindujtrie gefüḩrt. Anato=

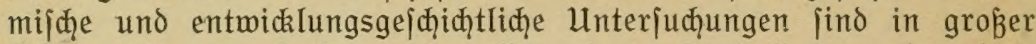
3ahi erjhienen. Aud manḑe allgemeinere Darjtellungen, bejonders über die Wale, wurden veröffentlid̨̧t.

So jteht das (bejamtbild diejer eigenartigen, jđ̧wer zu itudierenden एiergemeinjąaft heute um vieles klarer $\delta a$, als vor etwa einem Diertel= jaḩrḩundert. Dieles bleibt allerdings nod unjiḑer, manđ̧es in völliges Dunkel gehüllt. Immerhin mag es von Intereffe jein, eine kurze zu= jammenfajpende Darjtellung des (begenjtandes zu bejigen, wie iđh fie hier darbiete.

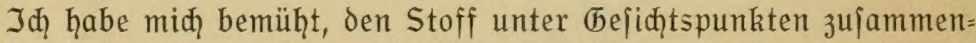
zufajien, welḑe den hauptriḑtungen des Interefies an dem eigen= artigen (begenitande entiprechen. Es liegt in der Katur der Sache, daßz eines dabei eine hervorragende und geradezu beherriđgende Stellung einmehmen muß̧te: der Begriff der Anpajfung. Die neuejte Entwick= lung der Biologie hat uns dahin geführt, mit diejem worte jehr vor= jiđ̧̣tig umzugehen. Es fḑeint an die Stelle der früh̨eren Dorliebe für Anpaffungserjheimungen bei vielen Biologen eine Scheu vor ihrem Studium getreten zu jein. Während man lange mit diejem Begriff die größten Rätjel des Eebens löjen zu können glaubte, fhyeint es, als wäre es nunmehr jelbit zum größzten Rätjel geworden. Iđ hoffe, daß̧ es mir hier gelungen ijt, einen gangbaren Mittelweg zwijhen phanta=

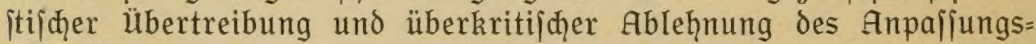
gedankens zu finden, einen $\mathfrak{D e g}$, auf dem er als brauđ̧barer führer zum Deritändnis der Seẹäugetiere dienen kann.

E. Ģentid̨el.

\section{Inḩalt.}

1. Kapitel. Die Meeresjäugetiere und iłre Derbreitung. . . . . . . 5

2. Kapitel. Körperbau und Anpaffungen ............ 23

3. Kapitel. Die Eebensweife . . . . . . . . . . . . . 45

4. Kapitel. Dorgejđiđhte der Seejäugetiere .......... 66

5. Kapitel. Die Seejäugetiere und der Menią......... . 77

Alle Ređ̆te, insbejondere das der überjęung, vorbeḩalten. 


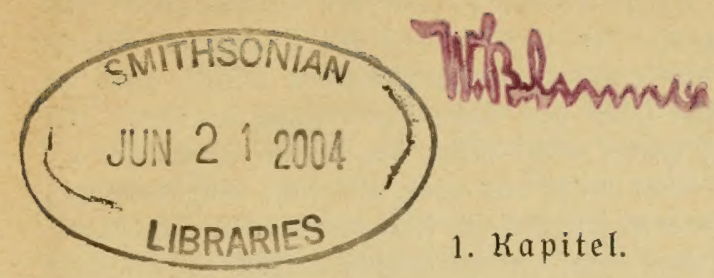

\section{Die Meeres|äugetiere und į̣re Derbreitung.}

Alljäḩrliđ menn der früḩling kommt und der Wind nođ kalt iiber das normegifhe Nordmeer bläjt, riđ̧ten die fangsleute ihre Sdyoner her für die faḩrt ins Eismeer. Der lange Winter ijt vorüber, oie Sonne ftrahlt über dem weiten Meer, aber hebel umlagern die dunklen Dorgebirge. Eangjam zieht ein Schiff naç dem andern zum fjord hinaus auf monatelange faḩrt. Scharf bläjt der wind in die braunet Segel. Der Steuermann zieḩt fid̨ die Kappe über sie Dhren und itampft fröjtelnd mit jeinen jhberen Stiefeln das najje Derdeck. Unter dem Segel hin jḩaut er aus nađ̆ der klaren Sinie, die por iḩm das Meer begrenzt. Die fangsleute jigen im engen Sdiffsraum zuammen, rauçend, Karten ipielend und von dem fange redend, den fie madhen mollen. So geḩt es lange cage fort, in denen nur der Auf = und riedergang der Sonne und der Dechjel des Wetters einige Deränderung bringt, bis endlid eines tages ein Mann aus der Tonne hod am Maitbaum ruft: Das Eis ijt da!

Da oben im Reiḑe des ewigen Winters, wo die Kälte, der Kebel, die öbe des Meeres und die Starrheit der endlojen flächen von überịnneitem Eije allem Eebendigen drohend entgegenzuitehen iđ̧einen, hat mit dem eriten frühling ein reiḑes Eeben begonnen. Die nor= megifḑen Sdifffe fahren auf die Robbenjagd, denn das Eismeer ift das Kauptgebiet für das Eeben der Seeḩunde. Ebenjo zogen vor Jaḩr= ḩunderten alljommerliđ viele Sçiffe aus den nordeuropäijđ̆en ந̨äfen bort hinauf, um Walfifhe zu fangen, und darum denken wir Europäer noç immer zunädjit an das Eismeer, wenn von den Säugetieren des Meeres die Rede ijt.

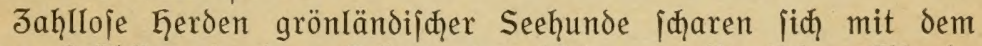
eriten frühlling in dem Gebiete des kleinen vulkanifhen Eilands Jan Mąen zujammen, um auf dem nod fejtliegenden packeije ihre Jungen $z^{u}$ werfen. Das weike, feinwollige fell diejer jungen See= hunde ijt es, um deffentwillen die Robbeniḑläger johon fo früh im Jaḩre iḩre kleinen Ķoļhäujer am itillen, feljenumitarrten fjord, iḩre bunten Dörfer, über denen hod oben die Sd̨neegipfel itraḩlen, verlaffen und auf das Meer hinausfahren. Dies weite, öde, bleigraue

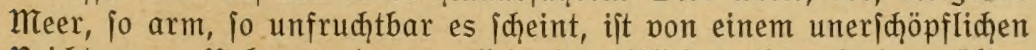
Reiđ̧tum an Kaḩrung, der es allein begreifliđ mađ̧t, wie fo unüber. 
jehbare Mengen grober Säugetiere dort allen den verniḑtenden (be= malten wideriteḩen mögen. Der grönländijøe Seehund (Phoca groenlandica), ein 『ier von etwa anderthalb Metern Eänge, wird im erwadjenen 3ujtande leiđht jelbjt auf weite Entfernung erkannt. Die alten Seeḩunde ( $\mathrm{Abb}$. 1) haben niđht mehr das meiß̧e Wollkleid der

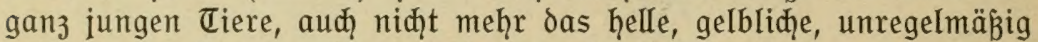

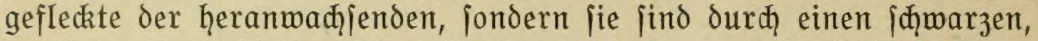
maskenartigen fleck auf dem Kopf und durch eine auffallende idimarze figur auf dem Rücken ausgezeiḑnet. Dieje figur ijt etma länglich hufeijenförmig, allerdings jehr unregelmäßig geitaltet, und hat der Grt zu ihrem zweiten, jehr zutreffenden Tamen Sattelrobbe ver= holfen. Dies ijt die häufigite und verbreitetite Art von den Robben, die dort im fernen Korden ihr jeltiames Eeben führen. Aud im Sommer, menn die groken Sdqaren fich wieder über das nunmehr aufgegangene und ins Treiben gekommene $\mathbb{E}$ is zerjtreuen, werden fie nod) mit der Büđjie gejagt; die Shiffe bleiben monatelang oraußzen, um eine volle sadung zu bekommen. Aber man erlegt dann auch alle andern Arten der "flofienfü̈ßer" (Pinnipedia), die dort leben, und von denen bejonders now drei eḑte Seehunde (Phocidae) vorkommen. 3u diejen gejellt jich aber ferner das für den fangsmann jo mertbolle Walroß̧, das eine jelbjtändige Stellung (Trichechidae) jenen entfernten Derwandten gegenüber einnimmt.

Imt "Weiteife", das öptliđ von (brönland liegt und durd einen verhältnismäß̧ig eisfreien 3mijhenraum an der weitjeite Spibbergens von dem "Diteife" getrennt wird, jieht man im Sommer häufig die KIappmüge (Cystophora cristata) (Abb. 1). Das ijt ein merkwüroiges Tier, deffen auffallendite Eigenichaft allerdings nur beim erwadjenen männḑen zu beobaḑ̧ten ift. Das đier ḩat eine Müḩe auf, die es zmar gemöhnlið in ziemlich unaufälliger Weije zujammenklappt, menn es aber erregt iit, jo dehnt fich dieje nü̈ge über dem Dorder= kopfe mäळhtig aus und gibt der Art ein jeḩr frembartiges Ausjehen. Dieje "Müge", der das Tier feinen Namen perdankt, ijt mun eigentlid, mit niđ̧ts anderem zu vergleiḑen, als mit einem Rüfjel, wie er bei anderen Säugetieren vorkommt und aud bei einer Robbe, dem loge= nannten See=Elefanten, deutlid, ausgebildet iit. Das fell ïber der Taje ift in hohem Grade deḩnbar. Da die rajenlödher der Robben

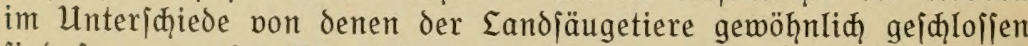

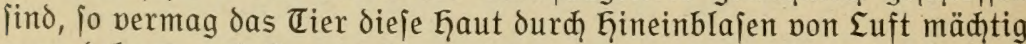
auszudehnen und kommt jo zu jeiner wunderIichen Müge. übrigens

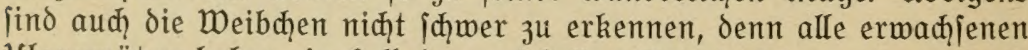
Klappmüzen haben ein fell, das auf hellem (brunde jehr groß̧e unregel= mäß̧ige flecken trägt. Dieje flecken machen das Tier bejonders jđ̆ön bunt. für die Unteriheioung junger Robbenfelle bedarf es einer groß̉en Erfahrung und übung. färbung und Jeiḑnung find oft jeḩr unbejtimmt und von Tier zu Tier jeḩr veränderlich. Will man die jungen Robben fiḑer erkennen, fo wird man weniger auf die fär= 
bung, mehr auf die 3ähnne, iḩre 3aḩl, Gejtalt und Stellung, fomie auf die (beitalt und Stärke der Sd̨nurrbartḩaare ađ̧tzugeben ḩaben.

Das "Diteis" zwijhen Spibbergen, franz= Jolefs=\{and, Kowaja Semlja und der nordeuropäijß̨en Küjte beherbergt vorwiegend die größzte der arktifhen Robben, die "Storkobbe" (großze Robbe) der Kormeger, die eine Eänge von nahezu drei Metern erreiđht. Das Tier wird im Deutiden Bartrobbe (Phoca barbata) genannt, weil es cinen mäd)= tigen Sdhurrbart itarker, iteifer Boriten auf der Dberlippe trägt. Seine färbung iit ziemlią eintönig. Und dann wäre, um die Reihe der eḑten Robben der Arktis abzuld̨liézen, als vierte nod die

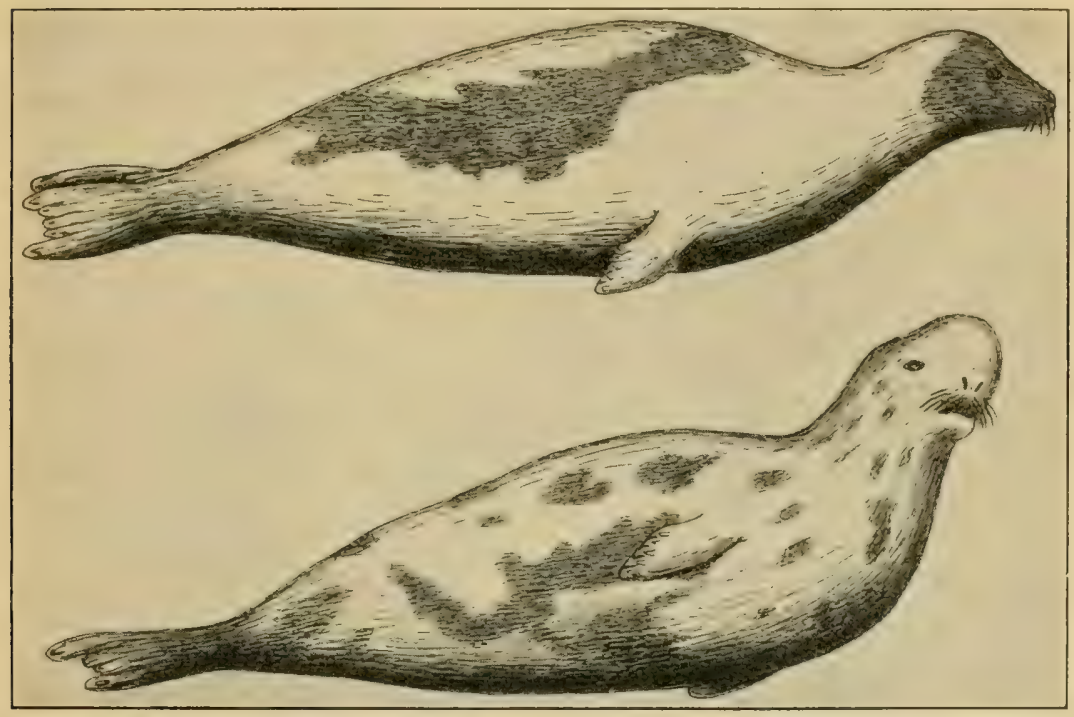

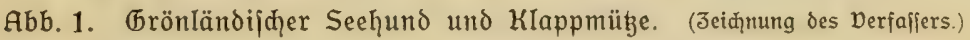

Ringelrobbe (Phoca foetida) zu nennen, die überall im Eismeer vorkommt und oft in kleinen (bejelliḑaften lebhaft iḑwimmend, den Dberkörper häufig meit aus dem Waffer hebend, das Auge crfreut. Bei diejer art ändert die färbung des felles jeḩr $a b$, jo daß̧ jie oft [đhwer daran zu erkennen ift, dođ zeigt fie gewöhnlid ringförmige flecken über den Rüken zeritreut. Don den genannten Tieren ift jie das einzige, welḑes auch in den deutjhen Meeren noch als ftändiger Bewohner zu finden ijt, obwohl ihre eigentlid̨e heimat das Eismeer fein dürfte. Don den andern drei Arten ift wohl nur die Sattelrobbe manḑmal an uniere Küjten veriḑlagen morden.

VTur in entlegenen Teilen des Eismeeres und meijt in der Kähe des Eandes über flaḑem Waffer kommt das walrob (Trichechus rosmarus) vor. An den nordjibirif̧en Küften und nördidy der Berings= 
ftrage iłt es nod? häufig. Im curopäifden Eismeer muß man es in den unzugänglidfiten Teilen Spifbergens oder weit hinauf an den cisumitarten felfenliuifen (bitgrönlanos, in der groken, itillen (blet= fhermelt non franz= Jofefs=Sand und beim nöroliḑen Momaja Semlja

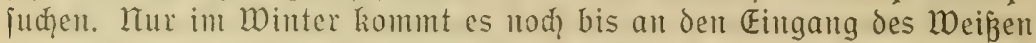
meeres im nördid̨̧en Ruß̧land. Dies riejige đier erreiḑt cine Sänge volt $6 \mathrm{~m}$ und ein gemaltiges (bemicht. Allerdings beruhen die Angaben über bas (bemiḑt oft auf Sḑäţungen von Jägern, die zuwailen jtark übertrieben find, aber man hat dod, Walroffe gemogen, die 1200 bis $1500 \mathrm{k}$;quer maren. Bekanntlich ift das Walroß por allen anderen Mceresfäugetieren durç feine beiden mäd)tigen hauer (Abb. 29) ausgezeidhnet, die bis $60 \mathrm{~cm}$ lang werden können. Es weiḍt ferner von der editer Robben (Seehunden) dadurch ab, daf es imitande iit, die floffenartigen Ginterbeine beim Siłzen auf dem (Eije rad porn unter den Eeib 3u iđ̧lagen, eine Eigentümliḑ̧eit, die es mit den (1) hirenrobben ("Sechären" und "Seclöwen“) gemein hat.

Sollten dic Meeresfäugetiere der Arktis hier vollitändig aufgezählt merden, fo miißste id nod cinige Wale, bejonders den (brönlandmal, den ITarwal und den weipmal nemen. Es mag jedod zunähjt die Derbreitung jencr Ģauptgruppe arktijher Secjäugetiere, der Seehunde, über die meere der ganzen Erde meiter verfolgt werden. Die vier genanten Robbenarten oringen vom Eismeer aus mur wenig naw Sübert. liur dic Ringelrobbe kommt, wie gejagt, in unjern heimijacn

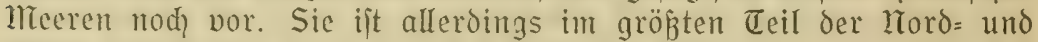
(Ditjee niḑt häufig, wird aber in der öptliḑen (1)itjea zur vorherriḑenden Art. Dou dem gemöhnliḑen Seehund (Phoca vitulina) unjerer meere ift fie, menn man dic Tiere flüß̨tig fḑwimmend oder auf dem Strande ruhend fieht, kaum zu unterjheiden, falls das fell niḩt die ausge= fproḑene Ringzeidhung hat. Denn unfer Seehund hat keine auf= fallenden äukeren nerkmale der (5ejtalt oder farbe. Eeiḑter zu crkenten ift die dritte Art, die fid, mit diejen bei uns vergejellidgaftet, die Kegelrobbe (Halichoerus grypus), da iḩ Kopf mit feinem längcren Sḑnauzenteil von den Rundröpfen der phoca=Arten weientliḑ abmeicht (Abb. 2 und 5). Sie foll in der (begens von Rügen newöhn= liderer fein als der "gemeine" Sechund; im ganzen kommt fie fonjt feltener vor.

Seḩr merkwïrdig ift es, daß̧ ein par Robbenarten aud tie im Intern des groken curopäijh=ajiatijhen fejtlandes gefunden werden, nämlid) im Baikallee (Phoca sibirica) und im Kaipifhen Meere (Phoca caspica). Die Erklärung für dieje fonderbare Erjheinung liegt für dic kafpifde Robbe woḩ darin, daß diejes Binnertmeer in lange vergangener Jeit durd flüfe und Seen mit dem Eismeer in Derbindung gejtanden hat. Aut ber Baikaljee it als Reit einer früher viel aus= gedehnteren Wafjermaffe 311 betrahten. Die in ihm Iebenden Seehunde ingeinen ebenfalls dem nördliḑen Eismeer zu entitammen, aus dem fie vielleiḑt durd die flüffe in das Binnenland eingemandert find. 
Die drei Seehundsarten der deutichen Meere gehen an den euro= päif)en Küjten mehr oder meniger meit hinab, verfdqwinden aber in den wärmeren (bewäffern ganj. An ihre Stelle treten bier als füblidfite Seeḩunde der nördliđ̧en halbkugel die jogenanmen mönḑs=
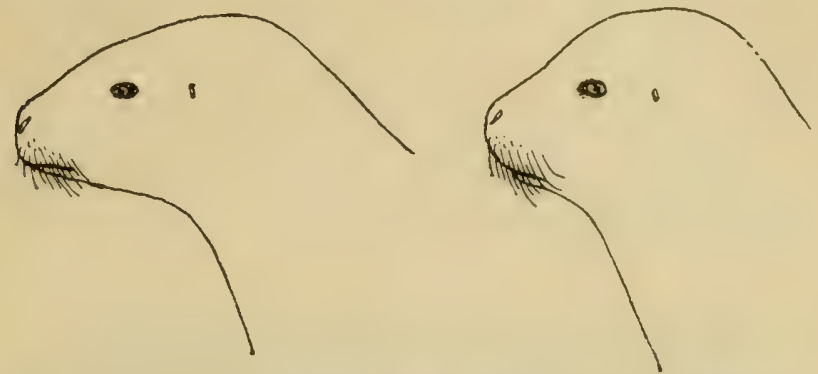

Abb. 2. Köpfe der Kegelrobbe und des (bemeinen Serhumos.

(3eiḑ̧nung des Derfajiers.)

robben (Monachus). Bei Europa kommen jie befonders im Mittel= meer vor, von dem aus fie nad Diten bis ins Sdqwarze Meer hinein, nad, Weiten bis Madeira und zu den Kanarifden Injeln gefunden

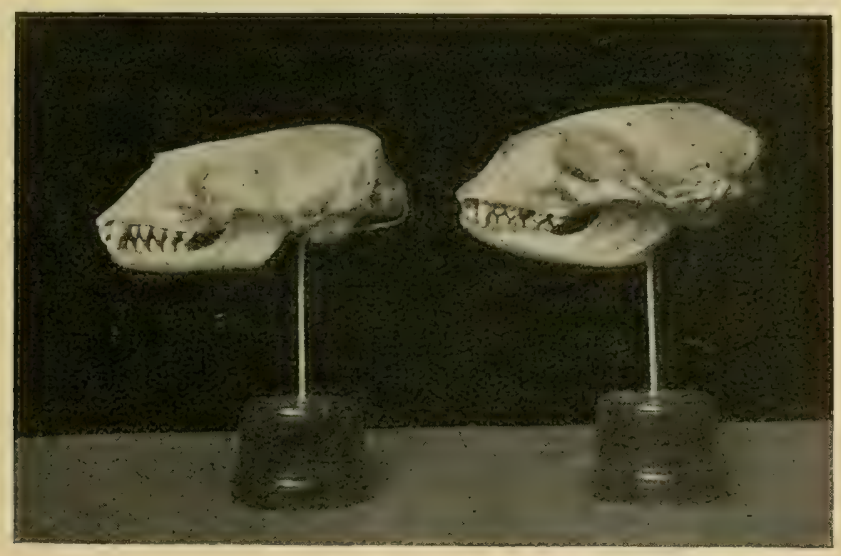

Аbb. 3. Sđุädel der Kegelrobbe und des (6emeinen Seehunds. (Aufnaḩme des Derfaffers.)

merden, übrigens bei weitem niđ̧t fo häufig, wie man das von nordi= idjen Robben gewohnt ijt. Fine nahe verwandte form lebt in cinem kleinen Teil wejtindiens. Und dann gibt es merkwürdigermeife nod? eine ntöndsrobbe weit entfernt von diejen plägen mitten im Stillen (1) zean bei der Injel Eanjan. (beht man im Atlantijd̨en (1) zean über die genannten Gebiete hinaus nod̨ weiter nad Süben, jo fehlen auf 
cine weite Strecke die echten Seeḩunde und die flofienfüper über= haupt ganz.

Erit wo die kalten Strömungen, nom jüठlichen Eije herkommend, die Küjten der Kontinente beipülen, treten jie allmäh̆liø wieder auf, aber dic Robbenfauna nimmt hier ein wejentlid anderes Ausiehen

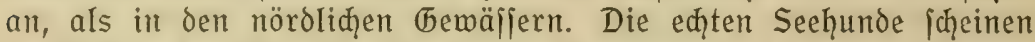
zunädjit ganz gefḑwunden zu jein, und man muß bis in das Eisgebiet der Antarktis jelbjt hinuntergehen, um fie nod einmal wiederzufinden. Dort zeigt es fid, daßj den vier Eismeerjeeḩunden des Kordens vier des Südens gegenüberitehen, von denen wir erjt durd die antarkti= jhen Expeditionen um den Anfang diejes Jahrhunderts genauere Kenntnis bekommen haben. Die häufigite art jąeint die weddel=

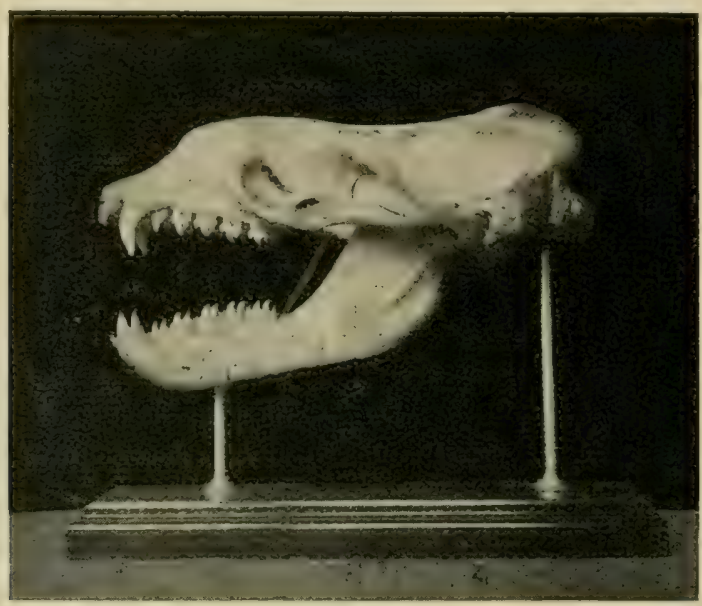

Аъъ. 4. SÆädel des Seeleoparden.

(Aufnahme des Derfaffers.)

robbe (Leptonychotes weddeli) zu fein, die man auf pḩotographien

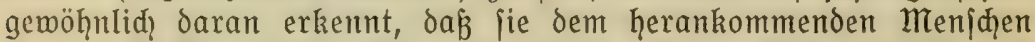
gegenüber fidl auf die Seite oder halb auf den Rüßsen wälzt und ihren Kleinen Kopf in eigentümliher weife erḩebt. Fin riejiges Tier mit gewaltigem, langgejtrecktem Sçädel und kräftigem (bebiß ijt der Sceleopard (Ogmorhinus leptonyx) (Abb. 4), der jeinen Iamen von der bunten fledkung leines felles bekommen ḩat. Seḩr auffallende Tiere find dic beiden andern Arten; Rof́' Seehund (Ommatophoca

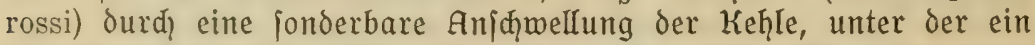
eigentümliđ gebauter Kehlkopf zur Erzeugung einer mäđhtigen Stimme vorḩanden ift, und der logenannte weike Seehund oder Krabben= frefier (Lobodon carcinophagus), der als einjiger unter feinen Der= mandten die bei anderen polartieren jo häufige weibfärbung des felles mehr oder weniger vollkommen angenommen hat. 
Gud das Walrob des Nordens hat in gewiffem Sinne fein (begen= itüdz im fernen Sïden. Auđh dort, alleroings nidh̨t im emigen Eije jelbjt, aber dod auf den unbewohnten, von kalten Stürmen umbraujtell Injeln des antarktijąen $\emptyset_{z}$ eans lebt ein Rieje unter jeinesgleiḑen, der angeblid bis $349 \mathrm{~m}$, gewöhnnlid bis $5 \mathrm{~m}$ lange See=Elefant (Macrorhinus leoninus) ( $(\mathrm{b} b .5)$. Er ijt der Klappmühe des Kordens am nähijtell verwandt und die Männden befigen in nod ḩöherem Maß̧e als dieje die fähigkeit, die Kaje mähtig aufzublajen, ja jie haben einen eđ̧ten Rüfiel, der aud in der Ruḩe über dem Maule herabhängt. Mit der Derbreitung diejes eieres ift es eine merk= würoige Saḑe. Einjtmals kam es in groben Mengen jelbjt bis an die Küjten pon Patagonien, Neufeeland und Tasmanion vor. Jegt

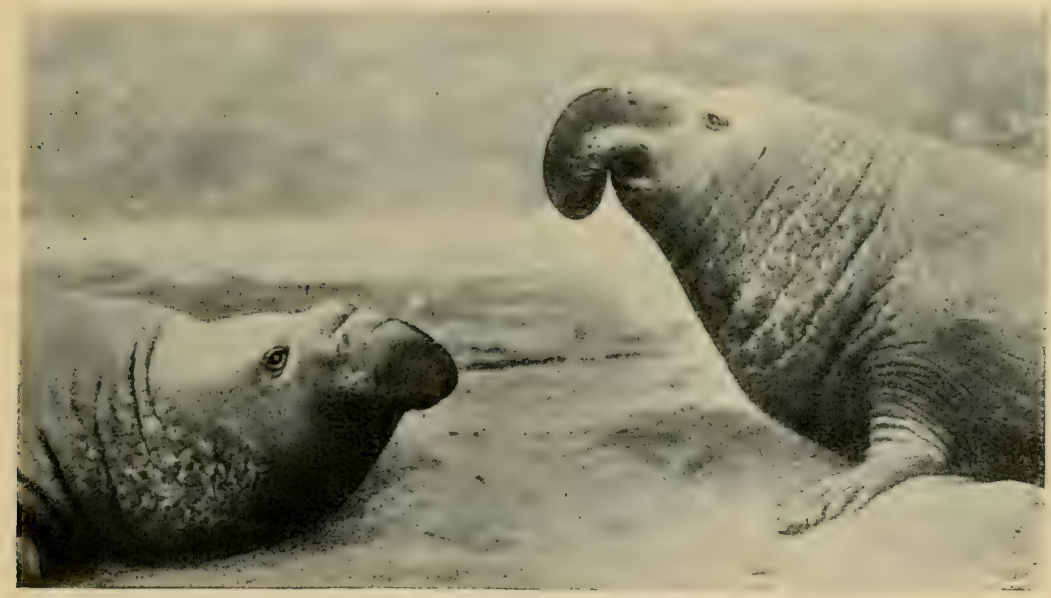

Abb. 5. See=Elefanten. (กaç एownsend.)

ift es infolge maklojer Derfolgungen dort ganz verjक̨wundan und aud auf den antarktiphen Infeln, wie Sübgeorgien, den Kerguelen uip. iit es felten geworden. AuBerdem aber gibt es nod ein zweites (bebiet, in dem See=Elefanten leben, wo jie aud früher in Maffen vorḩanden waren, nunmehr aber fajt ganz periḑwunden find. Dies bebiet liegt

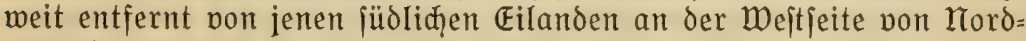
amerika, wo jie auf der Injel Gouadeloupe in nelleiter 3eit nod jiemlid reiḑlid gefunden worden jind. Ehedem bevölkerten jie dort auf eine meite Stredze hin die ganze Külte von Kalifornien.

Wie mag fich dieje jeltjame Derteilung auf zwei fo weit ponein= ander getrente (bebiete erklären? Gaben die Tiere in früheren Jeiten weite Wanderungen gemađ̧t? Sind fie, die Bewohner der kältejten Meeresteile, imitande gemejen, den Äquator zu überjđreiten? - Es muß wohl jo gemejen jein. Und in der Tat, wenn man die Temperatur = und Strömungsverḩältniffe im Stillen (bzean betrad̨̧tet, 
fo wird diejc Saḑe veritändidh. An der ganzen Wejtküjte von Anterika ift das Meermaffer auffallend kalt. Don Korden und Süden her ziehen zwei kalte Strömungen, der Kalifornifde = und der Peruftrom, den Kiijten entlang weit bis in die Tropen hinein. (bleidzzeitig oringen in den Breiten der Paffate an den Küjten jomoḩ nördlid wie jüdlid des Äquators fortwährend Kalte Waffermafien aus der Jiefe an die (Dberfläd)e. Durd diefe Derhältniffe wird den Kaltwaffertieren gleid)= jam ein Weg gewiejen, der ihnen 3 waten Wanderungen brauḑbar jein modpte und der aud die heutige Derbreitung der See=Elefanten ebenjo mie dic vieler anderer Meerestiere erklärt.

Daßj dicjer Weg in der Tat eine alte Feeritrake der Robben ijt, zeigt nun auf das deutlidjite dic Derbreitung dar oritten familiz oer floffenfüßer, der (Dhrenrobben (otariidae), die von den andern beiden, den Walroffen (Trichechidae) und Seehunden (Phocidae) auf den criten Blid durch den Bejig von äugeren (Dhren zu unterjaciden find.

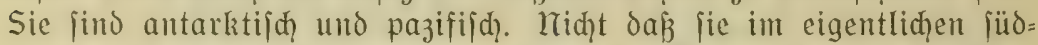
lidgen Eismeer lebten, aber fie umwohnen den Sübpol in einem Streifen, der ungefähr der jogenannten wejtwindtrift, dem Gebiet der wejt= liđ̧en Winde auf der jübliकhen Galbkugel entipriḑt. Sie kommen dort überall auf den Injeln, wie an den fübliḑen Küjten von Südamerika, Afrika und Auftralien vor. Während aber iḩre bekanntejte fübliche Art, dic Mähnenrobbe (Otaria jubata) an der Ditieite von Süd= amerika nux bis zum sa plata hinaufgeht, findet fie fich an der Weitjeite bis peru, aljo bis nahe an den ëquator. Eine andere (Ohren= robbe lebt unmittelbar unter dem Äquator jelbit auf den 历alapagos= Infeln. Weiter hinauf an der mittelamerikanifhen Küite fehlen aller= dings die Ohrenrobben, aber fhon bei Kaliformien treten jie mit iłher bekanteften Art, dem Seelömen (Zalophus californianus), wieder auf, der eine regelmäßige Erjheinung in don Joologifकen (bärten ift und jeiner merkmüroigen Kunjtfertigheit megen fid aud im 3irkus plagen muß zu hohei Entwidielung und gehen andererjeits auch an der ojtajiatificen Küite eine Stredke weit mieder nad Siiden hinab. Dort im Beringsmeer lebt der Scebär oder die Bärenrobbe (Arctocephalus ursinus) ( $A b b .6)$, berühmt megen ihres prahtoollen pelzes, des "Sealfkin", um deffentmillen alliährlich auf den unmirtliđ̧en Kommodorski= und Pribnlom=Injeln, wo die Tiere ihre Jungen werfen, ein grobes

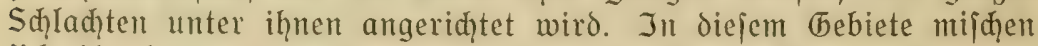
fiç die beiden Gauptfamilien der floffenfüßzer: Dhrenrobben uno Sechunde, miteinander, denu die aus dem curopäijhen Eismeer ex= wähnten Robbenarten treten hier zum Teil nebit verwandten formen ebenfalls wieder auf.

Id habe im Dorjtehenden den Derjud gemad̨t, eine überiaht über die widptigiten Arten der Robben - das Wort im weiteiten Simme veritanden - an der Gand ihrer geographificen Derbreitung zu geben. 
Denfelben Weg einzufdlagen, um in die Kentuis der anderen groken (ii)uppe nou Mreeresfäugeticren, der Wale nebit den Delphinen (Cetacea) cinzuführen, ijt mit mejentlid größeren Shpmierigkeiten verbunden. Diefe Tiere find in nod viel geringerem (6rade oder liber= haupt gar niḑt an die hähe von Eand oder Fis gebunden, weil das offene ineer ihnen zum dauernden Aufenthalte willkommen ijt, uno weil iḩre (Drganifation ignen geftattet, meite Danderungen, ja zum Teil Wanderungen von ganz auperordentlidger Ausdehnung zu maḑen. Die Derbreitung der einzelnen Wale läßt fid vielfad nid̨t in beitimmte

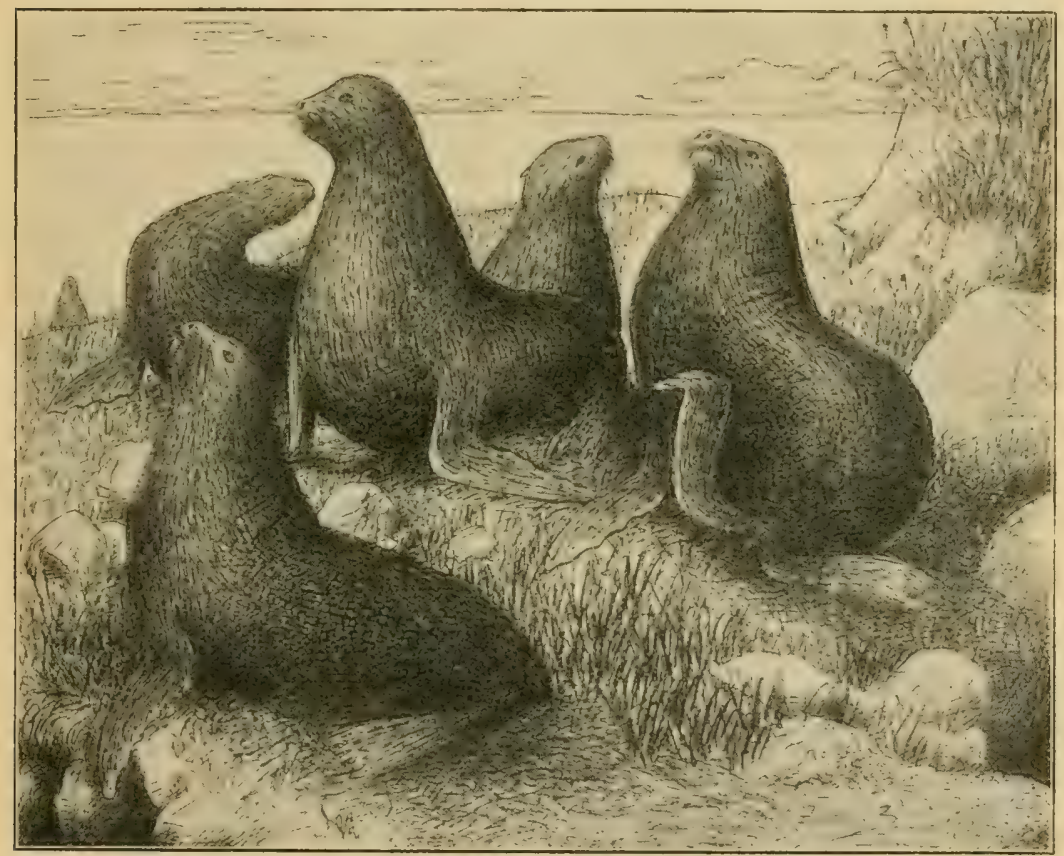

Аъb. 6. Seebären. (3eiąnung des Derfaffers.)

(5renzen faffen. Bis zu einem gewiffen Grade lafjen fid aber jonen unteriḑeiden, die mehr oder meniger ḑarakteriftighe Arten haben. So gibt es rein arktijhe wale, vielleidht aud bejondere antarktijhe, folche der gemäßzigten Jonen, die bedentiamer weife im Korden und Süden gleidhartig auftreten, und foldhe, die vorwiegend in den Tropen leben. 3wijhen dem AtIantijhen und pazifijhen (1)zean findet einiger= maken übereinftimmung in bezug auf die entiprechenden Jonen itatt. Einige, bejonders kleinere Arten gibt es [a]ließjlidy dod, die eine ganz wohlumjळriebene engere Derbreitung haben.

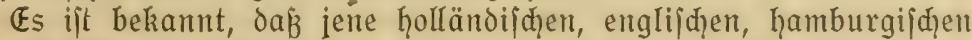

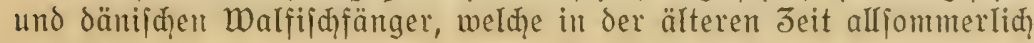


iḩre Jagden unternaḩmen, hinaufgingen ins Eismeer, taă Spigh= bergelt und Grönland, wo Jaḩrhunderte hindurd cine reihge und mertwolle Beute gemađ̧t murde. Der Wal, welchen jie dort vormiegend erlegten, fpielt in dem heutigen, $3 u$ neuer Blüte gelangten Walfijh)= fang faft gar keine Rolle mehr. Es war der Grönlandwal oder polarmal (Balaena mysticetus) (Abb. 16), ein Tier pon mur etwa 15 bis $18 \mathrm{~m}$ Eänge - was für einen Wal niđt jo jehr viel ijt - aber

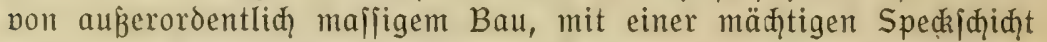
verjehen und mit wejentlid längeren Barten, als jie irgendein anderer Wal hat. Ganz unförmliđ groß ift der Kopf diejes Tieres, der etwa ein Drittel der Körperlänge eimnimmt. Der Dberkiefer bildat einen hod gewölbten Bogen, von deffen Wölbung an beiden Seiten die Bartelt herabhängen. Die längiten von ihnen find $2^{1 / 2}$ oder 3 , ja jelbit $4 \frac{1}{2}$ Meter lang.

Sdyon lange ehe man diejen wal kannte und jagte, war ein naher Derwandter von ihm der Gauptgegenjtand der Jago, cin Wal, der

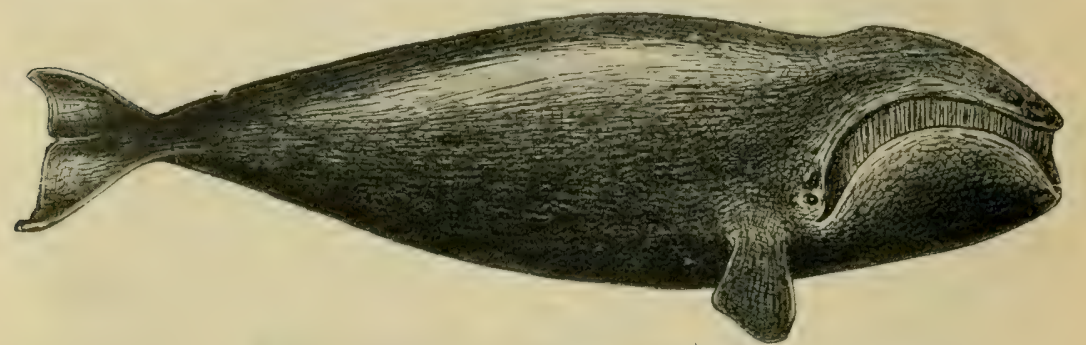

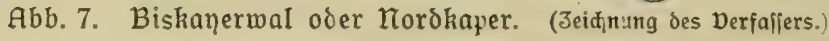

alleroings jest ebenio felten gemorden ijt und nod waniger bekannt zu fein pflegt als jener. Er wurde Biskaner oder Nordkaper (Balaena glacialis) ( $(\mathrm{bb} .7)$ genannt und fand fich von der Südgrenze des polarmals bis jüdlid nom Golf non Biskana hinab. Das Tier ift jḩlanker als der (brönlandwal, jeine Barten jind kürzer als bei diejem, feine Eänge überjhreitet kaum 12 Meter. Er hat ein begen= itück jenjeits des Äquators, den Südmal, der nod̨ jiemliç ḩä̈ufig fein joll, und ein anderes im nördiḑen Stillen (bzean, den Japaner= wal. Dielleid̨t gehören dieje nod wenig bekannten wale geradezu zur jelben Art wie der Torbkaper.

Als die groken Sharen der Biskanerwale und Grönlandwale durd jaḩrhundertelange Derfolgung auf eine jo geringe Jaḩ ḩerabgekommen

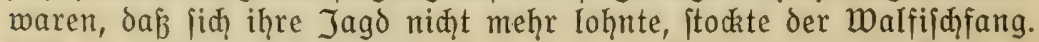
Erjt im vorigen Jaḩrḩundert fand man die Mittel, auḑ die Wale zu erlegen, welđ̧̧ heuţutage die Gauptrolle im Walfang ipielen. Es find das die fogenannten "furd̨enwale" (Balaenopteridae), welḑ̧e fid von jenen "(நlattwalen" (Balaenidae) äußBerlið dadurd unterjđ̧eiden,

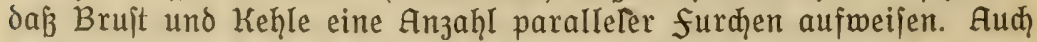
ourch die fąlankere Gejtalt, den Befig einer Rükenflofie und andere 


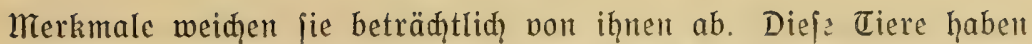

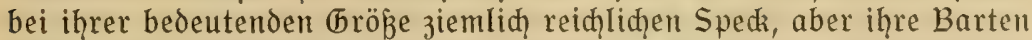
find wejentlid) kürzer als die der (blattwale. Es jind hauptjäḑlid orei Arten von Bartenwalen, die jegt gejagt werden, der Budrelmal (Megaptera boops), der Bla wal (Balaenoptera musculus) und der finnmal (B. physalus). Eine geringere Rolle pielt der kleinere und peltenere Seihgal (B. borealis) und dur mur bis $10 \mathrm{~m}$ lange 3 werg= wal (B. rostrata), mit denen die Reihe der nordatlantifįen furchen= male abgeidilofien iit.

Der Blaumal ift der längite von allen walen, das größte lebende Säugetier überhaupt. Er wird jiđerliđ $25 \mathrm{~m}$ Iang, vielleid̨t nod] cin paar Meter darüber. Ebenjo wie der kleinere finnmal (Abb. 8) ijt

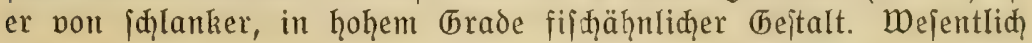

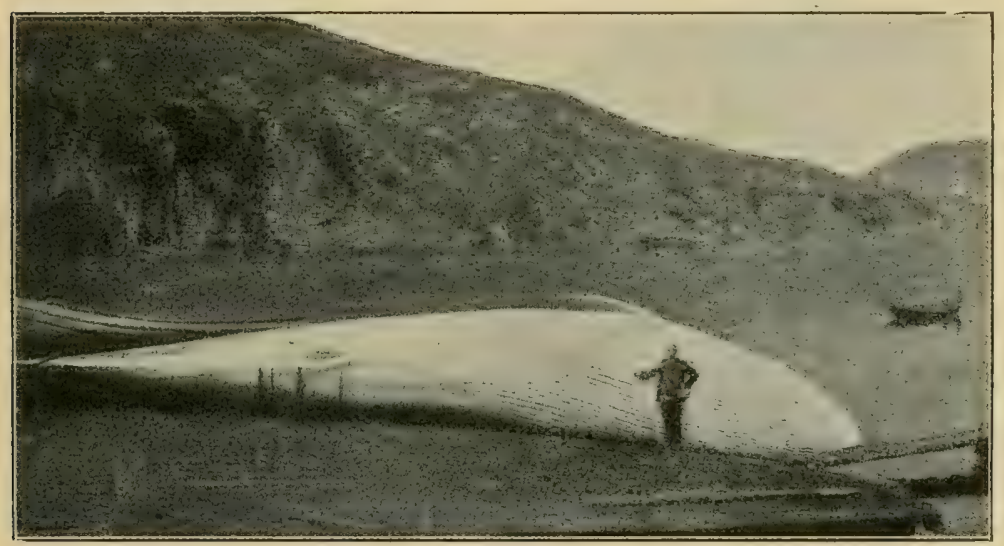

G6b. 8. finnwal, pon der Baudfjeite gejehen. (Aufnaḩme des Derfafiers.)

plumper ift der Buckelmal (Abb. 9) gebaut, dar im ermadfenen Jujtande etwa $15 \mathrm{~m}$ Eänge erreiḑt. An iḩm fällt bejonders die riejenḩafte Bruftflofje auf, welḑ̧e über ein Diertel der ganzen Körperlänge miß̧t uno damit alle anderen $\mathfrak{W}$ alfloffen an (bröß̈e übertrifft. Seinen Namen ḩat er vor der budkelförmigen Rückenflofie. Er wird von den Kor= wegern Knöloḩal genannt, weil er auf dem Dorderkopf eine Anzahl niebriger Knollen trägt, die je mit einem einzigen Gaar auf ihrem Gipfel ausgejtattet jind. Als ein größ̈erer Wal von bejđ̧ränkter Der= breitung muß nođ ber kalifornifđe (நra u wal (Rhachianectes glaucus) genannt werden, der nur in ber lähe der kalifornifđen küjte lebt und bort aud gejagt wird. $\mathbb{E r}$ nimmt in bezug auf das unteriḑeidende Merkmal der (bIatt= und furḑenwale eine mittelitellung zwijhెen diejen beiden ein, denn jeine Keḩle ijt mit nur zwei kurzen furchen ausgejtattet.

Mit den wenigen genannten Arten ijt der Befig der Dzeane an 
Bartenmalen (Mystacoceti) mahezu erjąöpft. Thre Anzahi iłt piel geringer als die der anteren Ģauptabteilung ber Wale, der Jaḩumale (Odontoceti), wenigitens wenn man, wie es gewöḩnliḑ gejḑieḩt, alle die mannigfachen formen nom größten pottmal bis zum kleiniten Delphin unter diejem Ramen zufammenfaß̧t: Allerdings gibt es unter innen nur einen wirklia großjen wal, eben den pottwal (Physeter macrocephalus) (Abb. 10, 20 und 28), der im männliđhen (bej̧̧leçt $18 \mathrm{~m}$ Iang mird. Dies đier bejigt aljo jtatt der Barten Jäḩna, jedod mur il dem merkwürdig jąmalen Unterkiefer, während der mäđ̆tige, breite, meit hernorragende, vorn fait jenkred)t abgeitugte oberkopf

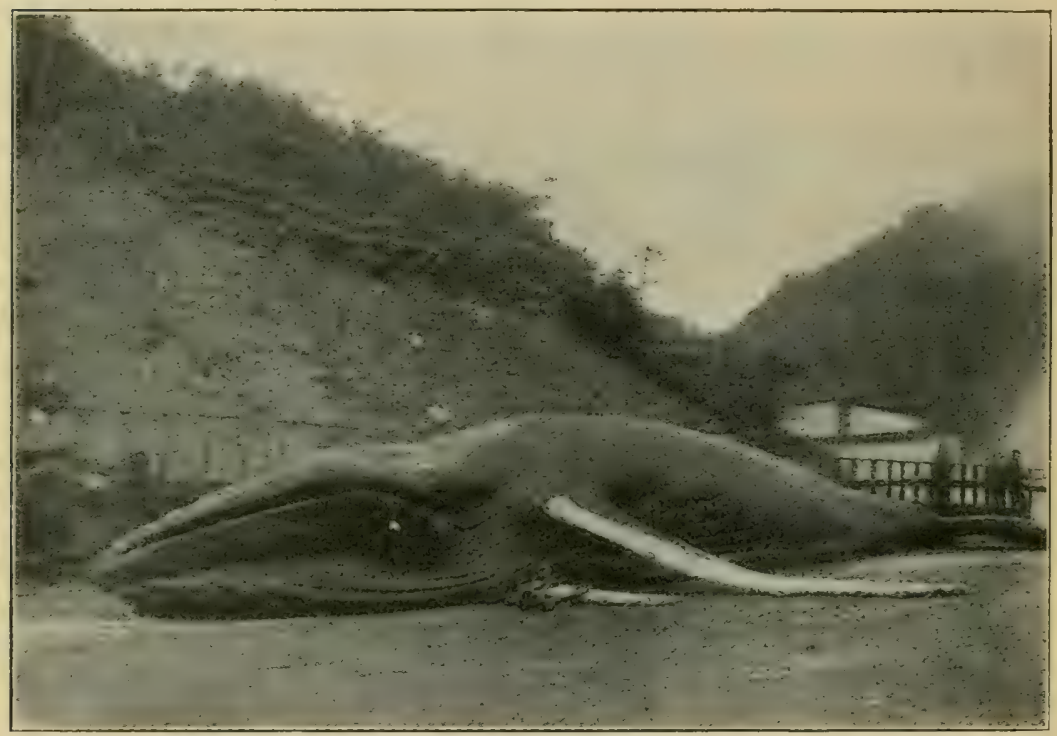

Abb. 9. Budielwal. (Паф đrue.)

fie pöllig perloren ḩat. Aud diejer Wal wird viel gejagt, meil die ölige fettmafie feines bis $6 \mathrm{~m}$ langen Kopfes das Walrat liefert und in jeinem Darm häufig die überaus kojtbare Ambra als ein maḩrjheinlich krankhaftes prooukt entiteht. Giier ijt nun aber das Jagogebiet ein ganz anderes als bei den Bartenwalen; der pottwal hat jeine Eeimat in den warmen Meeren, in denen er übar die ganze Erde perbreitet porkommt. Allerdings maḑt er ausgedehnte Reifen, eridgeint audh intmer von jeit zu jeit vereinzelt im (bebiete der Eisberge. Aber die beiten Walgründe für leinen fang liegen 3. B. bei don Azoren, bei den Kap Derdijh̨en Injeln, im Südatlantijh̨en (13ean, bei Madagaskar, bei Aujtralien uim.

Im Nordatlantifđen (1)zean, jđon in der Nähe des ewigen Eijes, wird nod) eit anderer Jaḩnmal - allerdings ein vollkommen zaḩn= 
lojer - gefangen, den man feiner fđ̆nabelförmigen Sd̨nauze wegen Entenwal, fonit aud) Dögling (Hyperoodon rostratus) (Abb. 21) nennt, ein bis $9 \mathrm{~m}$ langes एier, das ebenfalls, wenn aud in geringer menge, Walrat erzeugt. Die Norweger bauen eigene Dampfer, mit

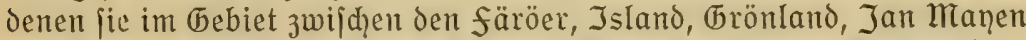
und Spifbergen die "Sḑulen" diejer Wale verfolgen. Fine andere nordatlantilḑe form, der (brindwal (Globiocephalus melas), ein

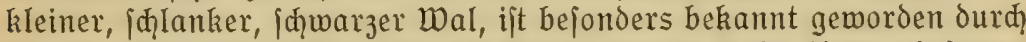
die Treibjagden, welḑe die färinger in der Käḩe ił̧rer einjamen ozeanifden Injelwelt um jeinetwillen veranjtalten. Ein oritter von diejen mittelgroken 3ahnwalen, der über die ganze Erde verbreitet

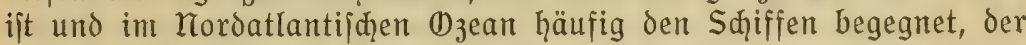
aber niđht gejagt wird, ijt der bis über $7 \mathrm{~m}$ lange $S$ đ̧wertwal (Orca gladiator) (Abb. 31). Er ift ein edites Raubtier unter den walen. Man jieḩt die f̧̧ön gezeiḑneten tiere oft in Sḑaren jąwimmen,

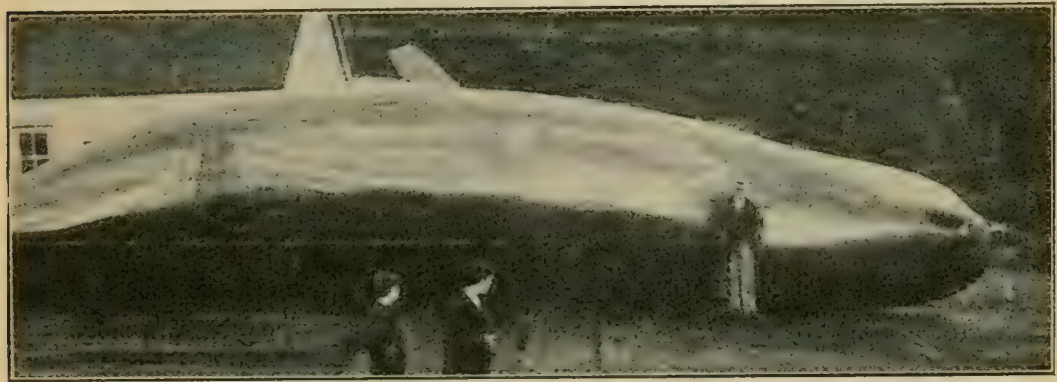

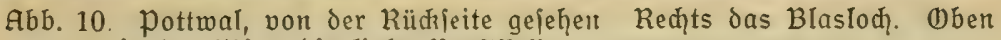
in der Mitte die linke Bruftfloffe. (Aufnaḩme des Derfaffers.)

wobei iḩre auffallend hohen und iđ̧malen Rüđrenfloffen wie Eleine

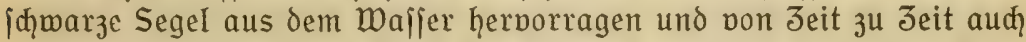
ber breite Rüdzen eines Wals für einen Augenblick auftauḑt. Dieje

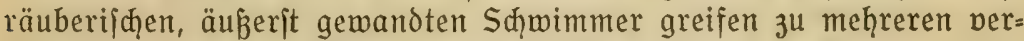
cint feibjt die großen wale an und jind imjtande fie zu töten.

Einige andere, meift feltenere Arten, müffen ḩier übergangen werden. Dođ! dürfen zwei merkwüroige Tiere niđht unerwäḩnt bleiben, die jđ̧on etwas zu den Delphinen hinüberleiten und eine Ђruppe von hoher Eigenart für fiđ bilden, zwei kleine, ḩöhit auffallende, eđ̧te Eismeerwale, der Marmal (Monodon monoceros) und der weíbral (Delphinapterus leucas). Sie geḩören, wie iđ jđ̆on oben erwäf̧nte, zu den eigentlidgen Charaktertieren des nördlihen Eismeeres, die fich nur ganz felten in unjere Breiten verirren. Es bejteht eine groß̧e ähnliḑkeit zwijđ̧en beiden, infolge wovon die Grönländer, wie be= hauptet wird, den weiß̧wal für das Weibḑen des Marwals halten. Aber fie unterjđgeiden fid dod wieder deutliđ noneinander, da der erwadjןene weipwal vollkommen weip ift, während der Narmal auf 
hellent (brunde mehr oder meniger duntel geflectit erfheint mo im

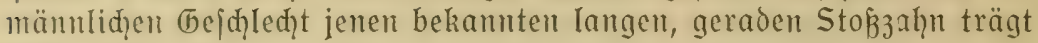
(Abb. 23).

Und mu jąlieflid) die J̈merge unter den Walen. In allen Meeren, an felteniten mohl in den Eismeeren, gibt es jenes hübjde Kleindolk der Delphine, das die fahrenden Sdiffe umpielt, mit gewandtem Sdpmung aus dem wajper fpringt, bald den dunklen Rüdien, bald die blendendmeißze Baudfeite zeigt, balo wieder lebhaft jąwimmeno und fpringend davoneilt und nod lange durd die über dem Waffer hin= gleitenden dreiedrigen Rückenflofjen jeinen Weg bezeiḑnet. Die etwa 50 Arten von Delphinen, weldye man aus allen Meeren bejąrieben

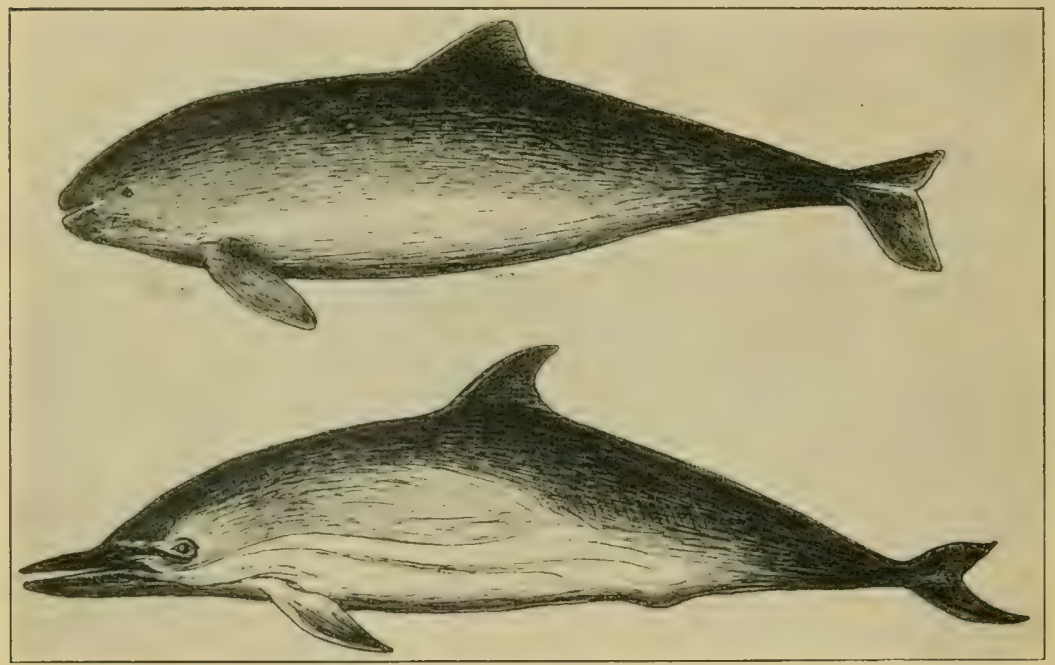

Abb. 11. Braunfijđ und Бemeiner Delphin. (3ciḑunng des Derfaffers.)

hat, find niḑt leid)t zu unterfheiden. Es dürfte aud kein groß̧es Bedürnts fein, in cinzelnen hier auf fie einzugehen. Die, welḑe man in den europäifhen Meeren am häufigiten fieht, mögen in Kürze genannt werden.

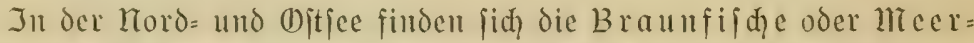
\{đuciuc (Abb. 11) (Phocaena communis) als regelmäßige Bewohner. Es find verhältnismäß̧ig red̨t kleine, ctwa anderthalb Neter lange Tiere, die durdy ihre abgeitumpfte Sdynauze fiळ von den meijten anderen Delphinen unteridgeiden. Die harakteriftijhe Art der normegifden kiuiten und fjorde, oer nordifd̨e Delphiu (Lagenorhynchus acutus), ḩat cinen ipigeren Kopf, und bei dem bejonders aus dem Mittelmeer be= kamten gemeinen Delphin (Delphinus delphis) (Abb. 11) ijt die Sđ̆nauze geradezu iđnabelartig verlängert. In iḩren fđ̈malen, ge= ftrediten Kicfern haben die Tiere lange Reihen ipiber fangzähne, 
mit benen jie jehre gejhidit fifde zu ergreifen varmögen. Dar mittel= meerdelphin, der ïbrigens aud aukerhalb diejes meeres wait ver= breitet gefunden wird, ijt cin ganz bejonders jdïnnes, in ḩohem thrade fifhähnlides Tier, das ourd die gejd̨wungenen Einien feines körpers, feines kopfes und feiner flofien, durdy den begenfag del fhwarzen und weifen farbe jeiner Gqut, durd die ïberaus gemanden $B e=$ wogungen, durd? fein heiteres Spielen im blauen, klaren Wajfer ganz bejonders das Auge zu feffeln vermag. - Es fei hier jąließ̧lid nod

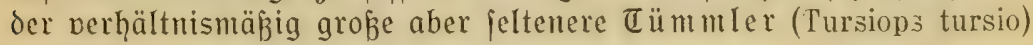
crwähnt.

Diele Delphine find imitande, den Wechiel pon Salz= und süßpwafier zu ertragen, und gehen freiwillig oft weit die flüfle hinauf. Andere, bejonders tropifhe, haben jid ganz dem meere entfrembet und find vollkommen zu Süpwaffertieren gemordert. So leben einige edjte Delphine in den Unterläufen afiatif̧er und afrikanifd̨er flüffe. Dazu kommen ganz abweidqende formen, wie der Gangesdelphin (l'latanistil gangetica) und der Delphin des Amazonenftroms, die bis ticf in das Innere der feftländer hinein gefunden werden.

Robbent und Wale bilden bsi weitem die Gquptmajie aller meeres= qäugetiere, fie allein pflegen der Mehrzahl der Menjd̨en bekannt zu fein. Was von anderen nod hinzukommt, ift an 3ahl nur wenig und es tritt in der 区ierwelt des Meeres an Bedeutung fehr zurüd. See= Ieute werden felten von dan Seekühen oder Sirenen (Sirenia) zu cr= zählen wiffen. Kur hie und da mag es an den Küjten und Injeln des

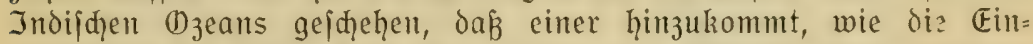
geborenen ein grokes Tier, das fie Dugong oder Dujong (Halicore dujung) nemen, auf den Strand fḑleppen, es zerlegen und verzehren. Der Seemann wird jđjwer jagen kömmen, was es ijt. Fine Robbe? nein, denn es hat keine Ginterbains, fondarn eine breite, wagerechte Sdiwanjflofie. Alfo vielleiḑt ein Delphin oser ein Wal? - Aber cintem Wal jię̧t dod wieder der Kopf ganz unähnlid. Die Katur= forfher haben lange Jeit die meinung aufreḑterḩalten, daß̧ die Sirenen mit den Walen pereinigt werden müß̈ten, denen jie im großjen und ganzer in der Körpergejtalt, im Befis einer breiten Sḍmanz= floffe und zweier Bruftflofien ziemlid ähnlid find. Je näher man

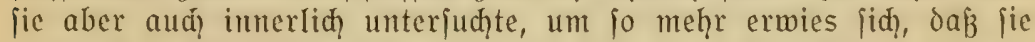
weder den Walen nod irgendeiner anderen entipredienden Säuge= tiergruppe cinfad зugezählt werden kömen, daß̧ fie vielmehr eine foldge (5ruppe für fidh ganz allein bilden mülfen.

Die Dugongs weiden im flaḑen Waffer an den Küjten des Indifdzh (1)zeans uni der weitliḑen Südjee die Tanggründe $a b$. Ähnlid leben im

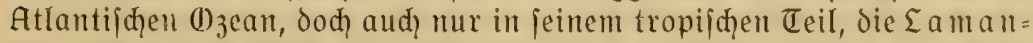
tiıe (Manatus) (Abb. 12), jowohl an der öjtlidgen Küijte von Süd= anterika, wic an der afrikanif̧en wejtküjte. Aus dem flaḑen Waffer aı den fluß̧mündungen, 3. B. Jes Amazonenitroms, gehen fie auḑ in 


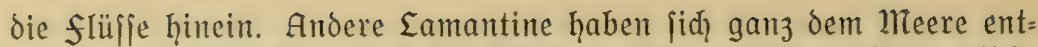
wöhnt und leben nur now im jüßen Wafjer, deffen reidge tropifhe Pflanzenfülle fie vielleid̨t beffer und mannigfaltiger mit Taḩung verjorgt, als der eintönige Pflanzenwudis des meeres. Sie find fo

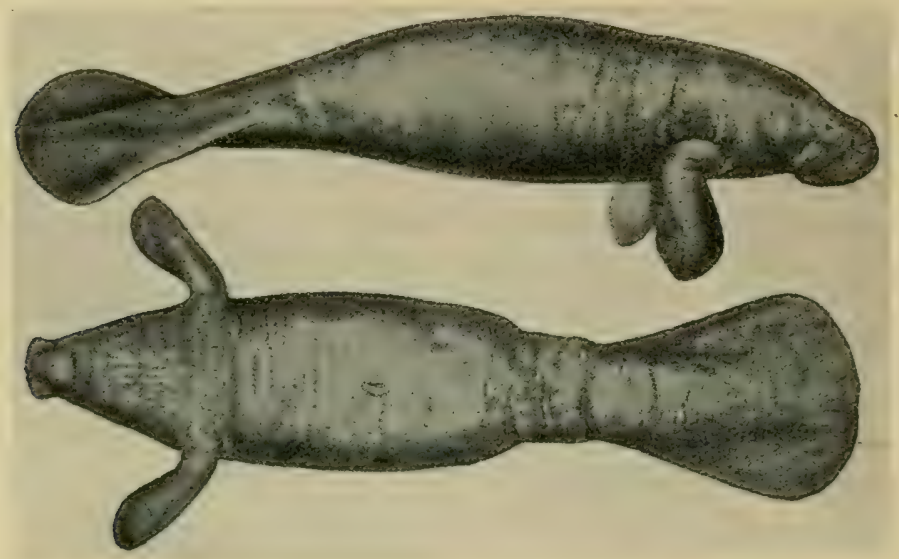

Abb. 12. Amerikanif̧̧e Eamantine, von der Seite und von unten. (Mach Murie aus Abel.)

ourd das ganze Brajitien bis an den fub der Kordilleren vor= georungen.

Sind die Seeküḩe heute auf die märmiten Teere bejđ̧ränkt, fo war bas bis vor kurzem niđ̧t der fall, "por kurzem" allerdings

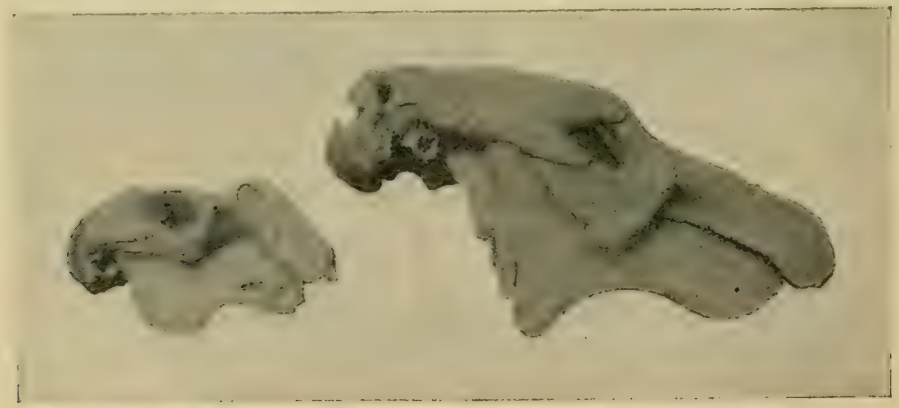

Abb. 13. Sđ̧ädel des männtiđ̧en Dugongs und der Stelleriđ̧en Seekuh. (Aufnahme des Derfafiers.)

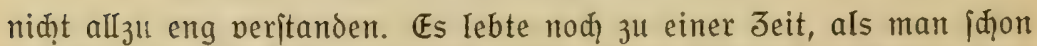
auf der ganzen Eroe wiffenjđaftliḑe Beobaḑtungen anjtellte, fern im Torden des Stillen (Wzeans eine Art diejer Tiere, welḑe die be= deutende Eänge von $8 \mathrm{~m}$ erreiđąte - Dugongs und Eamantine werden

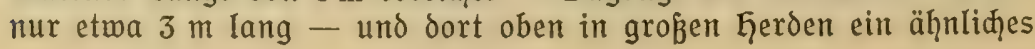


Eeben führte, wie die Derwansten unter den Eropen nod heute. Als im Jahre 1741 der deutiche Katurforifier Steller auf die Berings= infel perjḑlagen wurde, traf er dies Tier an, daßj man feitdem als Stelleride Seekuh, fonjt aud als Borkentier (Rhytina Stelleri) (Abb. 13) bezeiḑnet. Aber wenige andere Europäer haben nođ̆ etwas davon gejehen. Ehe now das nädite Jaḩrḩundert erjḑien, warent dieje

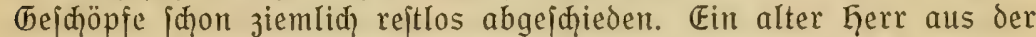
familie foll fid allerdings nod im Jaḩre 1856 gezeigt ḩaben, aber feitsem hat man niḑ̧ts meḩr von ihnen gehört. Einige von den

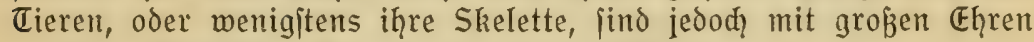
in den europäifḑen mujeen beigejegt worden.

Eier find wir nun ziemliđ am Ende der Meeresiäugetiere, dod, zwei müffen nodh genannt werden, die iņrer ganzen Derwandtichaft nach alleroings aufs Eand geḩören, die aber, die familientrabitionen

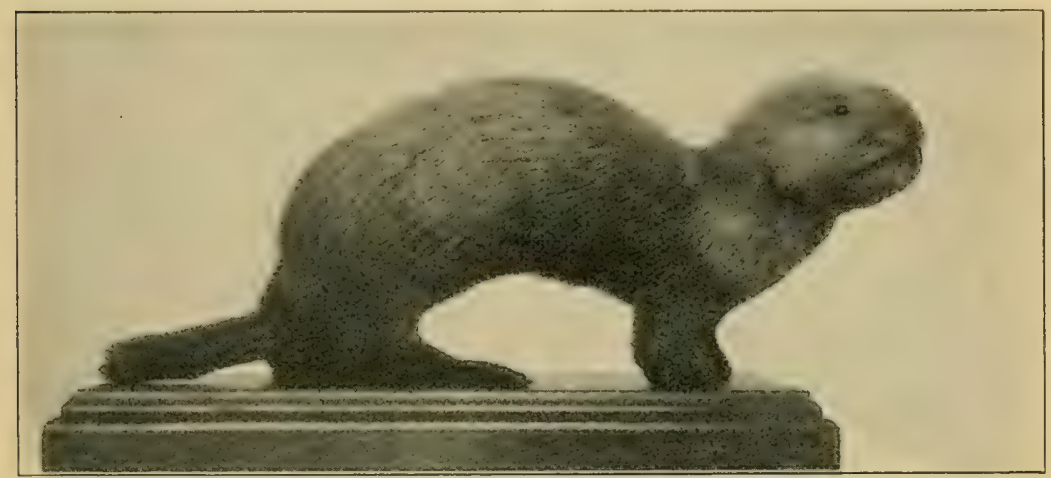

Abb. 14. Secotter, junges Männđ̧̧en. (Aufnaḩme des verfaffers.)

vernad̨läfijgend, ins Salzmaffer hinausgegangen find. Dent ausge= ftorbenen Borkentier mag der Seeotter (Enhydra lutris) (Abb. 14) angejd̨loffen werden, der aud aller waḩrjheinliḑkeit nad bald aus=

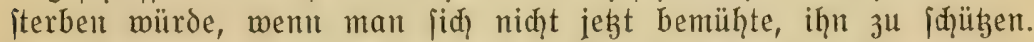
Den fijḑottern ähnlid), nur eigentlich ein fijḑotter des Meeres, lebt dies jđ̈̈ne Tier nur nod auf fđ̧wer zugängliḑen Klippen bei Alaska, den Aleuten, den Kommodorski=Injeln, aud nod pereinzelt bei Kam= tiø̧atra, den Kurilen und Veffo. (Es lebt "nur nod)", weil es zu jeinem Unglüdz einen jeḩr kojtbaren $\mathrm{pel}_{3}$ trägt, der jđ̧on vielen Taujenden feiner Dorfahren das Eeben gekojtet hat.

Und jąließ̧lid habe id nod ein Tier zu nennen, das allbeliannt iit, nur nid̨t als Seejäugetier bekannt zu fein pflegt. Aber wenn einer den Kamen "Thalassaretos maritimus" führt, $\delta$. hุ. wörtliđ ïberjegt "Der maritime Seebär", fo kann man ił̧m das Recht, hier aufgezählt zu werden, niđ̨t abjpreçen. Diejer Bär ijt kein anderer als der $\mathbb{E}$ is bär (Abb. 15). Wer je da oben war, wo er jeine Geimat hat, wer je 
gelehen hat, wie er über die unendidhen Eisfelder dahertrottet, wie er, all cine offene Stelle im Eife kommend, unbeliummert feinen Weg ourd; das Waffer fortjegt, wie er, am Rande des Eisfeldes ftehend, nad einer weit draußen treibenden Sdzolle hinüberwittert, auf der eine Robbe

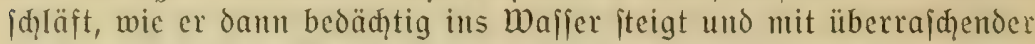
(bejd)windigkeit zu der treibenden Sḑolle hinüberjḩ̧immt, - wer je das Eeben der Eisbären im Eismeer gejehen hat, wird zugeben, dak̉ man ihn ebenfowohl Secbär wie Eisbär nennen darf. Jit er jđon niđ̧t viel anders gebaut als jeine Derwanden in den ruffifdien Däldern oder auf apiatifhen hodgebirgen, fo hat fid dod bei ihm die fähigkeit 3u ciner fđynellen, fiḑerell, gewanden, ausdauernden Bewegung im

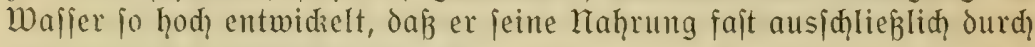

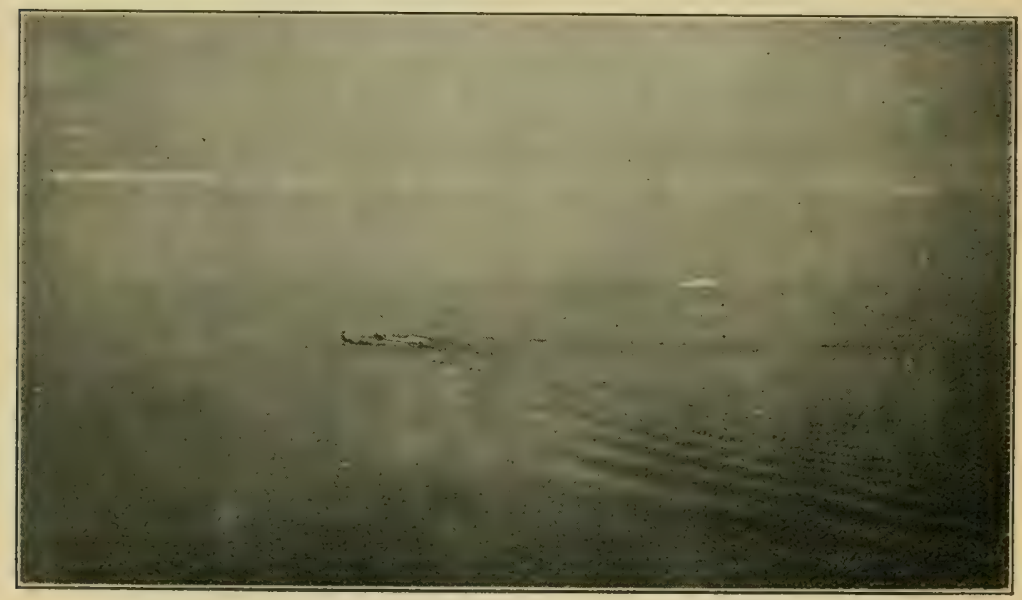

Abb. 15. Sd̨̧immende Eisbären. (Aufnaḩme des Derfaffers.)

den fang eḍter Seepäugetiere, der Robben, gewinnen kann. $E_{r}$ unteriḑeidet fich aber von allen zubor genannten Tieren gerade in dem nterkmal, das diefe in gewiffem Sinne miteinander vereinigt; er ift oas cinzige Seejäugetier, weldzes keine flofjer befibt. -

Die Säugetiere find in ihrer Gauptmaffe, fowohl nad ihrer Eebens= weije mie nad ihrer (Brganifation und aud unzweifelhaft nad ihrem lliprunge echte Eandtiere. über die ganze Erde, von dent vaḩen Eis= feldern der pole bis zu den üppigen Urwäldern äquatorialer Eänder, ourd Steppen, Kulturland, Wüjte und Wald, fumpfige flußzniederungen und hohe (bebirge findet man jie überall. Wenige nur find ins meer hinausgegangen, und mur eine Gruppe, die der Wale, hat es zu einem eḑt ozeanifhen Eeben gebracht. Es ijt eine dem Säugetier, wie man cs (iid) nad der Gauptmafie der bekaunten formen vorzultellen pflegt, frento welt, in die wir mit ihnen eintreten. Es mag aber hier nod flüdtig an cine andere fruppe von @äugern crimtert werden, die zu 


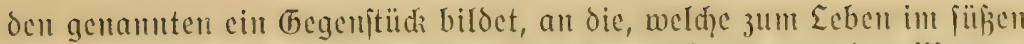
Waffer ïbergegangen find. Es gibt, wie ermäḩnt, unter den meeres= fäugetieren einige, welḑe aus dem Meere wicoer in dic Ströme hinauf= geftiegen find. Andere, immer nur vereinjelte, und ans ganz ber= jhifedenen Abteilungen, find unmittelbar nom Eeben auf dem Eande zun Seben in flïfen und Seen übergegangen ober fühţen dod? ein Wedplelleben zwifden Wajper und Eand. Sḑon bei den Beuteltieren gibt es joldye formen (Chironectes). Unter den Infelitenfrefieru ijt der Desman (Myogale) der unteren Dolga und die jog. (D)terfpigmaus (P’otamogale, o. দ̆. cigentlid) "flußzwiefel“) der flïfle Jentralafrikas,

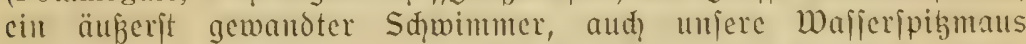
(Crossopus fodiens) zu nenten. Bei den ragetieren treten befonders oer Biber (Castor) und dic amerikanij̧̧e Bifamtatte (Fiber), bei den Raubtieren die fijḑottern (Lutra) hervor. Dou den Gquftieren kömute

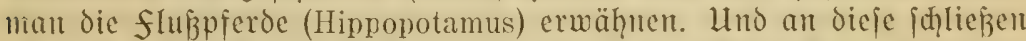
(id) näher oder ferner nod manḑe andere an. Diefe Tiere verdienen befonders deswegen hier eine \{urze Erwähnumg, meil jie nid̨t jelten ziemYid auffallende Gindentungen auf die meeresfängetiere in bezug auf die (1)rganifation zeigen, die im folgenden einer befpredgung unterzogen werden foll.

\section{Kapitel.}

\section{Lörperbau und Anpafjungen.}

Alle dic Säugetiere, welḑe hier in einer kurzen überjiḑt , zufammen= gejtellt wurden, haben anderen gegenüber das (bemteinfame, daßj fie das neer bewohnen. Sie haben fid als Auswanderer, die vom feiten Eande her kommen, in das an Eeben fo reidge Salzmajier hinaus= begeben und bevölkerm, über die ganze Erde hin, jomohl cie flaḑen Küjtengewäffer wie die endlofen Waffermaffen der lohen See. Es

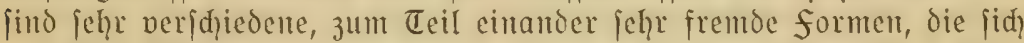
auf diefe Deife zufammenfanden. Es mag daher auf dell eriten Blidi

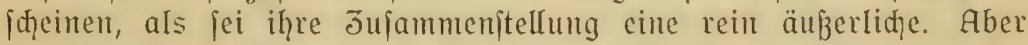
wernl aud dic Derwandfiçaft zwijd̨en den einzelnen (5ruppen der meeresfängetiere eine mehr oder meniger entferute ijt, jo gehören jie dod) in einem viel tieferen Simte wirklid zujammen, als ourdy das bloß̧е Jufanmenmoḩnen im gemeinjamen Meoium.

Jedem Tier hat die Ungebung, in der es lebt, etwas vour ihrer Figenart aufgeprägt. Die Abhängigleit von den DerḩäItniffen der Ummelt ijt cinc jo bielfältige und enge, daßj fic niḑt mur dic Eebens= weife, fondern aud die (beftaltung des Tierriörpers aufs tieffite beein= flü̧t. Um zu leben, muß das đier jeinen Eebensverhältniffen ent= ipreḑen, muß̧ für die Bedingungen feiner Umgebung zwedimäß̉ig ge= 
italtet fein. Wir nennen das Anpafjung. Gerade in den fällen, wo Tiere aus dem gewohnten Eebenskreife ihrer ganjen Derwandifdaft herausgetreten find, wo fie ganz neue Bahnen bif firitten haben, wo fie ganz bejondere Eebensmöglidgkeiten ausnuben, pilegt ihre An= paffung einc jehr auffallende zu fein. Je frember, je weniger ent= ipredend dic neue Eebensart der alten Organifaion ijt, um fo gemalt= famer muj fie umgejtaltend wirken, um jo ausorudswoller find die Anpajfungen. Und wenn verjdjedenartige Wejen in den langen Jaḩr =

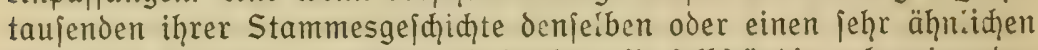
Weg gegangen jind, gleiđjam als jtrebten jie jelbjtändig rebeneinander

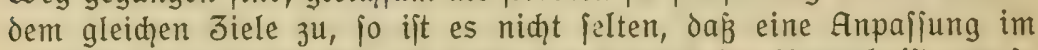
gleidyen Sinne itattfindet. Je tiefer der Einfluß ber Umwelt ijt, um jo häufiger wird das Eeben den verjđicdenen Tieren diejelben Merkmale aufprägen, um fo mehr wird das Medium, um fo meniger die Stam= mespermandtjd̨aft für die Körpergejtaltung bejtimmend fin. Die gleidfinnige Anpaffung wird frembe formen einander bis zu einem gewiffen Grade ähnlid maḑen. Wir nennen das Konvergenz.

Die Meeresfäugetiere bilden wegen ihrer hodgradigen konner=

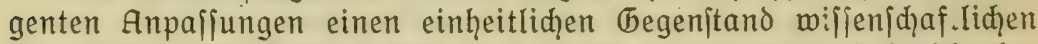
Intereffes. Das Meer ipriąt aus iḩrem Körperbau und ipricht be= jonders aus ihrer äuberen Erjheinung oft viel deutlidger, als das Säugetier. Daß̉ ein Wal dem Meere angeḩöt, erkennt man auf den

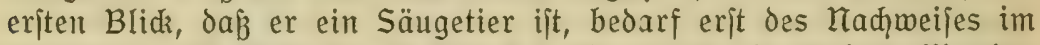
einzelnen. In wal hat in der Tat die Katur ein waḩres Wunder der Anpajpung geleiftet. Sind dođ Säugetiere jđ̄on jo ḩod entwidielte, fo vollkommen dem Eandleben angepaß̧te wejen. Dennod hat fich diejer Tiertnpus nod, einmal bis in feine tiefiten (bründe hinein um= zugeitalten vermod̨t, hat eine fait unbegreifiiḑe plajtizität gzzeigt, hat etmas ganz fremdes, Neues und überaus 3medzmäßiges aus [id herausgebildet, hat jozujagen das tmpifकite Wafjermirbsltier, den fifa, auf ganz eigenen Wegen zum zweiten male erzeugt. (berade die fijd)= ähnliḑkeit der Wale ift das Wunderbare, gerade dieje fłablonenḩafte Jaḑaḩmung eines alten Tiertnpus ijt um vieles merkmüroiger als die allgemeine Tatfaḑe, daß̧ das Waffertier dem Wafferleben an= gepakt ift.

Dieles in dem Körperbau des Säugetiers ijt der Drganifation eines fijhes io geradezu entgegengejegt, daß̉ im großjen und ganzen die Eebenskreife diejer Tiere einander völlig ausjhließ̧en. Die Bemegungs= organe der Säugetiere, für Saufen, Springen, Klettern, felbjt für den flug geeignet, die ganze Gejtalt ihres Körpers, die Bededzung der Dberfläḑ̧e mit diđ̨ten, erwärmenden Gaaren, die Ausbildung der Atmungsorgane, der Sinnesorgane, aud der Organe der Ernährung und anderes mehr - alles ijt für Eand= und Suftleben gebaut, alles zeigt Anpaffung an den feften, dabei vielgejtaltigen Boden, die trodiene,

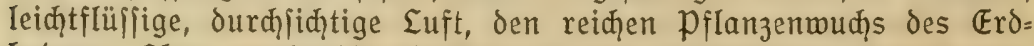
bodens. Aber gerade die vielfältigen und entjđiedenen Anpaffungen 
nađ̆ allen diejen Riđhtungen ḩin unteritreiđ̄en nur um jo deutliçer jene andersartigen, vielfath in gewiffem Sinne entgegengejegten An= paffungen, welche die meeresfäugetiere an allen den entfprechenden Teilen ihres Körpers hervorgebraḑ haben.

Es pflegt aus naheriegenden (bründen ganz pormiegend die äuß̧ere Eridgeinung des Tieres zu jein, an der die umgeitaltende Wirkung der Umgebung fid offenbart. Je tiefer man in die innere Drganifation eindringt, um fo mehr findet man die züge wieder, welḑe altes Erbteil und als jolches mit näheren und ferneren Derwanoten gemeinjames Eigentum find. Ju jtreng darf man es allerdings mit diejem Sag niđ̧t nehmen. äuberes und Inneres ijt zu eng verbunden. Beifpielsweije

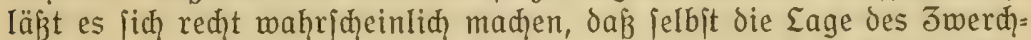
fells bei den walen in einem Jufammenhang mit dem Wafferleben iteḩt. Aber gerade die fifhiłhnlid̨keit, die bei den walen fo hoch entwikelt und bei den andern hier 3 bejprechenden Tieren mehr oder weniger angedeutet ift, bezieht fid vorwiegend auf die äufere Erjheinung.

Die gejamte Körperform zeigt eine f̧inneigung zu jenem fpindel= förmigen oder dod) jedenfalls nad vorn und hinten verjüngten Bau, zu jener Dermeidung von Doriprüngen jeder Art, weld̨e für das leiḑte und idnelle Durdjoringen des Waffers notmendige Dorbedingung ift, meldye daher aud im Bau von Sdiffen und Booten überall angewendet mirb. Ein bejonderer, deutlid non Kopf und Rumpf abgejester Gals fehlt bei den Walen ganj. ITur bei einigen kleinen formen, beim weikzal 3. B. und bei gewiffen eigenartigen Delphinen ift nod eine Andeutung davon zu erkennen. Bei den Sirenen ijt es nid̨t viel anders, wie denn überhaupt die Körpergejtalt diejer Tiere in hohem Grade derjenigen von walen ähnelt. Etwas deutlid̨er pilegt der Ģals bei den Robben ausgeprägt zu jein, dođ verhalten fich die verificedenen Arten darin niđht gleid; und beifpielsmeife bei einer der antarktijđen Robben, bei Roß̈' Seehund, geht die Derfd̨melzung von Kopf und Rumpf wic überḩaupt die entiprediende Umgejtaltung fo wsit, daß einer der neueren Beobachter von ihm jagen konnte, er jei von allen Seehunden am meiften Seehund und habe ganz die Dierfïßergeftalt verloren. Im Gegenjas dazu ift bei dan Ohrenrobben der Fals ver= hältnismäßig deutliđ, lang und bewegliđ.

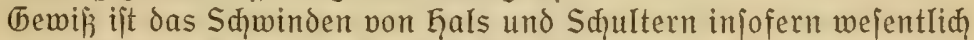
für \{âbimmende điere, als dadurd der Wideritand des Körpers gegen bas waffer verringert wird. Andererjeits fheint aber dabei aud die fejtere Derbindung von Kopf und Rumpf, die Derfejtigung des Körpers als Ganzes infofern eine Rolle zu ipielen, als fie das finnelle Durd)=

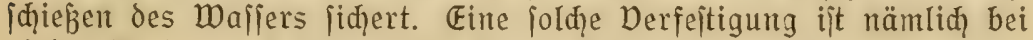

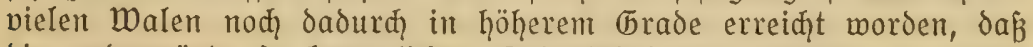

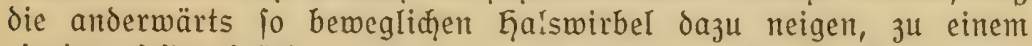
einzigent feiten Stüd miteinander zu verid?melzen. Bei den (biattmalen 3. B. bilden fämtliđ̧e fieben halswirbel ein einziges Stüd. Beim Dögling nimmt jogar der erite Brujtwirbel an der Derjđgmelzung teil. 
Der Walkörper zeigt, ebenfo wie der der Seekühe, cine ausge= iproḑene Reigung zur Jujpizung oder Jujd̨ärfung nad\} den Enden 311. Beill Kopf ijt das allerdings nid̨t immer der fall, ood tritt es an den großen furḑenwalen reḑt deutlid) hervor unto erreiḑt bei

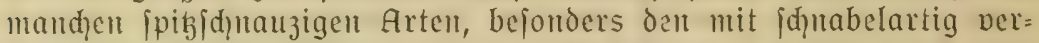

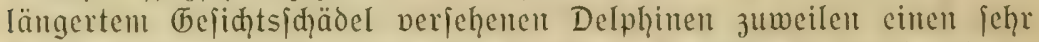
hohen Grad. Andere Arten, wie Weißwal, Latwal, pottwal und die Sirenen haben cinen breiten, felbit quer abgejdnittenen Kopf. Bcim pottwal zeigen die gewöhnnliḑen Bilder dies Derḩalten allerdings oft übertrieben. Sein Körperbau ift durḑaus nid̨̧t jeḩr plump, fondern

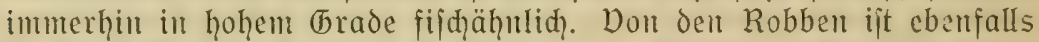
in diejer Beziehung nidłts Auffallendes zu beriḑten. Dagegen haben fie jạon in hohent (5rade eine Deriüngung das hinteren Körperendes crreiḑt, dic mit if̧ren gewandten sḑwimmbewegungen in engem Jufanmenhange jteḩt. überhaupt fällt bei den fo überaus beweg=

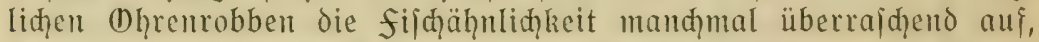
went fie pfeilfannell iḑwimment mitcinander fpielen. Sie pflegen oft in leid̨tem Sḑwunge fidh aus dem Waffer zu fqunellen und erinnern danı leb̧aft an ipringende Delpḩine.

Bei dell Robben wird die Deridmälerung des Körpers naḑ ḩinten miḑt durd cine bejondere Ausbiloung des Sḩ̧wanzes - der ganz kileill und unbedcutend ift - erreiḑt, fondern, abgejehen von ciner allgemeinen Derjüngung des Ginterleibes, bejonders dadurd, daß̧ die Finterbeine, anjtatt wie bei andern Säugem fenkređ̧t zum Körper zu ftchen, fid derart verlagert haben, daß̉ fie ilt der Eängstid\}tung des körpers liegen und jozujagen den Ginterleib nađ̆ hinten verlängern (Abb. 1), gleidffam einen breiten, zun Steuern und Rudern gecigneten Sḑwanz an iḩm erfegen. Die Wale und Sirenen berhalten fid in

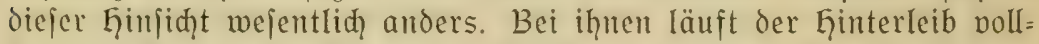
kommen fpiłz zu, der Sḩwanz jeģt fid gar niḑt bon iḩm ab, fondern nimmt als fein legtes und fark entwidreltes Ende fehr wejentlid, an diefer Jujpizung teil. Fier ijt aud die Ginneigung zu einer ge=

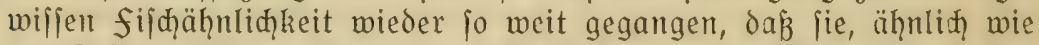
am Ģalje, jelbit das Skelett beeinflußt hat. In der Tat erinnert der Walfi̧wanz, wenn man von den floffenbiloungen abfieḩt, im Skelett= bau auffallend an den Sḑwanz eines fijhes (Аbb. 16 und 21). Die Wirbel werden in ganz regelmäßjger Abjtufung nad hinten inmter kieiner, und es haben fid, was befonders auffallend iit, an ihrer

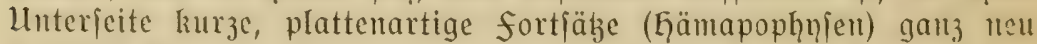

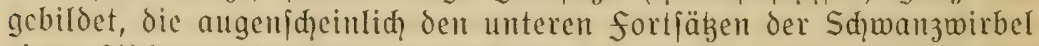
eines fijdes entipredien. So find bei den Walen, und jumal bei den Eleinflen WaItieren, den Delpḩinen, die filḑähnliḑ̧ten formen ent= itanden, welḑe wir unter den Seejäugetieren finden.

(5anz bedeutend gefteigert wird nun diejer Eindrud nod dadurd, daß dic Ğliedmaßen durḑaus mit der Körpergeitalt zufammen= ftimmen. Es find nidgt Beine, fondern floffen. Und aud bei ihnen 
Fönnen wir, fd̨rittmeife von cinfadyeren, Lanotierähnliḑeren jul voll= Eonmenercl: formen fortidgreitend, beobad̨ten, wie diefe nenen (blied= maß̧en fid gebildet haben. Ja, wir können hier nod weiter zurïd= greifen, wenn wir die Secottern mit in Betraḑt zichen. Ihre körper= geftalt ift ja niđ̧t jeḩe auffallend. Immerhin orüđat fid int der lang= geitrediten, walzenartigen form, wem nan jie mit derienigen ber ihnen verwanten MTarderarten rergleid̨t, id;on ziemlidg dzutlid etwas Leues, Eigenartiges aus. Betraḑtet mant aber iḩre Beine, jo erkennt man deutlid den Einfluß find allerdings nidyt viel anders als bei anderen Raubtieren gebaut; bei den Ginterfüßzen (Abb. 14) haben fid] dagegen die Jashen ganz be=

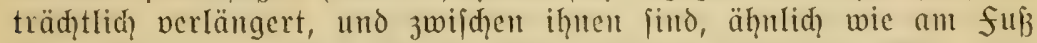
cines frofḑes, wohlentwidielte Sḑwimmf̧äute entitanden. Dies geḩt dann weiter bei den Seehunden; fie haben edgte flofien, fowohl vorne wie hintent, dod? find die Krallen, zumtal an den Dorderfloffent, nod? gut

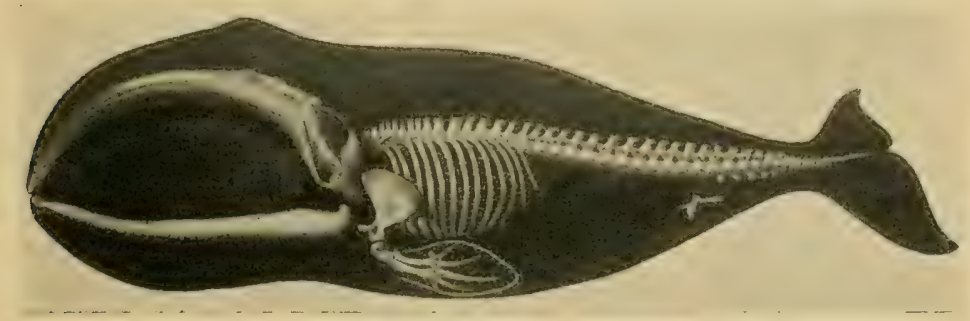

Abb. 16. Skelett des (brönlandwals.

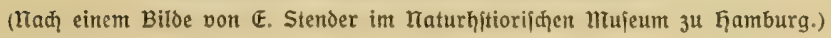

cutwidielt. Bei den Walrofjen verkümmern jie zu jd̨̧waḑen nägeln. Bei den Dhrenrobben jind fie an den Dorderflofien fajt ganz ver= \{ąmunden (Abb. 6). Überhaupt find unter den "floffenfüßern" die Ohrenrobben diejenigen, weldye in jeder Beziehung die vollkommenten floffen haben. An relativer (bröß̉e und zwedzmäßiger Gejtalt über= treffen fie dic der Seehunde und aud die der walroffe. Die itark entwidielte Sd̨wimmb̧aut dehnt fid bei iļnelt weit über die finger= ppigen aus und wird zum Teil nod durd knorpelige fortiäge der fingertinodien bejonders gejtügt.

כu diejen Deränderungen kommt nod hinzu - und das fällt wicder befonders bei Seehunden und walrofien auf - daj die

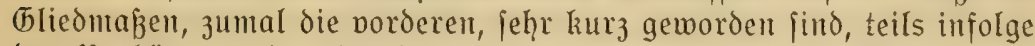
der Derkürzung der Armknodien, teils weil fajt mur nod die Gand aus dent Körper hervorragt, der Arm aber größtenteils von der allge= meinen Körperḩaut perdedat ift. Die Gliedmaß̉en der (Dhrenrobben ragen etwas länger hervor und find deswegen niđ̧t mur zum Sd̨wim= men, fondern aud) zum Eaufen auf dem Eande geeignet.

zu der legten, vollkommeriften form der floffe, wie fie fid bei 
den walen findet, leiten die Seekühe in bedeutfamer weije hinüber (АЬb. 12). Dic hinteren Gliedmaken fehlen ihnnen wie den walen bekanntlid ganz. Die Dordergliedmaß̉en haben noch einen gewiffen (5rad von Gelenkigkeit beḩalten, fie dienen niḑt nur dem Schwimmen, fondern it geringem бrade aud now, bei der Bemegung auf dem meeresgrunde zum Stügen. Aber von fingern ijt an ihnen niđ̨ts mehr zu jehen, die flofie ijt infofern viel vollkommener geworden. Dod) find von den Iägeln bei manḑen Arten nod verkümmerte Rejte

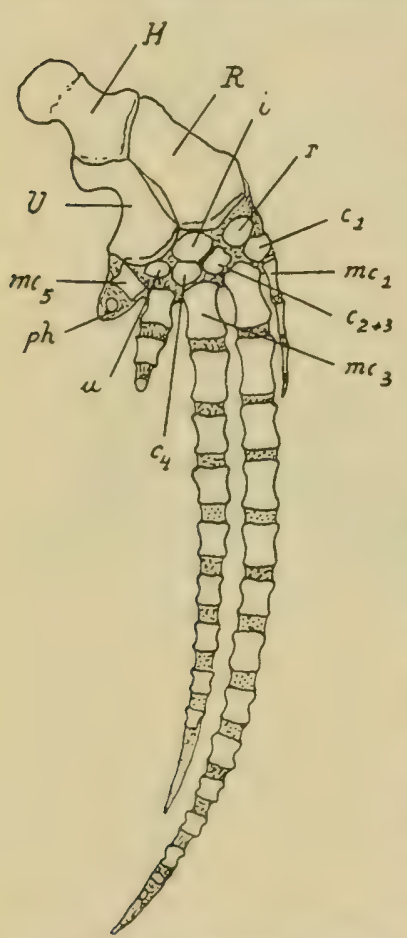

Abъ. 17. Skelett $\delta$ er Brultflofie eincs (brindwals. (Mach Abel.)

zu bemerken. Und dann phließ̧lid die Wale! Eine vollkommene flofie ift an Stelle des Beines getreten, nur in wenigen fällen find noch die fingerpipizen an ihrem Rande zu unterif̧eiden, die nägel find itets perifhwunden, die belenkung ift eine ganz einfaçe wie bei der fijhflofle ge= worden.

Fier ift es mun aber von ganz be= fonderem Wert, einen Blic ins Innere $3 u$ werfen, die umḩüllenden weið̧teile der floffe 3 u entfernen und ihr Knodgengerült 3u betraditen (Abb. 16 und 17). Doll= kommen ift da noc der Säugetierarm und die Säugetierhand erhalten: der einfache (1)berarmknodien, die beiden Unterarm= knodien und die zahlreidien Knoḑen der Gand. überall erkennt man deutlich die Rejte einer hodjentwidkelten Säugetier= gliedmake in der nad (bejtalt und funk= tion fo jehr vereinfaçten floffe. Aller= dings kommen an den fingern Derände= rungen vor. Die Mittelhandknodien find meift den fingergliedern äh̨nlicher geworden, als das fonjt der fall zu jein pflegt. Die Jaḩl der finger kant fich verringern oder aud) eine Neigung zur Dermehrung zeigen, die zahl der fingerglieder iteigt zumeilen ganz bedeutend. Wir haben in der langen jđłmalen flofie des (brind= wals beifpielsmeife einen finger mit mehr als einem Dugend (நliedern. Bei dent wal, der von allen jemals dagewejenen cieren die größte flofie hat, dem Budkelmal (Abb. 9), find alle Teile der f̧and und des Unterarms ins Koloffale gedehnt, während die Oberarmknoḑen var= hältnismäß乃ig Kurz bleiben. In den äußeren Teilen der flofian hat (id) aljo der cinfluß ber umgeitaltenden Mäḑte bis auf bas Skelett erjtredst und je naç den jpeziellen Bedürfnifien das allen Säugetier= gliedmaß̧en zugrunde liegende Knoḑenjpitem in verphiedener weife ausgejtaltet. 
wenıt man fieḩt, wie fiđ hier mit erjtaunliđ̧er Jäḩigkelt die fejten Bejtandteile der Dordergliedmaßen erḩalten haben, jo muß es

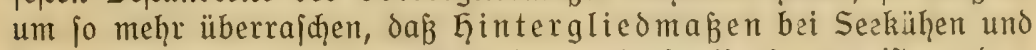
Walen vollkommen fehlen. Iid̨) der geringite Doriprung ijt an dem ipindelförmig verjüngten Ģinterleibe zu bemerken. Aud̆ die breite,

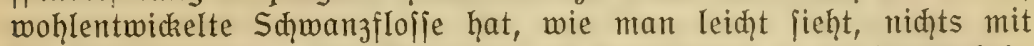
den Sinterbeinen zu tun. Die Natur, jo Konjervativ fie am Dorderbein war, hat das ganz entiprechende Ginterbein radikal perniḑtet. Man wiro jedod aud hier einmal, um der Saḑe auf den frund zu kommen, hinter die Kuliffen ję̧en dürfen. Sollten die füße etwa ganz in den Körper hineingejunken fein? Dder, menn fie verjđ̧wunden wären, find nicht Rejte von ihnen geblieben? Und wie verhält es fich mit

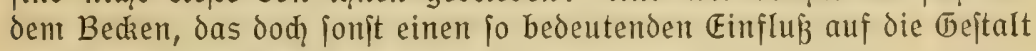
des Ginterleibes hat? -

Merkwüroig genug! Wenn man an der Wirbeljäule die Kreuzbein= gegend juळt (Abb. 16), in der das Bedzen mit iḩr vermadyen zu jein pflegt, fo findet man - niđhts. Gleidfförmig reiḩt jich vom Brujtrorb bis zur Sdiwanzipige ein Wirbel an den andern. Eenden= und Bedren= region jind nid̨t gegeneinander abzugrenzen, nur die Sḑwanzmirbel find durd die ermäḩnten Anḩänge (Ğ̈̈mapopḩnjen) an iḩer Unter= peite mieder bejonders ausgezeiḑnet. Alles, was die gejtaltenden Kräfte in der langen Dergangenḩeit der Säugetiere aufgebaut hatten, alles iđgeint bis auf die Wurzel wieder verniđ\}tet zu jein.

Es jheint fo. Aber etwas ift da doch noch vorhanden. Etwas, das allerdings in den riejigen fleifd̨mafien eines groken walkörpers leiḑt überjehen wird, und das an den waljkeletten der Mujeen, wenn

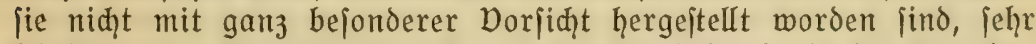
ḩäufig feḩlt. Unterhalb der Region der wirbeljäule, in der man das Becken vergeblid fuđht, tief in der Muskelmaffe des finterleibes ver= borgen liegen zwei freie, längliđ̧e Knođ̧en von einfađ̧er, dod ziemliđa meḩjelnder (bejtalt, bei großen Walen je nach der Art etwa 30 bis $45 \mathrm{~cm}$ lang. überall, bis zu den kleinjten Delphinen hinab, findet man dieje merkwüroigen Knoḑenipangen. Und es hat jich naḑweifen Iafjen, dẩ dies Rejte des Beckens find, dẩ es die beiden inmmetrijhen ᄃ̨älften des Beckens find, melche fid von der Wirbelfäule und vonein= ander getrennt haben und in hohem Grade zurüdkgebildet - wie man zu jagen pflegt: rudimentär geworden find.

Dieje merkmürdigen Bedenrudimente, über deren Uriprung gar kein 3weifel mehre möglid ift, werden nun nod ganz bejonders be=

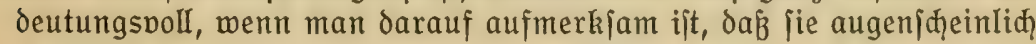
mehrfad) unabḩängig voneinander entitanden find. Jaḩnwale und Bartenwale haben fich im wejentliçen jelbitändig nebeneinander ge= bildet, wiederum die Delphine haben vielleiḑt einen ganz bejonderen Uriprung. Und weit entfernt von diejen allen itehen die Sirenen. Und bei allen ijt der gleiḑe rüdimärtslaufende Entwidkelungsgang, ift die gleiḑe Ruoimentation vor fid gegangen. Eine Art Konvergenz 
im Dernid̨̧tungsprozeß hat die Bedien der veriđiedenen Seejäugetiere in hohent (brade ähnlid gemadit.

Bei den großzen Walen kommt es vor, daß̧ aud von den Beinknoḑen nod Rudimente vorhanden find. Man findet dann cinan rundiajen Khorpel oder einen nod in feinen äußeren Teilen knorpeigen Knod)en,

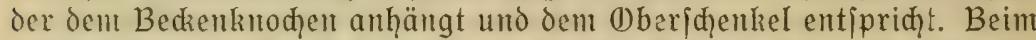
(brönlandwa! (Abb. 16) kommt aud nod ein Rejt das Unteriḑenkels zur Bcobachtung. Ebenio ijt bei Eamantinen zuwailen ein Rejt des (1)ber= iđenkels erhalten. Weldyer Art die anatomijđen Beziehungen diejer Knoḑenteile zueinander und zu iḩrer Umgebung find, die Bezię̧ungen, aus denen ih̨r Deritänonis mögliđ̆ wurde, kann hier niđ̧t erörtert werden. In einem andern Jujammenhang werde id darauf zurüđkommend zu crwäḥnen ḩaben, weld miđhtige Dokumente für diejen Reduktions= prozeß dic Reite ausgejtorbener Sirenen uns liefern. Fier fei nod cines Beweisgrundes dafür Ermähnung getan, den junge Embrnonen uns darbieten. Bei ihnen, 3. B. bei denen des Braunfijdes, jenes be= kannter kleinen Delphins der Nord= und Ditjee, finden fid nod, dentliḑe äußzere Anlagen von hinteren (bliedmaßzen. Es find zwei kleine vorragende Japfen am Ginterleibe, die fidh in der waiteren Entwidre=

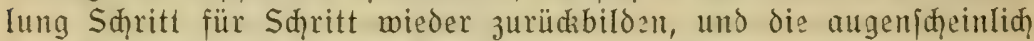
den Anlagen der Finterbeine anderer Säugetiere entipredien. Es

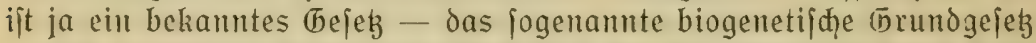
- daßj vielfach an Embrnonen Merkmale der lange ausgejtorbenan Dor= fahreen [id] nod angedeutet finden, von denen an den crwadjenen Tieren keine Spur mehr vorhanden ift.

Wenn man den gejamten flofienapparat der fijḑe mit $\delta: m$ dar hödjitentwidkelten meeresfäugetiere - Sirenen uno male - ver= gleiḑt, jo findet man gewiffe Unterjhied?, findet aber nod viel auf= fallendere übereinftimmungen. Ein Paar Bruftflofien find bei beiden vorhanden. Ein Paar Baudfloffen finden fid nur bai den filden. Ebenjo fehlt den Säugern die Afterflofie. Dagegen find Sḑmanzfloffe uno Rüdielfloffe mit merkwürdiger übereinitimmung bei beiden aus: acbildet. Daj alle nteeresiäugetiere Brujtflofien habsn, ijt nad dem Doritchenden: Ieid̨t peritändid. Daß̧ Wale und Sirenen cine Sđ̧wanz= flofle, dic meijten Wale auळ eine Rüdzenflofie bejigen, ijt überrajd̨end, weil fidl in der tnpijđ̨en Säugetierorganifation keinerlei ähnliḩe бrundlage dafür findet, wie eine folḑe für die Dordergliedmaßen dod? vorḩanden war. Sie fąeinen durø eine aukerordentlid̨e ge taltende Kraft fo vollitändig frei aus dem Miḑts hervorgebrad)t worden zu fein, wie die Gintergliedmaßße vollitändig ins niđhts zurüđigedrängt worden jind. In der Tat ift aud bei den Embrnonen zunähjit niḑts von diejen flofien zu finden und beim erwadjenen एier haben beide flofien= arten keinerlei knöđherne oder aud nur knorpelige (5rundlage. Es find platten feiten und elajtipdenen Gewebes, walḑe auf dam Rüdren und zu beiden Seiten des Sḑwanzes dem Körper einfad angejegt fint. Gewiffe verwandte Bildungen kann man alferdings anführen, dođ muk 
man jie ziemlid meit herḩolen. Der Sđ̧wantz des Bibers ijt bakanntlián zu einen fladen Ruder perbreitert und deutet damit entfernt auf dic hier vorliegenden Derhältniffe hin. Was die Rüdrenflofien betrifft, fo glaubt man, fie mit den Budeln vom Jebu und den Kamelen ver= gleiḑen zu dürfen. Inmerḩin ijt mit diejen verwandten fällen nid̨̧t viel erklärt. Die eigentliđ̧e Erklärung $m u \tilde{B}$ in einer bemunderns= werten Mađ̧t liegen, melḑe die Umgebung unter Umitänden auf den (1) rganismus ausübt, einer Mađht, die jeltiam zmedzmäßig am Tier= körper zu geitalten vermag und wunderbar jḧ̈pferif heues erzengt, iheinbar aus dem reinen lidits. -

Unter den Merkmalen, welḑe die Säugetiere von allen anderen Tieren unterjheiden, ijt im allgemeinen das auffallendite, dab ingre Gaut mit Gaaren bedecht ijt. Man darf anmehmen, daßz dieje Eigen= tïmliđ̧keit ähnlid wie der Bejig von federn bai den Dögeln in einem Jufammenḩang mit der erḩöhten Blutmärme iteḩt. Die Beitändigkeit der hohen Bluttemperatur wird dadurch gejiḑert, daß̧ Euft zwijhen den Gaaren und federn vorhanden iit, die ebenjo wie dieje felbit es

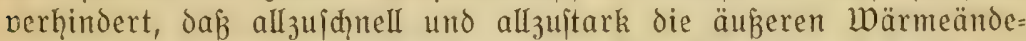
rungen dem Inneren mitgeteilt werden. Der Körper wird durch eine jolḑe Eufthülle in bezug auf Wärmeveränderungen meḩr oder weniger ifoliert. Dringt anjtatt der Euft Wafjer zwijhen die Gaare ein, fo ift dieje Jfolierung im wejentliđ̧en aufgehoben, weil das waffer viel jhineller und beffer die wärme überträgt, als die Suft. Dic Faare werden alfo im waffer nujlos merden. Damit wird es zu= fammenhängen, daß̧ fie vielfach bei den Säugetieren des Meeres ver= ¡đ̧woutden jind.

Aud) in diejer Beziehung finden jiđ zwifḩen den Eandjäugetieren cinerieits und den edptejten Seejüugetieren andererjeits mehrere Stufen des Übergangs. Jaḩlreiḑe Robben haben nod eine didte Bẹaarung, ja der Pelz der Seebären oder Bärenrobben ijt meltberüh̨̧m. Nod? kojtbarer ift der Secotterpelz, der zu den teueriten Raudqwaren über= haupt geḩöt. Die meiften anderen Robben haben ein kurß̧̧ariges,

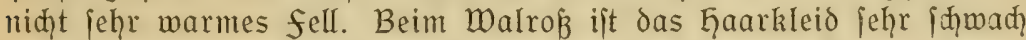
und bildet fich im saufe der Jeit meḩr und meḩr zurüd, jo daß alte Tiere fajt ganz nadit find. Don hier aus führen mieder die Seekühe weiter. Der Körper ift fajt haarlos, nur menige einzeln jtehende großze দ̧aare überragen die haut, über die jie in gleiḑmäßigen Abjtänden ver= teilt jint. Die Wale jąließjlid haben im ganzen eine vollkommen glatte, haarlofe Gaut, nur um das Maul herum itehen nereinzelte Gaare.

Man wird fid des Eindrudis niḑt erwehren kömen, dak der (5rad der Behaarung hier mit dem Grade der Dollkommentheit des Wafferlebens in Jufammenhang fteht. Tiere, weld\}e einen Teil ihres Eebens auf dem Eande oder Fife verbringen, werden von ihrem GaarKrleide einen mejentliḑen Dorteil haben; folḑe, die das wajfer niđ̧̣t verlajien, haben keinen ruben davon. Aber bedürfen niḑt aud die 


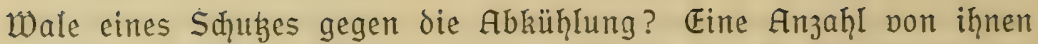
gehört den kalten, felbjt den polaren Meeren an, wo die wärme drs Waffers fid das ganze Jaḩr hindurd nur wenig über den ஞefrierpunkt erhebt. Dabei ift ihre Blutmärme jo hod oder jelbjt höher als die der Eandtiere. Man hat Temperaturen bon $36-37^{\circ} \mathrm{C}$ in ihrem Körper gemefien. Es ijt ja aud ganz bekannt, dáb dieje Liebḩaber der ewig winterlichen meere in der Tat reht warm eingepadat find. Was die Gaare niḑt mehr leijten konnten, das leijtet die didke Gülle von Spedi, die iḩren Körper umgibt, eine Ģülle, welḑe beifpielsmeife bei dem Riejenwal der Arkitis, dem Grönlandmal eine Didke von $25-50 \mathrm{~cm}$ erreidţt.

Das Shbinden der Gaare und die ftarke speckbildung find die beiden auffallenditen Unterf̧̧iede, melḑe die Gaut der Dajperjäuge= tiere gegenüber berjenigen der Eandjäugetiere auszeidnen. Die Ent= jtehung diejer Unterjhiede ijt aus den Bedürfnifien des "Wärme=

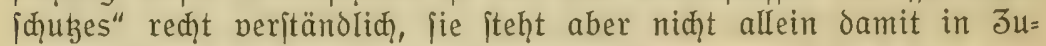
jammenţang. Die mähţtigen Anjammlungen bon fett haban not= wendigerweije aud eine meḑanijhe Wirkung; jie werden das ipezit fifd̨e б̆emidht des walkörpers ganz beträđtlid herabjagen. In der

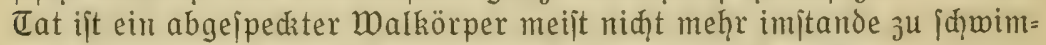
men, während ein frifक erlegter wal gewöhnlid niḑ unterjinkt, fondern an der Dberflähe treibt. Man findet aud bei mandien Walen fettanḩäufungen, deren Bedeutung niđ̨t in der wärmenden Umḩülung der Eingemeide gejuð̨t werden kann, fondern einzig aus dem $\mathrm{Be}=$ oürfnis, das (bewid̨t des Tieres herabzujegen, veritändlich wird. Es ift bekannt, daß̧ der größte pon den Jaḩnwalen, der pottwal, einen ganz riejenhaft entwidkelten Kopf bejigt. Die Derjüngung des Kör= pers nad porne, die 3uppigung oder Jujḑärfung des Kopfes ijt zwar an feinem Sçäbel ebenjo wie bei andern Arten vorhanden (Abb. 18). Aber die weid̨teile des Dberkopfes find zu einem gewaltigen, unförm= liḑen KTumpen entwickelt, der dem "ier eine mäh̆tige breite "Stirn" gibt und den Dorteil, welḑen die fiłh̆ähnliđg̨e Kopfform ḩat, im weient= liçen wieder aufhebt. Öffnet man die dicken wände diejes Kopfes, fo flieft ein wafferhelles öl daraus hernor, das an der suft bald zu einer feiten, mahsartigen Majie, dem Walrat, eritarrt. Der Raum, welçen dies öl einnimmt, wird dadurch erzeugt, dab̉ der Sdjädel an feiner (Dberjeite nađ vorn eine weite und tiefe mulde bildet. über diejer Mulde hat jid die dikke Kopfhaut zu einem hohen Gewölbe aus= gedehnt. AuBerdem ift diejer merkmürdige fettbehälter nad norn noh bis $2 \mathrm{~m}$ weit über die Spife des Dberkiefers hinausgewadjen und wird badurh geeignet, viele fäffer des kojtbaren öles in den un= зähligen groß̉en zellen eines lockeren (bemebes, das ihn erfüllt, aufzu= ipeiḑern. Man kann die Bedeutung diejes jeltjamen Gebildes, da; aud) 3. B. beim Dögling in Kleinerem Maßitabe vorhanden iit, nur darin erkennen, daß̉ es das ipezifijhe Gewiąt des über $6 \mathrm{~m}$ langen Kopfes verringert und das Sđ̧wimmen erleid̨tert. 


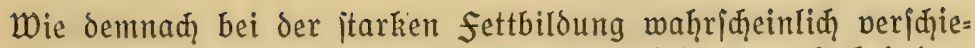
dene Urjadien zujammengewirkt haben, jo wird es aud bei dem sd̨winden ber haare der fall gemejen lein. Es ijt ja gemiß̈, dak für das Gingleiten ourch das wafjer, für die oft reißzend jđgnellen Bewe= gungen, wie fie ein fliehender wal oder wie fie ipielende Delphine ausführen, eine vollkommen glatte (Dberfläḩe des Körpers von fo entjđiedenem Dorteil jein wird, daß̧ jelbjt der geringe Widerjand, den die Beḩaarung zu leiiten vermöchte, niđ̧̨t oḩne Bedeutung ift. In

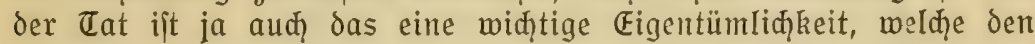

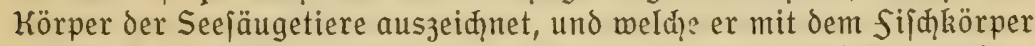

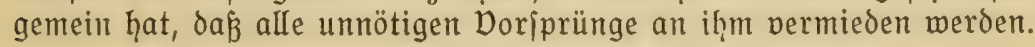

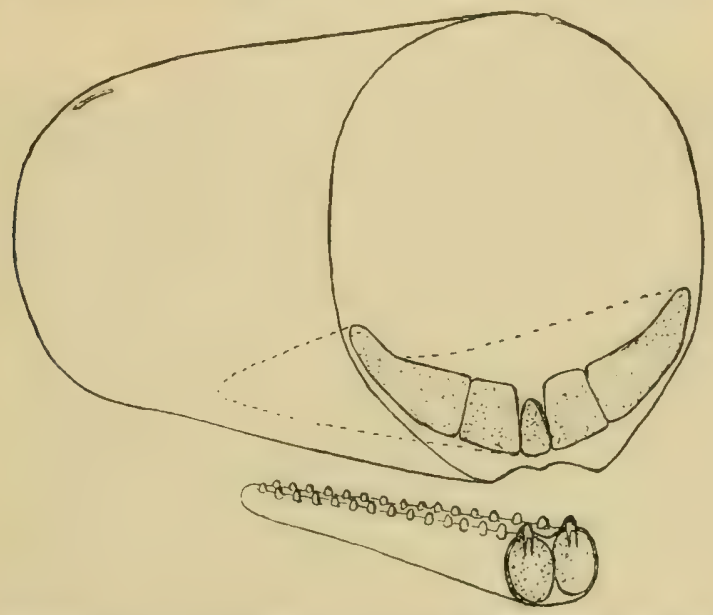

Abb. 18. Dorderkopf eines Pottwals, it der SąädeImitte abgeiđnitten. Die Knochenquerihnitte find punktiert, der Umrif des (Dberkiefers ourch punktierte Einien angedeutet. Đben Iinks das Blasloch. (3eidnung des Derfaffers.)

Die bei den Eandjäugetieren jentreḑ̨t nom Körper abjtehenden blied= maken find dem Körper anlegbar, wie die Dorderfloffen, oder fie ver= lagern fid in die fortfegung des Körpers, wie die Finterflofien der Robben, oder jie berjđ̧winden ganz, wie die der Sirenen und Wale. Die Rüdren = und Sthwanzfloffen ragen zwar jtark hervor, aber jie jegen dem wafier beim Sḑwimmen mur eine jąmale Kante entgegen. Seḩr auffallend, und woh̆l zum Teil aus diejem Gefid̨tspunkte der Derringerung des wajferwideritandes zu deuten, ijt dann now der Sd̨wund der äußeren Dhren. Wenn man an die woḩlentwidielten (Dhrmuiḑeln der meijten Eandjäugetiere denkt, jo wird man jelbjt die deutliḑen äuß̧eren Ohren der Dhrenrobben (Abb.6) nur für geringe Rejte, nur für Rudimente halten können. Bei allen andern Robben, Seehunden und walrofjen, jowie Sirenen und walen feḩlen die Dhrrmuj̧̨̧eIn ganł.

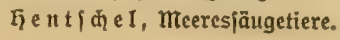




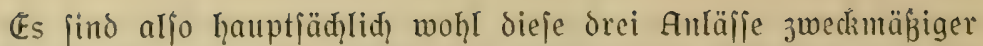
Deränderungen gewejen, weld̨e eine bejtimmende Wirkung auf die Gqaut und Körperoberflädhe ausgeiibt haben, die Erhaltung des Wärme= gleidgemidtes, die Derminderung der Reibung und die Gerabjegung des ipezifijdien bewid̨tes. Wie jie zujammengemirkt haben, welḑe zum erjten Anjtoß der Umbildungen wurde, was für andere Beweg= gründe dex Entwidkelung neben iłnen nođ̆ gewirkt haben mögen, das find nebenjäđliḑe und zum Teil unlösbare fragen, auf die hier

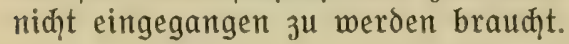

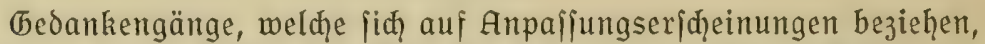
ḩaben ill vielen fällen das Miß̧liche, daß̧ ein mejentliḑer Bejtandteil

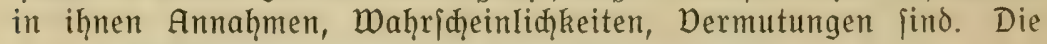

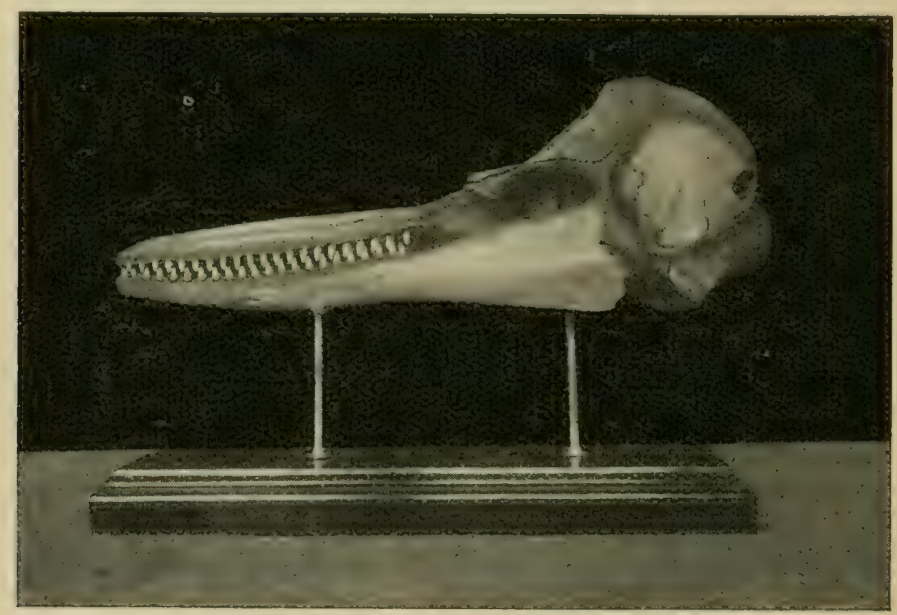

Abb. 19. Delphinifđ̧ädel. (Aufnahme des Derfaffers.)

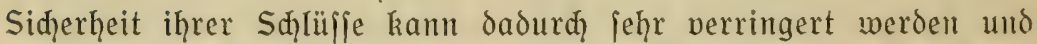
es gejhieht nid̨t jelten, daß̧ die hillfe der phantajie, welḑe bei der Derbindung von Innen und Außen, von Drganifation und Umgebung unumgänglich ift, zu einer Beherrjđ̧ung ourdh die phantajie ausartet und leere Erdidhtungen zur folge hat. Am wenigiten wird man diejer

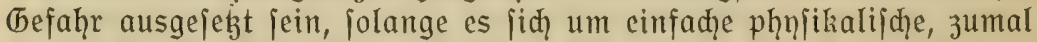

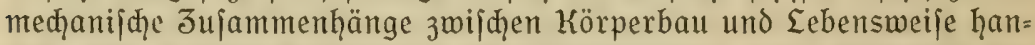
delt. Dic äukere Erjheinung der Seejäugetiere, ganz bejonders der Wale, ijt in diejer Weije mit verḩältnismäß̧ig großzer Siđherḩeit meḑanifd ausdeutbar, und jie dient deswegen von jeher in der bejzen= dertztheoretijdyen Eiteratur als ein beliebtes Beipiel. Niđjt jo einfad veritehen (id) vielfad die inneren (1)rganifationsverhältnifie, um fo meḩr, da der Einfluß der Auß̧enwelt hier felten jo tiefgreifend ift wie dort. Idy merde auf jie nur in geringem Maßje cingehen und 
möglidjit nur bei den Eridgeinungen vermeilen, deren Deutung als Anpaffungen und deren Entitehung unter dem Einflub der umgebenden Eebensmöglid̨̧keiten ziemlid unzmeifelhaft von jelber cinleuditet.

Es kommen dafür bejonders nod die (Drgane der Dermitte= Iung in Betrađ̧t, Körperteile, welđhe die eigentlid\}en inneren (Brgane mit der Aukenwelt in Beziehung legen, wie 3. B. die (1) rgane der Tahrungsaufnahme, der Fint= und Ausatmung und der Sinneswaht: neḩmung.

Die hervorragende Stellung, welde in allem Eeben bei Tieren wie bei Pflanzen die Ernährung einnimmt und die groß̉e nTannigfaltia= keit der jiḑ bietenden Quellen der Taḩrung haben zur folge, daß̧

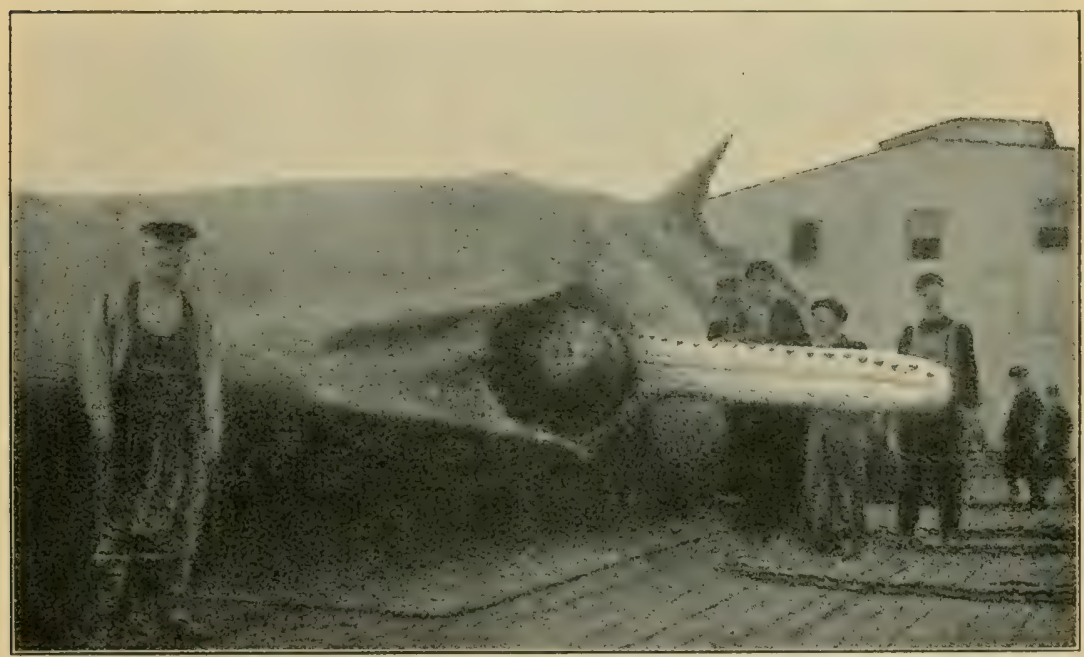

Abb. 20. Aufgeipeertes Maul eines Pottwals. Dben das linke Ange und die linke Bruftfloffe. (Aufnaḩme des Derfaffers.)

zwiłđen Kahุrung, Ernäḩrungsweife und Ernäḩrungsorganen überall eine enge Derkettung eintritt. Man wird niḑt 3 u weit gehen, wenn man annimmt, daß̧ in vielen fällen die Auffindung neuer Tahrungs= quellen, die Entdediung neuer Ernährungsweifen für die Zatur zum Anjtoß tierif̧er Teubildungen wurde. Man wiró dies auक für die meeresfäugetiere annehmen dürfen. Auफ hier zeigt fich in vielen fällen wieder eine merkmürdige Annäherung des Säugers an den fijd. In andern fällen - bei den Bartentwalen - ijt es dagegen zu ganz eritaunlichen Teubiloungen gekommen, für die in dem gewöhn= lichen Körperbau der Säuger gar keine Dorbereitungen auffindbar fheinen; Keubildungen, die aber wieder zeigen, mit weldeer Dollen= oung das Eeben zweckmäßig $3 u$ geitalten vermag.

Die 3 ähne der fijhe und die der Säugetiere unteriđgeiden jidh

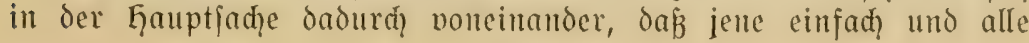


Intereinander ähnlic, diefe kompliziert und untercinander varfhieden find. Dies hat zum एeil unzweifelhaft gejđhidhtliđ̧e (bründr; die Ein=

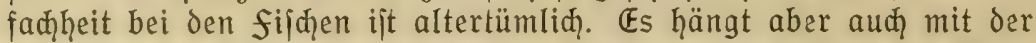
funktion der jähne zujammen. Die Jähne in den Kiefern der fijđ̨e dienen niđ̧t zum Kauen, fondern uur zum Ergreifen der Kaḩrung. In der Tat wird das Kauen im Wajfer bei waitem nidit fo gut aus=

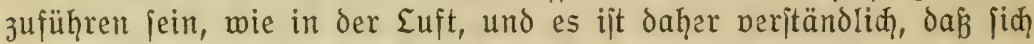
ein zum Kauen geeignetes (万ebiß erit bei Eandwirbeltieren ausgebildet hat, und daßj es bei der Rüdikeḩr zum Eeben im wajfer wiederum

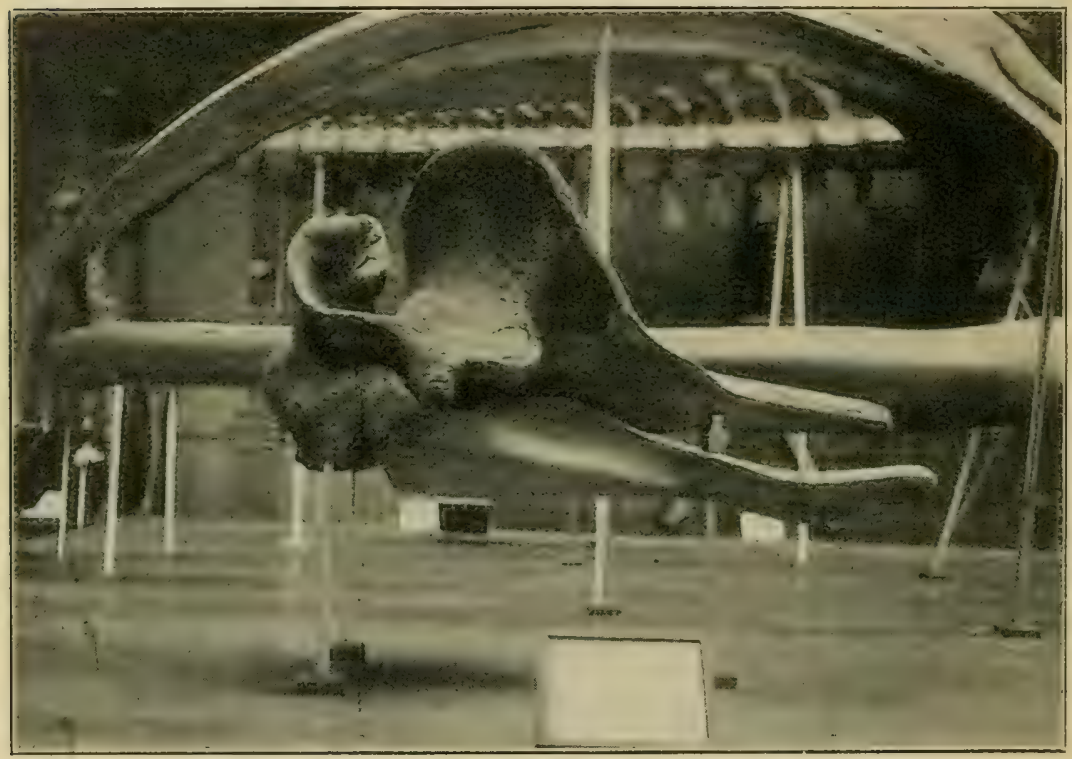

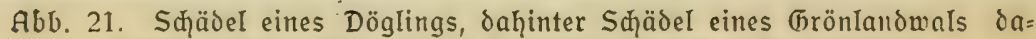

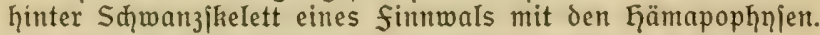

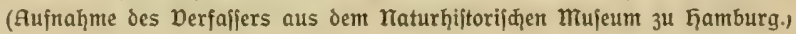

mehr oder meniger zurüdzgegangen ijt. Das (bebiß̧ eines Deiphins mit jeinen zaḩlreiden, \{pizen, kegelförmigen zäḩnen (Abb. 19) erinnert jehr lebhaft an das cines fijh̨es, und ähnliđ die (bebiffe vieler größerer wale. Es ift in diejer form zum Ergreifen von fijhen und Tinten= fijdzen jehr geeignet. In mandhen andern fällen ijt aber die Rüdz= bildung nod weiter fortgeiđhritten, ift die Jaḩl der Jähnne, die bei den Delphinen aukerordentlich permehrt war, jehr zurüdkgegangen,

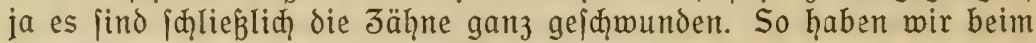
pottwal nur im Unterkiefer Jähne $(A b b .20)$. Bei dem feltenen Klei= neren Wal Mesoplodon findet fid in der Mitte jeder Unterkieferh̨älfte nur ein einziger groß̧er $3 a h n$, der an den Reißzzahn (Breçzahnn) eines Raubtieres crimmert. Beim Entenmal (Abb. 21) feḩlen die zäḩne ganz 
oder treten wenigitens niemals aus den Kieferknoḑen hervor. Diejer

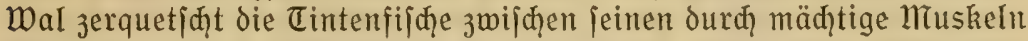
bewegten Kiefern und jhlingt fie dann hinab. Man wird, wenn man dieje Ieģtgenannten fälle in Betrađ̧t zieḩt, zu der überzeugung kom= men, daß̧ der Einfluß

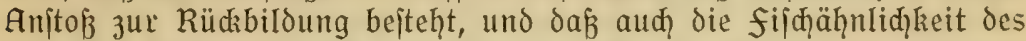
Delphingebiffes vielleidįt mentiger als eine spezialifierung für den fang, vielmeḩr als ein Stehenbleiben auf einem gemiffen, für die Eebensweife der Tiere niḑt ungeeigneten Stadium der Rüdabildung aufzufafien ift.

überḩaupt können wir bemerken, daß̉ die Deränderungen im (bebiß der Meeresjäugetiere fajt überall auf Dereinfađhungen hinaus= Iaufen. Dieje aber find naturgemäßß feltener deutlid als Anpaffungen ḑarakterifiert, als das bei fortfhreitenden Bildungen der fall fein

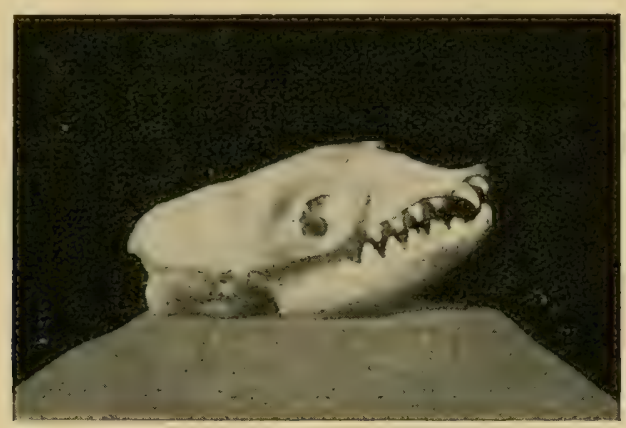

Abb. 22. Sdädel des Weiben Seehunds oder Krabbenfreffers. (Aufnahme des Derfaffers.)

würde. Dereinfą̧t ijt das (bebißz der pflanzenfreffenden Sirenen, wem man es mit dem iḩrer nädhiten Derwandten, der Guftiere, vergleid̨t. Bei der Stellerihen Seekuh find die Jähne ganz gejđ̨munden (Abb. 13). Dereinfađ̧t ift aud das (bebiß der Robben, das man auf ein Raubtier= gebiß zurüdifüh̨ren muई ( jąmal, von den Seiten her zujammengedrüdat, und mit mehreren in einer Reiḩe jtehenden zadien bejest. Je jelbjtändiger, höher und

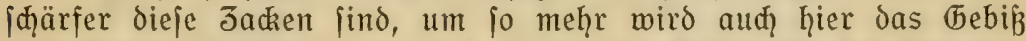
zum Greifen geeignet pein. Und in der Tat haben wir bei dem See= leoparden des jüblidhen Fismeers diejen Jujtand jo hod ipezialijiert, daß̧ jeder Jaḩn in orei jelbitändige ipige Kegel ausläuft, die je an einen Kräftigen Delphinzahn erinnern (АЬЪ. 4). Das Tier mit diejem reçt für den Raub geeigneten 3aḩnbau friß̧t fijđ̨e und jogar pinguine. Andererfeits aber finden wir au币 bei der Weipen Robbe der Antarktis etwas ganz Ähnliđies (Abb. 22), obwohl diejes Tier niđ̨t von größzeren Beuteitücken lebt, jondern pon ganz kleinen Krebsdien, die in Maffe das wafjer bebölkern und die diejer Seehund in ähnliḑer weije mit 
aufgeipertem Maule fangen foll, wie es ein Bartenwal tut. Allerdings fino dic hohen Jakien der Jähne bei diefer Robbe niḑt jđarf zu= gejpigt, fondern abgerundet und in merkwürdiger Weife nad hinten gekrïmmt. Andere Robbenarten wieder haben ein verkümmertes (bebís, wic jo viele Wale.

Einige der feltiamiten ı:nd auffallenditen Jaḩ̧nildungen, welḑe mir bei Meeresiäugern finden, nämliđh die Gquer der Walrofie und Dugongs fomie der merkmürdige lange Stoßßzahn des Karmals; Iaffen (id) nod) meniger als die gewöhnliḑen Jähne für befonders angepaß̉te (5ebilde arjehen. Denn wern jie aud bejtimmte funtitionen im seben der Tiere zwedimäßig ausfïhren, fo bleibt es dod jehr zmeifelhaft, $o b$ es dieje funktionen find, die jie erzeugt haben, ob ihre Entitehung und Erhaltung aus Anpaffung heraus befriedigend crklärt merden kömen. Auf die Gauer des Walroffes werde id ipäter nod meḩrfad

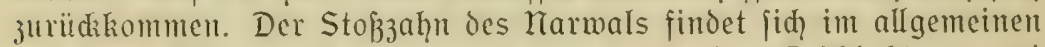
mur beim Mäınḑen. Es werden aber bei beiden (befd̨leḍtern zmei

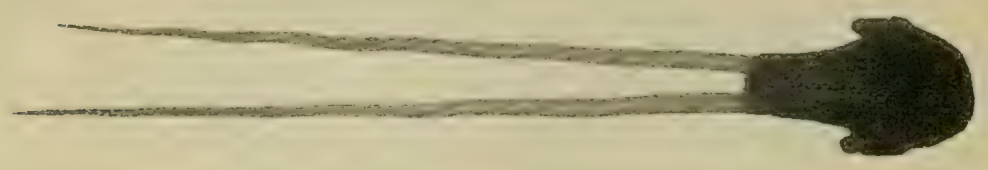

Abb. 25. Abnormer Sḑädel eines meibliḑen Karmals mit zwei Jäh̆nen im 2Toturf̧iftorifḑen Mufeum 3u Eqamburg. (Aufnatime des Derfafiers.)

Jähne in (Dberliefer angelegt, wic man durd öffnung der Sḑädel

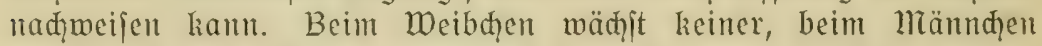
gemöhnlid mu der linke aus dem Sđädel herwor. Selten hat das Mämmden zwei ausgebildete zähnue, und in einem einzigen falle ḩat man dies aud beim Weibçen beobad̨tet (Abb. 23). Der Stokzzahn fđ̧eint unter anderm den Mämnḑen bei iḩren Kämpfen um dic Weibḑen als Waffe zu dienen.

Tađ dem allen ipridit aus der Bezahmung der Meeresfäugetiere die Eigenart der Ecbensbedingungen im Meere zwar merklid), aber bei weitem niđ̧t mit der Deutlid̨heit, wie ctwa aus den Bemegungs= organen. Dagegen ift jenes andere Mittel der Kaḩrungsaufnaḩme, das in einer beftimmten (5ruppe von Waltieren die zähne erjegt hat, nänlidy die Barten, wieder ein reḑtes Meijtermerk der Anpajung. Ähnliọ, wic bei der Rüdken= und Sḥwanzfloffe, die auf den eriten Blick in der Sängetierreiḩe ganz alleinitehende Bildungen zu jein

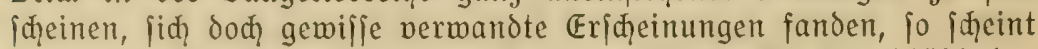
es auđ bei den Barten niđłt ganz daran zu feḩlen. Die Mundhöḩle der wiederkäner enthält an iḩren wandungen mannigfaḑe fortjäge, die zapfent $=$ falten $=$ oder leijtenförmig in den Innenraum hineinragen. Bei 
den Giraffen beifpielsweife hängt vom Gaumen herab eine Reihe von nady unten ausgezaditen Querblättern, an denen man fiø recht gut die Entitehung bartenartiger Anḩänge Jurą eine einfache Derlängerung

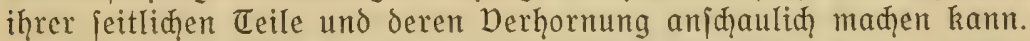

Die Barten ( jąmaler oreiediger platten, welḩe an beiden Seiten des (baumens an Stelle der Dberkieferzähnte herabhängen; Platten von fij̧̨ein, die ant interen Rande ausgefranjt find und durh die Jujammenlage= rung der fo entitehenden fijd̨beinfajern an jeder Seite der Mundḩ̈̆hle

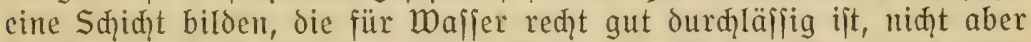

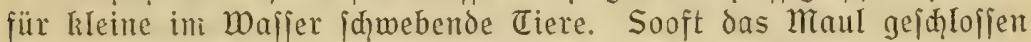

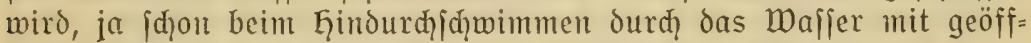
netent Maule, muß notwendig eine Durdfiebung oder filtration des wajfers mit hillfe diejes Apparates itattfinden, und darauf beruh̨t die Ernährung der Bartenwale. Sie jegt naturgemäß voraus, daßz kleine Eebewejen in ungeheuren Mengen im Wajfer vorhanden find, und itellt infofern eine ganz eigenartige und hodigradige Anpafiung an die Eebensbedingungen im Teere dar. Bei der Wirkjamkeit des Barten= behangs zum Erwerb der Kahrung find nun nod) verfđ̧iedene Eigentüm= liḑ̧eiten in Bau des Kopfes mit beteiligt, dic einerjeits auf eine $\mathbb{E r}=$ meiterung der Munohöhle, anderer= leits auf iḩre möglidjit vollitändige Entleerung bei jedem Sąließzen des

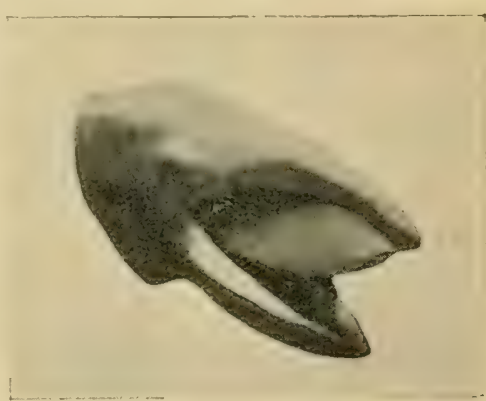

Аъь. 24. Kopf des auftralijøen Jmergmals Neobalaena; Modell im Iaturhijtorijd̨en Mujeum zu Gamburg. (Aufnahme des Derfajiers.)

Maules hinzielen. Während bei den meijten Jaḩnmalen der Dorderteil des Sdäbels \{d̨nabelartig gebaut ijt, indem die verlängerten Knoḩen des bber = und Unterkiefers fich eng aneinanderlegen, hat fich der

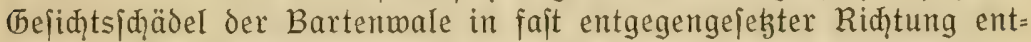
widkelt. Die Kieferknoḑen find an ihm weit auseinandergewiđhen, fo dẩ ein mäळ̧tiger dreifeitiger Gohlraum entitanden ijt. Das ijt bejonders bei dem (5rönlandmal jeḩr meit gegangen. Gier ijt der jtark verlängerte fđmale Dberkiefer in einem hohen, fajt halbkreisförmigen Bogen gewölbt (Abb. 16 und 21). Die beiden Unterkieferknoḑen find, im бegenjas zu denen der Jahnnwale, mur mit if̧ren Spigen verbunden, im übrigen aber weit auseinandergebogen und nad außen gewölbt. Die দ̧öhe der Mundhöhle bedingt es, daj die Barten zumeilen jeḩr lang find, länger als bei irgendeinem andern Wal. Sie find fđamal und überidreiten zumeilen eine Eänge von $2,5 \mathrm{~m}$, fo $\delta a \hat{z}$ jie jiđ beim Sd̨ließ̧en des Maules biegen müffen. Ihre Anzah̨l ijt fajt 400. Dagegen iit die Mundhöhle bei den furḩenwalen niedriger, die Barten find 
Fürzer und breiter. Bei diejen Tieren findet jid aber eine Einriątung, die dazu dient, die Mundḩ̋̈hle beim (bebraud der Barten aktiv zu er= weitern. Dic Ģaut der Keḩle hat eine großße Jaḩl langer und tiefer furdhen. Wird ber Rachen aufgeipert, um das Kahrung ipendende waffer aufzuneḩmen, jo deḩnt fiđ zugleiđ̧ die Keḩlḩaut vermöge diejer furąung aus und ermeitert damit den Mundraum nady unten (Abb. 25).

Beint Shließen des Maules und dem Ausfließen des Waffers zwi=

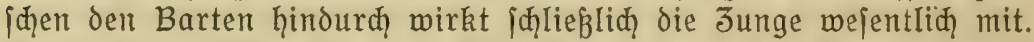
Sie mađ̧t gewiffermaß̧en einen Mangel der ganzen Einriđtung, nämlich die Aufnahme groß̧er Wajfermajien in den Körper, wieder gut. Die Junge ift zumal bei den (bIattwalen ganz aukerordentriç großj und

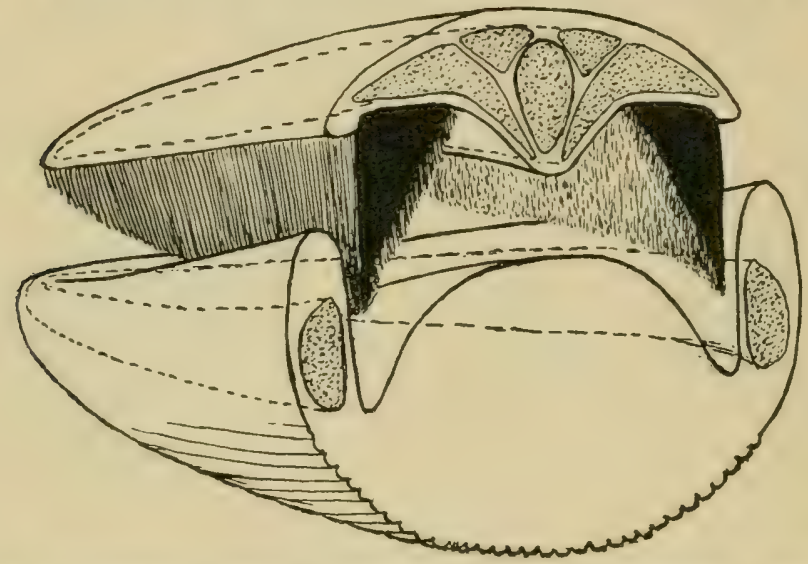

$\mathrm{Abb}$. 25. Dorderkopf eines furdienmals, in der Sđäbelmitte abgejanitten. Die Knodenquerihnitte find punktiert, die Umrifie des Shädels durc punktierte

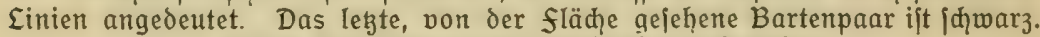
Unten find Junge und Kehlfurąen erkennbar.

(3eiḑnung des Derfaffers im Anjąlub an DeIage).

muskulös. Beim öffnen des Maules kann fie tief herabgedrü đat werden, beim Sd̨liejen hebt jie jid zwijhen den beiden Bartenitreifen bis zum Gaumen in die Ģöhe und füllt den Mundraum fajt pollitändig aus. (bleid darauf \{ḑiebt jie permöge einer Sd̨luchbewegung die auf= gejammelte Kaḩrung in den Sđ̧lund hinein. -

Es mag hier noc kurz bemerkt pein, daß̉ aud die inneren $\mathbb{E} r=$ nährungsorgane deutliđ̧e Anpaffungen an die Figenart der Iaḩrung und der Ennährungsweife zeigen. Bejonders ijt es eine notwendige folge von feḩlen des Kauens, daß̧ der Magen die Eeiftungen mit übernehment muß, welḑe fonjt beim Kauen die Derdaung vorbereiten, und daßj er demgemäß bejonders ausgeitaltet ijt.

Was am auffallenditen einen Wal non einem fijd unterideidet, ift die Art der Atmung. Denn der wal atmet in der Suft, der fijc im Wafjer; der Wal bejigt Lungen, der fijळ Kiemen. Kein Säugetier 
Kann dauerno unter Waffer bleiben. Jeder Wal, jede Robbe muß immer wieder an die Dberfläḑe Fommen, um die Suft jeiner Eungen zu erneuerit. Dic eigentliḑen Atmungsorgane haben infolgedeffen reine

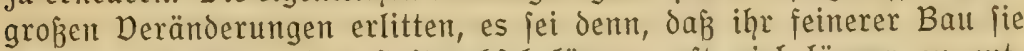
bejonders befähigt, den Euftweḑjel länger, oft viel länger zll ent= behren, als dies bei anderen Säugetieren möglid iit. Dagegen zeigen aud hier die Dermittelungsorgane, die Drgane der Ein= und Aus= atmung, ḑarakteriftijhe Ampafiungen.

Bei den Robben jind, im thegenjał zu den meiften anderen Säuge= tieren, die Kajenlöder im gewöhnliđen Jujtande niąt geöffnet, fonden durd bejondere Muskeln gejक̨lofien. Dadurd, wird natur= gemäß perhindert, daf́b beim Tauḑen das Wajper in die Kaje cindringt. wenn die Tiere atmen wollen, fo mïifen jie artio die Kajenlöḑer öffnet. Auf diejen Deriăluß der Taje ijt es, wie iđgn erwäḩnt wurde,

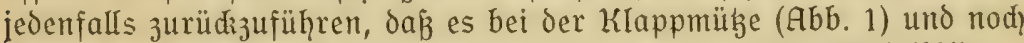
mehr bei dem See=Elefanten ( gekommen ift. Das Aufblajen der gejolofienen Kaje mag zu einer

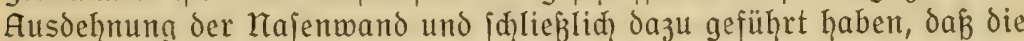
Taje den Sdädel müzen= oder rüfielartig überwuds. Aud bei den

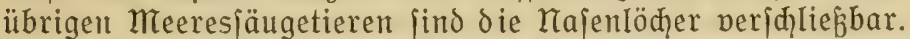

Bei den Walen ift aber meientrid auffallender eine andere Figen= tümliăkeit der Kaje, nämliळ die Deriḑiebung dar Kajentöđher vom Maule meg auf die höhe des Kopfes. Die Bedeutung diejer Deränderung, die jelbit auf den Sळ̆ädelbau einten tiefen Einfluß geḩabt hat,

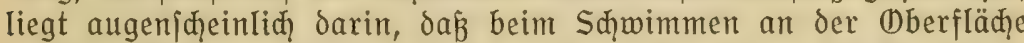
die Atemöffnungen leid)t und dauerno an die Suft gebrad, werden können. Man bezeiđntet die Vajenlöđ̧er hier als "Spriglöd̨er" (beffer Blaslöd,er), weil beim Auftauđhen des Wals aus iḩnen die Suft einem Waflerjtraḩ ähntiđ fiø̨tbar herausgejtoken wiro.

während bei allen mit cinem ipigen oder zugejđäriten Kopfe ver= feḩenet Walen die Kajenöffnung ziemliđ weit rüdzmärts Yiegen muß́, um hoch liegen zu können, liegt fie bei dem pottwal mit feinem didken, breiten, fenkred)t abfallenden Dorderkopf ganz porn (Abb. 18). Es ift nur ein einziges, linksfeitiges, aljo uninmmetrif gelagertes Blas= lod vorb̧anden, von dem aus ber Kajengang iąräg durd die oben ermähnten fettmaflen hindurd nađ̆ der im Grunde der Sđ̆ädelmulde gelegenen knödernen Kajenöffnumg verläuft. Damit hängt es zujam= men, daßz der Strahl aus dem Blaslod beim pottmal jđyäg nađ vorn geriđhtet ijt, woran man diejen Jahnwal jhon aus der ferne leidit von den groken Bartenmalen unterineiden kann.

Gber die Einwirkung der Eebensbedingungen auf die Aufnaḩme= organe des Atemapparates geht nod tiefer; aud der Kehlkopf ift, zumal bei den Jahnwalen, in bedeutjamer weije umgejtaltet. Bekannt= liđ̆ bildet der Keḩlkopf das Eingangstor der Euftröhre und liegt an der Stelle, wo fid im Fintergrunde des Rađiens die Euftröhre von der Speiferöhre trent. Die Suf̣t hat bei den meiften Säugetieren zmei 
Jugänge, nämlid Kaje und Mund. Beide führen in den Raḑen hinab. Durd) dell Mund in den Radhen hinein bewegt fid aber aud die Kah= rung, ie hat aljo zum Teil mit der Suft denfelben weg und es bedarf ciner bejonderen Ginriḑtung, des Kehldedels, um zu verḩindern, daß fie in die Euftröhre hinein kommt. Bei den Walen ijt nun eine voll=

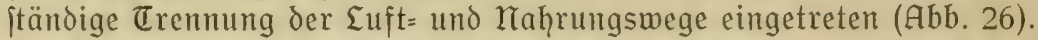
Die Suft tritt mux durd die Naje ein und wird unmittelbar in den Kehlkopf meitergeleitet. Diejer hat jiđ nämlid nady oben, aljo in den Rađ̧en hinein und ourḑ ih̨n hindurd̨ röhrenartig perlängert und ragt

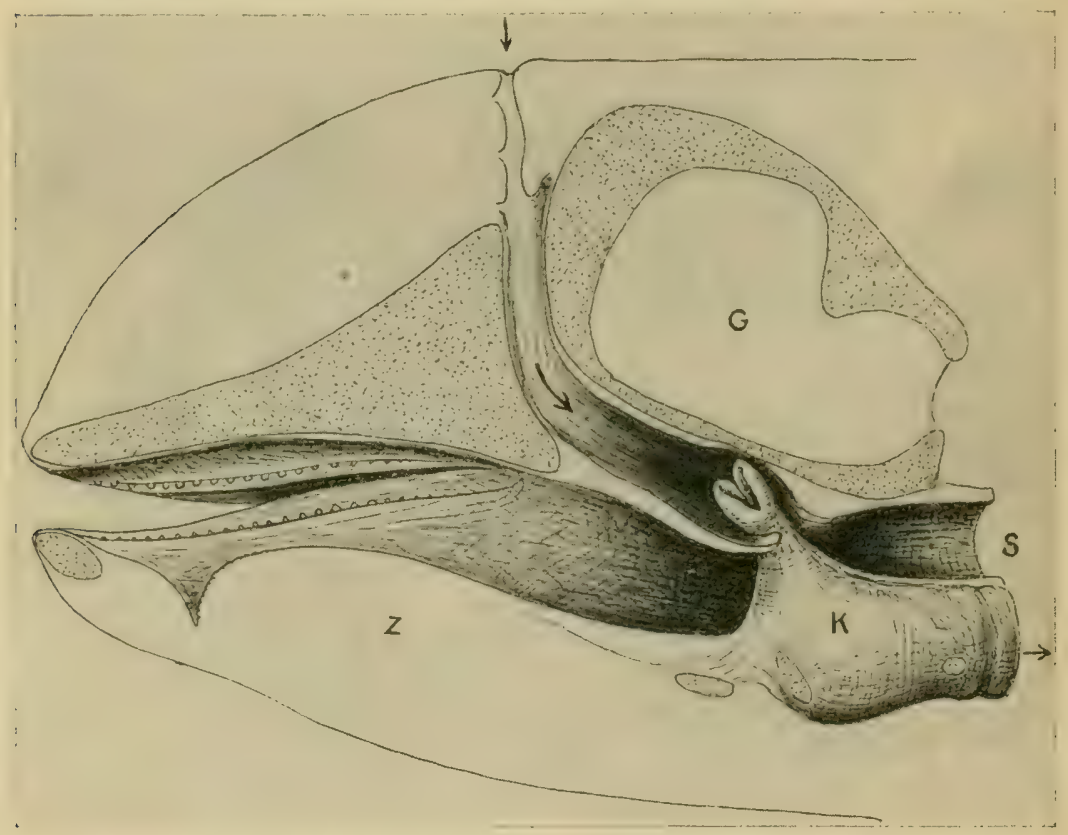

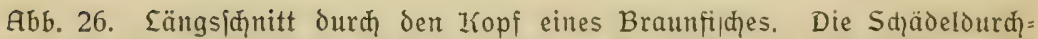
jąnitte find punktiert. G (behirn, Z Junge, K Keklkopf, S speiferöhre. Die pfeile bezeidynen den weg der Atemluft. (3̧ciđ̧nung des Derfaffers.)

mit diejer Derlängerung an der Dedie des Radjens in das innere Ende des Kajenganges hinein (Abb. 26). Kafenlödher, Kajengang, Kehlkopf und Euftröhre bilden ein gefḑlofienes Roḩr, das zur Eunge füḩrt. Nundöffnung, Nundhöh̨le, Rađ̧en und Speijeröhre führen ebenfo gefdyloffen in den Magen. Da der Luftweg den Kahrungsweg von oben nady unten durçbohrt - etwa jo wie ein Suftiḑađht auf einem

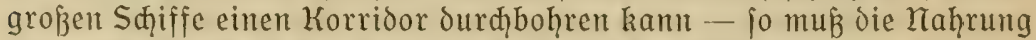
hier rehts und links neben dem Euftrohr vorbeigefđioben merden, mährent fic fonjt über den Eingang der Euftröhre hinmeggejđ̧oben wird. 
Dic groke jowedimä̧̧gkeit diejer Bauverḩältniffe des kehlkopfes leuđtet ein. Sie verhindern fo vollkommen wie möglid, cin Eindringen non Wafjer in die Euftwege. Es ijt ḩödjit merkwïrdig, daß ganz diejelbe Einriḑtung zul einem ganz ähnliḑen zmed fich nod einmal bei den Säugetieren wiederfindet, nämliđ̆ bei den Jungen der Kängu= ruḩs. Dieje Jungen werden bekanntliđ in jehr unvolfkommenter form geboren und im Beutel des mütterlichen Tieres den Jizen angejegt. Sie jaugen zunädj|t nid̨t an den zigen, jondern die Mild wird iḩnen cingeiprigt, und daß̧ fie dabei niđ̧t in die Euftwege gerät wird dadurd? erreiḑt, daß dieje wie ḩier bei den walen in unmittelbarer und ge= fक̧loffener Derbindung mit den Najengängen jtehen.

Der groke Dorteil, welhen der Bau der Suftwege bei den Walen fiit die Atmung hat, ijt nun mit cinem Kaḑ̧teil fïr dic Ernährung verbunden, denu der Sd̨lund wird bedeutend verengert. für die Barten= male ift dies menig wejentlid, weil ihge Tahrung aus jeḩ tilcinen Tieren bejteht. Bei dem pottwal, deffen Sḑlund weit gemug iit, um cinen Meniden zu verid)ludien, wird der feḩler dadurd möglidhit mieder gut gemadht, daßj der Kehlkopf auf die linke Seite nerjhoben ift und die Rahrung mur red)ts daran vorbeigleitet. Nit diejer $\mathcal{D e r}_{\mathrm{c}}$ lagerung des Kehlkopfes dürfte die linksfeitige sage des einzigen najenloḑes zulammenhängen und vielleiđ̧t aud eine höhif auffallende Eigenjąaft, die Aln̨mmetrie des Sḑädels, die fid̄ bei allen Jahnmalen bis zu den kleiniten Delphinen hinab deutlid beobaḑten läß̧t. Aller= dings kann dieje Ajnmmetrie, die fich aud bei manḑen Bartenmalen in der färbung der Barten ujw. findet, nod keinesmegs als genügend erklärt gelten.

Sd̨ließ̧lid̆ mögen hier der Reihe von Beifpielen zur Anpaffung an das Eeben im wafjer nod cin paar Bemerkungen jiber die Sinnes=

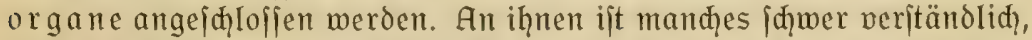
weil die Wirkungsmeife diejer (1) rane vielfad auf dem feineren Bau cinzelner Zellen beruḩt, deffen Bedeutung mir nur menig begreifen. Wir werden bei diefen Dermittelungsorganen zwifhen Innen= und

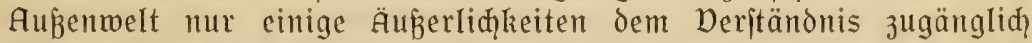
finden. (berud und (bejđ̧ntad jheinen allgemein eine geringe, zumeilen fajt gar keine Rolle im Eeben der Seejäugetiere zu fpielen, was infofern von Bedeutung ijt, als bei vielen Eandjäugetieren der (万erud jelbjt dem

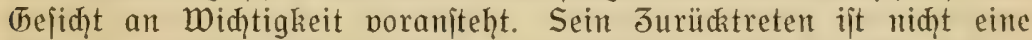
Anpafiung, aber dođ cine folge des Eebens im Wafjer. Die fähig= keit zu Tajtempfindungen hat augenidzeintid bejondere (Drgane; jene wenigen ftarken Gqaare, welḑe bei Sirenen uno walen beim Derlujt des Ģaarkleides zurüdzgeblieben jind, erweijen fid als Sinneshaare, Tajtḩaare, denn an jedes von ihnen tritt ein feines Blutgefäß und ein Kerv heran. Aun der itarke Sdnurtbart der Robben, der bejonders bei der Bartrobbe und dem walroß auffallend entwickelt ift, dürfte Tajtempfindungen vermitteln.

Auge und Dḩr müffen naturgemäß den eigenen akujtijd̨en und 
optijd̨en Derhältniffen im Waffer entfpreḑend gebaut fein. Es würde 3u weit führen, wollten wir dicfen Jufammenḩang in den Einzelheiten

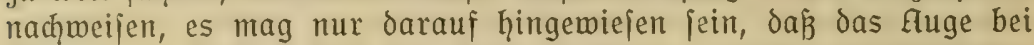
Dalen und Robben dem der fijhe in jeinen optijđgen Derḩältniffen

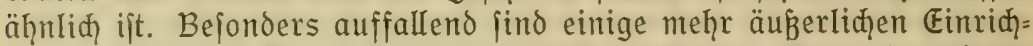
tungent all diejen Brganen, die ihrem Sđ̧ußge dienen. Der auß̉erordent= Iiđ ḩohe Drud, dem fie in großen Tiefen ausgejegt werden, hat, wie bei allen öffnungen des körpers - aud Taje, Gfter, Ģarn= und бe=

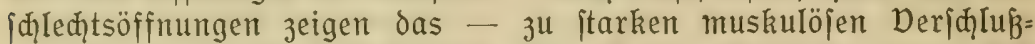
cinriđ̧tungen geführt. Auß̧erdem aber ift das Auge von ciner faft jteinḩartell Fiülle umgeben, die dem zarten, kojtbaren Organ eine ganz

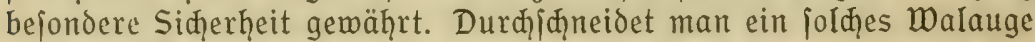
(Abb. 27), fo fieht man, daß̉ das eigentliḑe Sinnesorgan, der zur E $\mathrm{r}=$

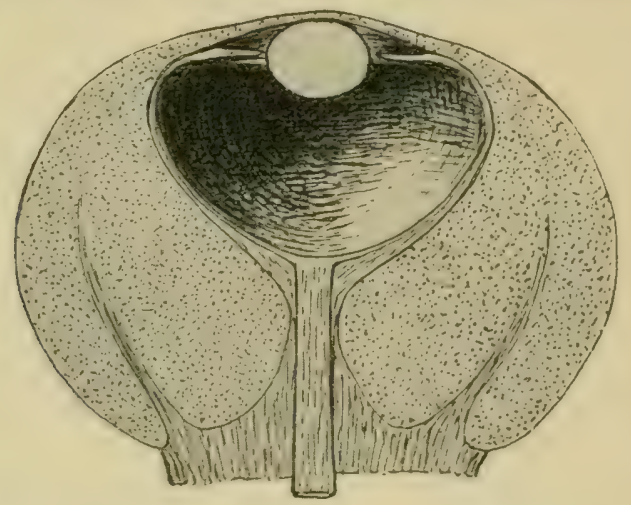

Abb. 27. Auge eines Wals in Eängsiđnnitt. Die Einje ift weip, die jtark verdidite Gornhaut punktiert. (Jeidnung des Derfaffers.)

zeugung des Bildes und zum Sehen dienende Eeil, verḩältnismäß̧̨ig

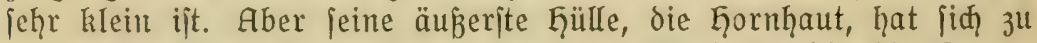
einer gemaltigen, didwandigen Kapjel veritärkt, welḑe die Ģaupt= maffe des Auges ausmantht. Es ift dies das auffallendite Beifpiel aus einer bejonderent, eigentümlid̨̧en (5ruppe von Anpafiungseriđ̧einungen, aus den Anpaffungen an den gewaltigen Drudz der Waffermaffen, welḑe über den Tiefen der $\mathbb{B}_{3}$ eane Iajten.

nimmt man alles, was hier bejhrieben wurde, zujammen, umfaß̧t mant mit einem Blide das ganze AuB̉en und Innen eines fold̨en ḩodh= entwiđeltent Meeresjäugetieres, eines Walfijhes, fo wird man mit Derwunderung feḩen, wie ḩier die Tatur gleidj̧am als ein groß̧er Künitter aus dem Injtrumente des Tierleibes etwas jo ganz Eigenes, Seltjames, dabei jo vollendet Einḩeitlinges hervorgebraḑt hat. Mit fouveräner Mađ̧t und freiheit geitaltend ḩat fie dođh der Eigenart des Initrumentes in allem Redhnung getragen. Die groß̉e Melodie des meeres klingt ḩell und deutliđ ḩeraus. Es ppriđ̧t daraus die Eajt der 
Wafjermaffen von Taujenden von faden, die Tragkraft und Wider= itandskraft des flüffigen Elements, es iprid̨t daraus die befondere

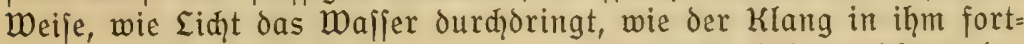
geleitet wird, es ipriđ̧t daraus der unerjđöpfliđ̨e Eebensreiđ̧tum der endlojen Meere. In vielfältigen Dariationen hat die jđ̧̈pperijđ̧e Kraft der Vatur dies Thema zur Ausführung gebrađ̧t. Der Sinn des Wunder= werkes aber ijt die nod immer unbegriffene fähigkeit der Natur, das Eebende zwedzmäßig zu geitalten und umzugeitalten.

will man dies alles nod befier, nod jđärfer, nod heller beleudtet jehen, jo wird man den Bliḑ über die Grenzen hinausgehen lajfen müffen, welḑe diefem Bud\}e gejtedzt jind. Man wird jehen, daß es be= fondere, eigenartige, ganz dem meere verbundene formen aud unter den Dögeln gibt. Es feien nur die merkmürdigiten, Alken und pin= guine, hier genannt. Weiter haben die Reptilien Schlangen und Sḑildkröten ganz bejonderer Art ins Meer hinausgejandt. Kod viel feltfamere formen, Riejenreptilien mannigfaḑer Art, haben zur

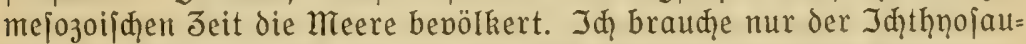
ren Ermähnung zu tun, die für das Jeitalter der Reptilien das waren, was heute, im Jeitalter der Säugetiere, die Wale find. Die fijhe aber, die wir hier nur im (broken und (banzen ihrer Drganifation zum Der=

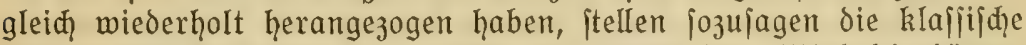
cöfung der probleme dar, welḑe das Meer dem Wirbeltierkörper aufgab.

Wir können vom Meere in das Süpmaffer hinaufgehen und wer= den, wie jđon gelegentlid, angedeutet wurde, viel heues und Eigen= artiges zu unjerem (begenjtande finden. Wir können von den wirbel= tieren zu den Wirbellojen hinabiteigen und werden wieder und wieder fehen, wie die Mađht des Meeres die weiten Kłüfte überbrüd, welḑ̧e die Stammesgejhidhte zwijhen den verjhiedenen Tiergruppen hat entitehen Iafjen. Das alles kann an diejer Stelle nur angedeutet werden, um zu zeigen, wie fid die Aufgabe, welḑe in diejem Kapitel beḩandelt

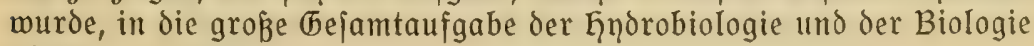
überḩaupt einfügt.

\section{Kapitel.}

\section{Die Eebensweife.}

Unter dem vielen frembartigen (betier, das einem einjamen Sthiff

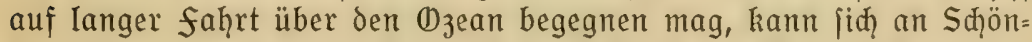
heit nur meniges vergleidhen mit einer sł̧ar der iđhnellen Delphine, die plöglid in der Weite des Meeres eridgeinen und das fahrzeug ppie= lend eine Strecke weit begleiten. Unabläfjig auf= und niedertauḑend, in wellenartiger Bewegung einen Augenblid mit der Rückenflofie und einem Teil des Rüdkens aus dem Waffer kommend, dann fđ̧nell wieder 
verfd]windend und in geringer Tiefe, nom Bord aus now fintbar, $\delta a=$ himftreidhend, fo gleiten fie lange am Sdiff hin und wieder. Sie unt= iḑwimmen pfeiliḑnell den Kiel, tauḑen unter den Shiffsrumpf, fpielen

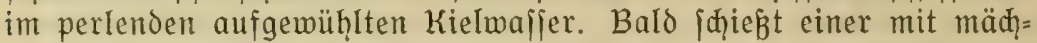
tigem Sdiwung über das Waffer empor, bald wirft fid ciner unter

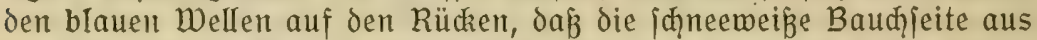
der dämmernden Tiefe hernorleuđhtet, bald jagt die ganze Sḑar mieder eilig von dannen, mit den jđ̧önen dreieckigen Rüđkenfloffen zmijh̨en den wellenkämmen hin ihren weg bezeidnend.

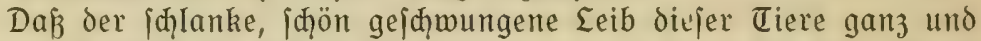
gar ein fijhleib ijt, daß in der vollkommeniten Weije jich dies Säuge= tier in die Maske eines fijdhes verkleidet hat, das zeigt aud das tote Tier, went einmal die fijher den jeltenen (5ajt auf den Markt jdilep= per. Aber wie jehr der Delphin fifd gemorden ift, wie vollendet er feiner Derkleidung gemäß feine Rolle zu fpielen vermag, bas wird mur der wiffen, deffen Auge, gefeffelt von aller iḩrer sđ̧önḩeit, (be= wandheit und Kraft, bei dem Sḑaupiel gegenwärtig gewejen ijt, das jie mit ihren Spielen auf offenem Meere dem Seefahrer bieten. Leib und Leben hängen eng zujammen. Der Körper erzäh̆lt gar deutliđ̆ und peritändid pon der Sebensweife der Tiere. Aber man mus fie im Eeben jelber gejehen haben, vielfad und genau in allen Einzelheiten

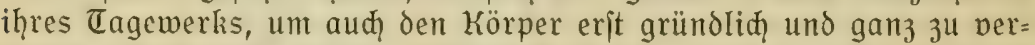

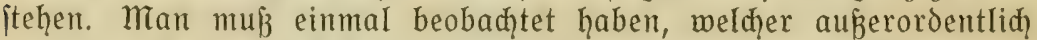
vielfaḑen, leiḑten und dod kräftigen Bewegungen, welḑ̧er Biegungen, Sd̨̧wingungen und Krümmungen, weld̨er deutliḑen und zmedkmäßigen Antworten auf jeden Reiz eine joldhe Walfoffe fähig ift, um zu be= greifen, wie menig damit gejagt ift, menn man diejes (bebilde mit einem Ruder oder Steuer vergleidht. Erjt das tiefere Studium der funktionen beutet die Drgane recht; erit die Eebensweije leḩrt den Körperbau veritehen. Was im Dorhergehenden über den seib der Robben, Sirenen und Wale, mas über das Körperlide "des Meeres= fäugetiers" gejagt wurde, jenes ganz eigenen 『iertnpus, den das Meer einheitlid aus verfđiedenartigen Elementen geiḑaffen ḩat, das mag daher im folgenden aus ihgrer sebensweije heraus cine weitere Erläuterung finden.

Eeider wiffen wir von diejem (begentande wenig. Die Sdpwierig=

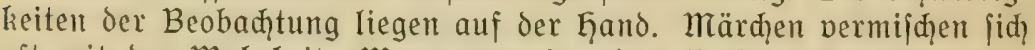
oft mit der waḩrḩeit. Wenn man in alten Büdhern die Seemanns= gejohithten von walfifhen und Sirenen liejt, jo hat man wohl jeine helle freude an dem Unfinn, aber viel lernen tut man nid̨t daraus. Wir finden in der Tat nur recht wenig verläßli ḩe Angaben, meift mur vereinzelte Bemerkungen hierüber in Büđhern und zeitj̧̨riften ver= ftreut. Nur mühjam und unvollkommen läßt fiđ aus ifnen ein Bild davon gewinnen, mie dieje Tiere fich bewegen, wie fie atmen, wie fie fid ernähren und fortpflanzen, wie ihre Sinne ausgejtattet find und wie es mit ihren geijtigen fähigkeiten bejtellt ijt. 
Ant bejten find wir nod über bie Robben unterriḑtet, die fid ïberall in den Joologifḑen Gärten finden und einen groken Teil iḩres Eebens auf dem Lande oder dem Eije perbringen. Sie zeigen in bezug auf ihre Bewegungen nod in willkommener Weife cine Doppel= natur, da jie jowohl im Waffer wie auf dem Eande leben. Es finden (id) bei if̧nen jehr bemerkenswerte Unterihiede zwijhen den ver= fạiedenen Gruppen. Am beiten vermiögen jiđ die Dhrenrobben auf dem sande zil bewegen ( $(\mathrm{bb} .6)$, obwoh̨l jie andererjeits aud $3^{4}$ den ausgezeiḑnetiten Sd̨wimmern gehören. Es ijt ja bekannt, baßj die in

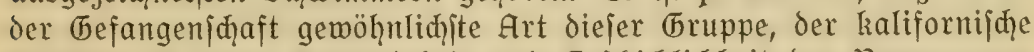

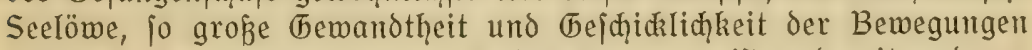

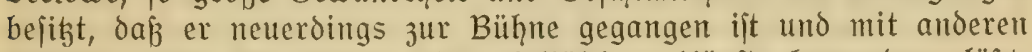
Artijten unter den Tieren jeine vielfältigen Künjte bewundern läpt. was diejen Robben den eḑten Sechunden gegeniiber zu einer jo groben uberlegenţeit in bezug auf ihre Bewegungen verhilfft, ift die bedeutende Eänge, die belenkigkeit und der kräftige Bau iḩrer flofjer. Sie können die Dorderfloffen nod re⿻,t gut als Beine benuben, und da fie die Ginterfloffen naळ pormärts unter den Eeib zu iḑlagen vermögen, fo find jie imitande kräftig fortzumatjđeln. In der Cat können fie auf iḩren vier (bliedmaß̧en, ,ftehen", können den Seib völlig vom Boden erheben, wozu kein Seehund imitande ijt. Jhre Bemegung auf fejtent Grunde ijt weder ungewandt nod unjḧ̈n. Sie klettern, ipringen und watjąeln mit weit auswärts nad den Seiten gejtell ten flofjen ziemlid gejdmind. Die berühmte Sealfkinrobbe, dar nord= pazifif̧̧e Seebär, foll, menn er ermadjen ijt, fajt mit einem Menjhen

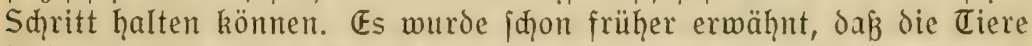
diejer Art fid allfommerliđ auf einigen Injeln im Beringsmeer zum Jweck der fortpflanzung verfammeln. Sie verbringen dann den größjten Teil der Sommerszeit am Eande und die Männdien gehen monatelang niḑt ins Meer zurüd. Sie führen am Eande heftige Kämpfe aus,

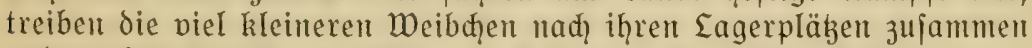
und rauben jie fiđ gegenjeitig. Auð können fie größzere Entfermungen zurüdzlegen. Die Robbenidläger pflegen die Tiere, um fie zu erlegen, in Sdyaren ins Innere der Injel zu treiben. Dabei foll die Gejellihaft interḩalb einer Stunde ungefäḩr einen Kilometer zurüdzlegen können. Dieje Robben beherriden aljo reḑt gut das Eeben auf dem Sande.

Alle anderen floffenfüßer find, wie gejagt, auf feftem Boden weniger gut bewegliă und pflegen aud niđit jo dauerno auf Eand oder $\mathbb{E}$ is 3 verweilen, wie die Whrenrobben. Sie entfernen fid im allgemeinen niḑt weit nom Waffer. Wenn fie fid im Eismeer zum Sdylafen aufs Eis legen, jo gejhieht es meift am Rande ciner Sḑolle oder in der nähe eines jener wafjerlödher, welḑe jie winters in Eife anlegen. Ilur jo kömnen fie im falle einer befaḩ id̨nell genug

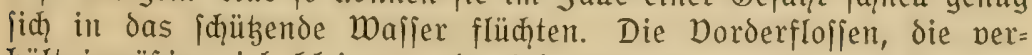
hältnismäß̈ig viel kleiner und viel weniger gelenkig als bei den Đhrenrobben find, fpielen bei diejen Bewegungen keine oder mur eine 


\section{$-48-$}

ganz untergeoronete Rolle. Don den Giinterflofien maden mur die walroff einen ausgiebigen Gebraud, da jie die fähigkeit haben, jie, ganz wie dic Ohrenrobben, nađ vorwärts unter den Baud zu drehen. Sie bemegen fid daher teils wie die Ohrenrobben, teils wie die See= hunde, benugen aber aud if̧re groken Gquer zum Klettern und fort= jareiten.

Das Jurüditreten der (bliedmaßzen bei den Bewegungen auf fejtem Grunde erreiđht dann bei den Seehunden den ḩöhiten Grad. Die Dor= derflofjen, nidht mehr geeignet als füßje gebraucht zu werden, dienen mur gelegentlid, unteritügend bei der (bejamtbemegung des körpers. Die ganz nad, hinten perlagerten hinterfloffen werden blob nad)= gejalleppt. So kommt es, daß die Bewegung der Robben auf dem sande fajt mur noch ein fortidnnellen, eine Art Springen mit dem ganzen Körper iit. Der Ginterleib wird etwas angezogen und dann der Dorderleib pormärts gemorfen. Sie erimmern damit oft an die Bewegung einer đ̧nell kriechenden Spannerraupe. Wenn cine Robbe nicht weit nom Rande des Eijes ruḩend liegt, und es naḩt jið ein Boot, fo legt jie mit ein paar kurzen Rucken die 1-2 Meter weges zurüd und verjdymindet im wajfer. Siegt fie unmitteibar am Rande der Sđjolle, fo wälzt fie fiđ aud einfah hinein. Um auf die Sdiolle

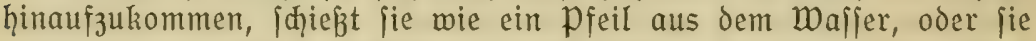
wirft fid] mit dem Dorderkörper joweit hinauf, daß die floffen einen Galt gewinnen und das Tier jiđ hinaufheben kann.

Eine cigentümliḑe Bewegung fieht man oft bei ruh?ndsn Robben. Sie erḩeben zumeilen den Dorderkörper und den Sḑwanz und fḑaukeIn dann, nur auf dem Bauḑe liegend, auf und nieder. Bei der größten ber feehundartigen Robben, dem See=Elefanten, ift dieje Bewegungs= weife am weiteften entwidzelt. Die mädtigen Tiere erheben, zumal wenn jie weit jehen wollen, die vordere Gälfte ihres körpers fajt jenk= ređ̧t, ebenjo riđ̧ten fie den Sçwanz iteil in die Göḩe und bewegen fich danı in ḩöjit komijḩer Weije wie ein Sḑaukelpferd. Man fieḩt aud oft, wie zwei von iḩnen in diejer Weije aufeinander zukommen und (id) ipielend oder ftreitend mit der Brujt aneinander legen, wobei

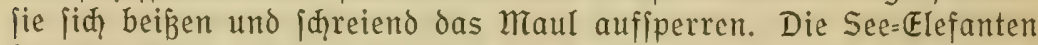
benugen übrigens beim Kriedien auf dem Eande, wobei ihre fettreidie

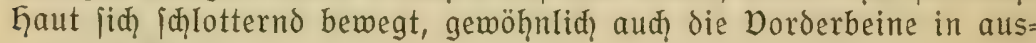
giebiger Weije.

Was wir jonjt nod bon Säugetieren des Meeres kennen, ift aus=

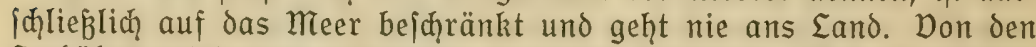
Seekühen mird dies allerdings zumeilen beḩauptet, aber jorgfältige

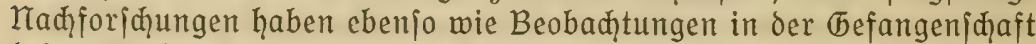
keinen Beleg dafür gegeben. Mand\}mal jheint es allerdings, als ob dieje Tiere, die ja im flachen Waffer die Seegräjer abweiden, fiđ̆ der flofien zum Stügen bedienen, wenn fie diḑt über dem Boden

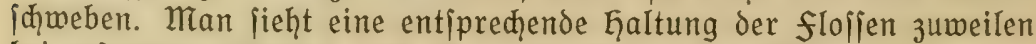
bei gefangenen Tieren, dod ift fie vielleicht nur zufällig. Die Spuren, 
weldhe die Dugongs (Halicore) des Indifhen (1)zeans beim Äjen zurü ḑ= lafien, deuten niḑt darauf hin. übrigens will ein Beobad)ter gejehen haben, daß́ ein Samantin (Manatus) beim frefien die Dorderflofie zumeilen wie eine দุand zu hillfe naḩm.

Die ganze Körpergeitalt und der Bau der (bliedmaken deuten auf das Sdprimmen als die eigentümlidhe Bewegungsweife der See= jäugetiere hiit. Ihr Sḑwinmmen ijt dem der fijđ̧e im ganzen ähnlid und mit menigen Worten zu Kennzeidnen. Es ijt bei den walen und Sirenen meift der Sđjwanj, der, unterjtüht von feiner flofje, mit Kräf= tigem Sḑlag oder Drud den Körper von der Stelle bewegt. Die übrigen flofjen wirken mur jteucrnd mit, ganz wic bei den fijd̨en. Man hat aus anatomifhen (5ründen die Dermutung ausgeiprodien, da $\tilde{B}_{\text {die }}$ Sdywanjfloffe der Wale ourd beftimmte Bewegungen in ähnliḑer weife auf das waffer wirke wie eine Shiffsfinraube, doch iit dies nidht durch Beobadytungen befätigt. Die mageredyte Stellung der Sdymanzflofie ijt für das Tauchen von groß̉er Bedeutung. Bei den Robbin treten an die Stelle der Sq̧wanzfolfe die Ginterflofien, und deren Wirkung ijt infofern der Wirkung des fifdjḑwanzes ähnliḑer, als jie wie biejer und int Gegenjał zur Walflofie mit ihrer fläḑe jenkreḑt jtehen. Sie find übrigens vieler feinerer Bewegungen und Stellungen fähig, die gewiß bedeutjam find, fid, aber kaum genauer perfolgen Iaffen. Die Dorderflofien dienten aud bei den Seehunden nur zum Stellern, werden aber von den Dhrenrobben zum Rudern benugt.

für die Beurteilung der ganzen Bemegung kommt naturgemäß in hohem (Jrade das ipezififḑe (5ewiđht in Betraḑt. Id habe iđ̧on früher

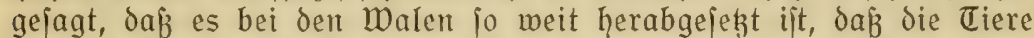
gemöhnlid) um eine Kleinigkeit leiḑter als das Seemafjer find und daher in Juftande der Bewegungslofigkeit an der Dberfläḑe treiben. Auf dieje weije find fie fähig zu ruhen, aud zu fकllafen, da bei diejer Eage die Kajenlödher jid in der Luft befinden und die Atmung ungehindert itattfinden kann. (5anz im (hegenlag zu den Walen haben die Seekühe ein verhältnismäß̧ hohes (bewidht. Während das (be= wiḑt der Walknodien auffallend gering ift, find die der Sirenen \{f̧wer. Aud die fettentwidilung ijt geringer als bei den Walen. Infolgedeffen ruhen die Tiere gewöhnliđ vollitändig unter Waffer an peht flaḑen Stellen, wo jie volt 3eit zu zeit durd eine Gebung des Kopfes die Kajenlöḩer an die Oberfläđ̧e bringen, um zu atmen.

überhaupt liegt es ja auf der Gand, dak der ganze Aufenthalt, daßz alles Ruhen und alle Bewegung im wafjer durh das Atembedürnis

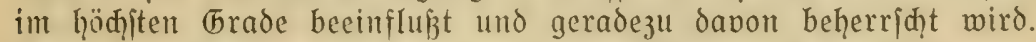
Dies tritt zumal beim Sḑwimmen unter wajfer und beim Taudhen in die điefe hernor, wie es allen Meeres\{äugetieren für den Ermerb der llaḩrung unumgängliḑ notmendig itt. Don der 3eit, welçe die Tiere unter waffer zubringen, foll jogleid now die Rede jein. Wie tief jie hinabgehen ijt natürliđ jehr jđ̆wer zu beurteilen. Da har= punierte Wale in die Tiefe flieḩen, fo läß̆t fiđ̧ an der Eänge der

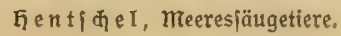


Garpunenteine cinigermaken ein Urteil darüber gewinnen. Einen anderen Anḩalt Kann die Kaḩrung geben, die man im Magen erlegter wale findet. Beiteht fie aus Bodentieren, io ijt es wahrif̧einlich, daß̧ der Wal in der betreffenden (begend den (5rund erreiđt hat. Anderer= jeits hat man fịçe und Tintenfijhe der Tieffee in den Mägen von

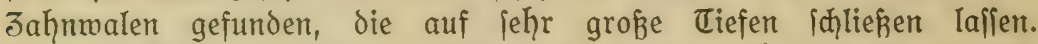
Fine đauß̧tiefe bis übor 1000 meter kann wohl für die groken 3ahnwale als ficher gelten. Die Bartenmale idjeinen weniger tief 3u gehen.

Derartige Tiefen geben, ment man fic dabei dos gewaltigen Druckes erinnert, weldier dort unten herridt, einen bedeutenden Ein= bruds von den auserordentlicien Kraftleitungen, deren ein groker

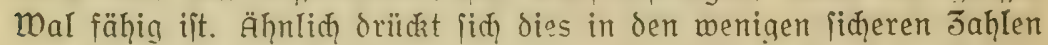
aus, dic man über die sthmimmfähigkeit der Wale, über die Dauer,

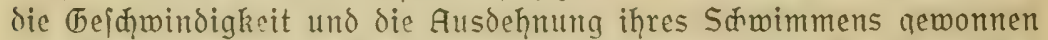
hat. Durđ Iangiährige Beobaditungen $\delta^{\wedge} r$ nermegifden Walfänger hat

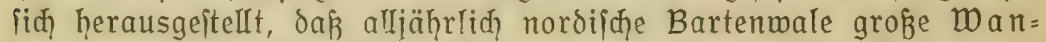
derungen im Atlantijhen (B)zean unternehmen. Die Buckelmale, weløe in dicjer Beziehung am beiten bekannt find, ziehon im frïhling nađ̆ Süden, vielleiđ̄t bis zu den Azoren und Antillen, mährend jie ppäter im Jahre im Tormegilden Tordmeere leban. Auh die Blaumale, die regelmäßzig im Mai an $\delta: n$ normenifकen Küiten von Süben kommend erigeinen, mađ̧en groß̧e Reifen. Man hat in Walen, die an den euro=

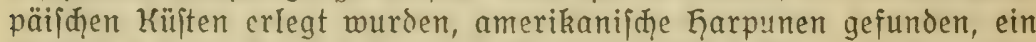

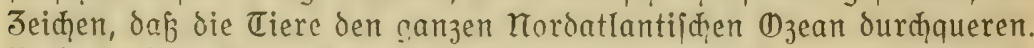
Nod merkmürdiger it es, daß miederholt curopäißje Garpunen, 3. B. in ber äIteren zeit holländijhe, die zmeifellos bei Spigbergen benught worden waren, im nördliden Stillen (1) zean wiederaefunden wurden. Finig? folḑe fälle führt Chamiffo in der Bif̧reibung der Rurik= Erpedition von den Küiten Kamtiçatkas und Koreas an. Sie zeigen,

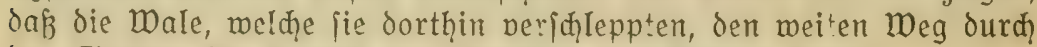
das Eisnteer im Norden von Amerika zurüdgelegt haben.

Gud von den viel kleineren Robben find folche gewaltigen wan= derungen bekannt. Went die grönländijąen Seehunde im frühling in der Gegend von Jan Manen auf dem "Weiteife" iḩre Jungen abgejegt haben, ziehen jie teils jübmärts an die Küijten von Island, teils nadq Kordoiten, dem "Mordeife" nördliđ von Spibbergen zu. Ganz ebenjo madien fic alliäḩrlid, große Wanderungen im wejten von (brönland, dic Davisitrafe entlang. Dabei mag ihnen das treibende Fis zum Aus= ruhen auf der langen faḩrt dienen; fie find aber aud fern von allem Eande und Eife im offenen Waffer angetroffen worden, wis fie in großjer Anzahl in lang ausgedehntem Juge in bejtimmter Ri:htung dahinichmammen. Don den wanderungen der Seebären im Stillen (1) zean wird päter nođ einmal die Rede fein. Es ijt begreiflid, daß̧ alle derartigen wandsrungen nur jehr unvollkommen bekannt find,

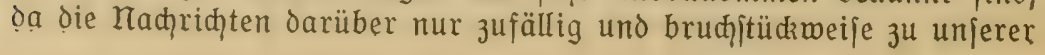


Kenntnis kommen. Aber fhon das wenige, was wir darüber wiffen, ift geeignet, davon zu überzeugen, daß̉ es jiđ hier um eine der merk= wïrdigiten Erjheinungen aus dem Eeben der Meeresjäugetiere, ja eine der grokartigiten aus dem an großen zügen jo reiḑen Eeben des meeres überḩaupt handelt.

Wic fid hier eine eritaunliḑe Kraft und Ausdauer des Sd̨wimmens offenbart, fo ijt aud die befdymindigkeit, welhe die Tiere im Waffer erreichen können, ganz bedeutend. Don Robben ijt darüber nid̨t viel Beitimmtes bekannt. Don den Walen ijt oft erzählt worden, wie das harpunierte Tier, jo lange es nią̧t gefährlid) getroffen ift, oas fang= boot in rajender fahrt hinter jid fortreißst, und wie jelbjt ein kleiner Dampfer, der mit poller Kraft in entgegengejegter Riḑtung zu fahren

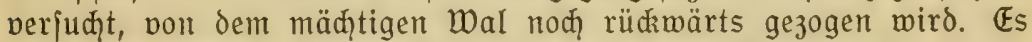
jind neuerdings ein paar jolḑe faḩrten aus Süogeorgien bekannt geworden. In einem falle zog der Wal den Dampfer mit einer (be= iḑwindigkeit pon 3 bis 4 Knoten in der Stunte von Sonnabend mittag

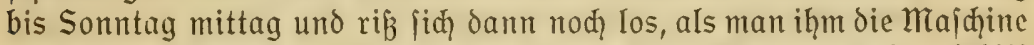
entgegenarbeiten liej. In einem anderen falle iđ̧leppte er das Schiff orei volle Tage lang. Bekannt ijt es auđ, dak ein Sçwanjld̨lag des harpunierten Wals für die fangsleute eine der größten Ђefahren ift, da er eill jtarkes Boot vollitändig zerjḑmettert. Fins der fiärkiten Jeugnifia für dieje Riejenkraft, welde in ber mäḑtigen muskulatur

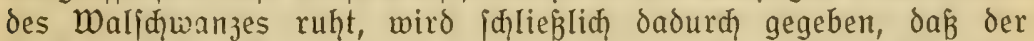
Budkelmal, der pottwal und manḑe andere imitande find, fid über

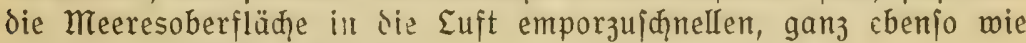
ein kleiner, leiđhter Delphit.

Wie jhion mehrfach bemerít wurde, bejteht ein enger Jujammen= hang zwildien der Bewegung der Seejäugetiere und ihrer Atmung. Je volfendeter beide funktionen zur Ausführung kommen, um jo ent= fhiedener treten jie in einem gewiffen Wideriprud zueinander. Sie würden fid gegenjeitig ftören, wenn niḑt bejondere Anpafjungen wie in der (bejtalt jo aud in der Wirkjamkeit der Atmungsorgane dieje Störungen vermieden. Und zwar gejđieht das dadurd, daß̧ beide funktionen einigermaß̧en miteinander abwecḩeln, daß̧ die Atmung in den paujen der Bewegung, die Bewegung in den paujen der Atmung itattfindet. Der Rḩฤtḩmus, welđ̧er der Atmung aller Eandwirbeltiere

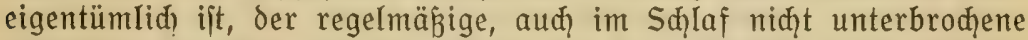
Rḩntḩmus des Ein= und Ausatmens hat jeine Urjađ̧e darin, daß̧ die Eungen in die Tiefe des Körpers verlagert find, während bei vielen anderen Tieren, zumal aud waffertieren, die Atemorgane an der Dberfläḑe liegen. Es muß diejer Eage megen die faueritoffhaltige Euft eingelogen und die kohlenjäurereiđ̧e Euft wieder ausgeitoken merden. Dic fäḩigkeit, diejen Rḩntḩmus zu unterbreçen, das ḩeiß̧t

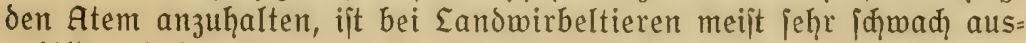
gebildet, daher jie unter wajjer jeḩr iđnell erjticken. Gerade darin aber liegt die wiđhtigite phnfiologijhe Anpalfung ber Atmungsorgane 
an das Eeben in wafjer, daß̧ bei den Meeresfäugetieren dieje fähig= keit im hö̋jiten Grade gejteigert ift.

Als id oben bon den Anpafjungen der theftaltung bes Säugetier= rörpers an das Eeben im Waffer iprad, habe iç nur in Kürze der Secottern Ermähnnung getan, da bei ihnen, abgejehen von der flofien= bildung an den Ginterfüßen, nidit viel Auffallendes diefer Art zu be= merken ijt. Daß̧ jie vollendete Sḑwimmer find, die den Robben Kaum ctwas nadgeben, hätte im Doritehenden ermähnt merden können. In der Tat jollen fie mit groker (bemandtheit jelbjt das itürmifa auf=

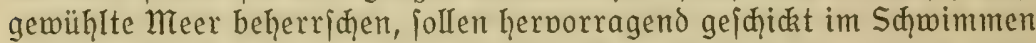
auf dem Rüdren fein, wobei die weib̧̧en oft iḩe Jungen in Arm mit fid) herumtragen, follen fid oft längere zeit an ber Dberflädhe treiben laffen, follen nach Art der Robben gleiḑ̧am aufre⿻̧一t int wafjer itehen können, follen auđ ähnlid) wie die Delphine zu Suft= iprüngen befähigt jein. Was aber wejentriđ merkmüroiger ijt und hier bejonders herborgehoben zu werden verdient, it die Anpaffung der Atmung an das Eeben im waffer. Die Seeottern find imitande, cine gute Dierterftunde lang $3 u$ tauchen und weit unter Wajfer zu f̧̧wimmen. Sic find alfo in bezug auf die fäḩigkeit, den atem anzu= halten, den Eandjäugetieren ganz bedeutend überlegen. Und diejer उug aus ihrer Eebensmeife ijt um jo meḩr geeignet, iḩre amphibijąe Katur

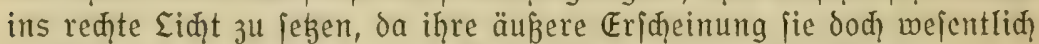
mehr den Eandtieren als den wajfertieren zuzumeifen idgeint.

Dout den orei Gauptgruppen der Meeresfäugetiere fheinen unter

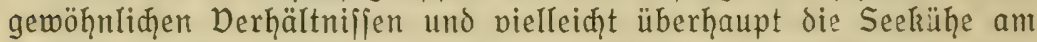
wenigiten lange imitande zu jein, unter Waffer zu verweilen. Es mag das damit zujammenḩängen, daß̧ fie nur in ganz flaḑem Waffer leben. Die Seegrasgründe an den fandigen Küjten Guitraliens, walthe die Dugongs abweiden, gehen nur bis $6 \mathrm{~m}$ unter die Dberfläḩe hinab. Don zwei neueren Beobaḑtern gibt der eine an, dá̧ ihre Atempauien dort bis $2 \frac{1}{2}$ Minuten, der andere, da $\hat{\beta}$ jie 3 bis 5 minuten dauern können. Gewöhnlid bleiben jie nur etwa eine Minute unter Wafjer. Im Roten Meere jollen jie bis zu 10 Minuten taudhen.

Aud für die Seeḩunde ijt unter günjtigen Derhältniffen die Atem=

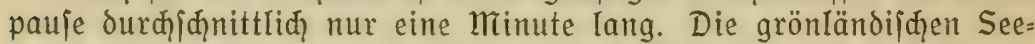
hunde bleiben beim Jagen im allgemeinen hö̋jitens 7 bis 8 minuten, in jeltenen fällen angeblid bis 15 minuten unter waffer. Weiter jđeint die Tauđfähigkeit bei Robben keinesfalls zu gehen. Auf dem Eande oder Eije öfnen jie alle 5 bis 6 Sekunden ihre lajenlöđger, unt zu atmen. Es jheint aljo eine Atmung durळ das Maul iiberhaupt niđ̧t vorzukommen. Dies bejtätigt aud eine Beobađ̧ung an einem Dugong, den man auf dem Eande eritidate, indem man ihm die Kajen=

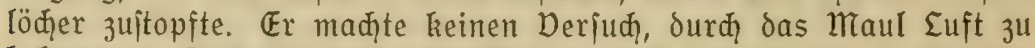
bekommen. Dieje Tiere iḑeinen übrigens aud unter Wajfer zu ¡ळ]lafen. Dabei kommen fie von zeit zu zeit, wahriḑeinliø unbewubt, mit der Taje an die Dberfläḑe. Ähnliḑ ijt es mit den Seehunden. Man 


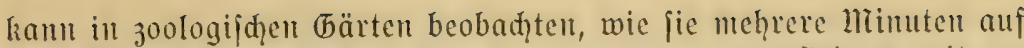
dem (brunde ihres Beckens liegen, dann träge cmporjteigen, mit ge= iḑlofienen Augen atmen und wieder verjinkert.

Die Waltiere gehen nun in himjį̧t der Atempaujen am weitejten.

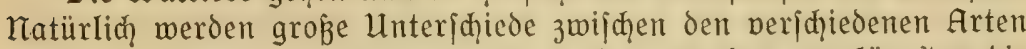
bejtehen. Someit unjere Kenntniffe reiḑen, tauḑen am Iängiten dic

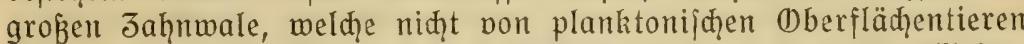
leben, fondern ihre Raḩrung vom Jrunde, oft aus jeḩr groben Tiefen, heraufholen. Beim Dögling ijt cin Tauḑen vou oreiviertel Stunden

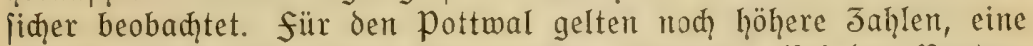
Stunde, felbit eine Stunde und zwanjig Minuten. Bei den Barten= walen jind die paujen durđ̨weg geringer. So tauđ̆t der Grönlandwal gemöhnlid nur 5 bis 10, im ḩödịtfalle 15 bis 20 minuten. Budielmal und Blaumal follen 30 Minuten, der Sübmal 50 Minuten, ja jelbit bis 3u einer Stunde tauđ̧en können. Es find über diejen Gegenjtand viel= fach übertriebene Angaben berbrcitet worden, dođ könmen die hier gegebenen zahlen als jiđer gelten.

Die Sd̨wierigkeiten, welḑe das Atmen für dis wajierjäugetiere bereitet, werden aljo durh dieje fäḩigkeit, feḩr Iange den Atem anzu= halten, bis zu einem gewiffen (5rade überwunden. Diefe Schwierig= keiten werden now bejonders vergrökert, wenn in nordijhen und arktijhen Gebieten der winter das Meer mit $\mathbb{E}_{i j}$ bededit. Jum Teil fliehent die Ticre dann in wärmere Gebiete. Der Grönlandwal, der niemals die Nähe des erijes verläßt, findet fiđ im Sommer in der Baffinsbai unter 75 bis $78^{\circ} \mathrm{n}$. Br.; im winter geht er bis jum 58 . Grade, alfo bis unter die Südpige (Trönlands, hinab. Andere, jumal kleinere Arten, fomie Robben jind imjtande, jelbjt im härtejten winter Eöder im Eije offen zu halten, zu denen jie von 3eit zu 3eit herbei= kommen, umi Euft zu jhöpfen. Dieje Eöher jind kreisrund, glatt= randig und erweitern fiळ nađ unten. Sie merden durd die häufige Bewegung des wafjers, durh den Atem und durh Arbeit mit den Krallen offen gehalten.

Der Dorgang des Euftwedjiels jelbit, das Fin= und Ausatmen, ijt von allen Sebenseridheinungen der wale am beiten beobaditet, weil jie bei diejer (belegenheit gezmungen jind, an die Dberfläđ̨̧e zu Kommen. Das "Blajen" der Wale, das Ausitopen der Atemluft, ift ja das Merkmal, an dem die Walfänger jđgon auf meite Entfermung hin von der Tonne am Majt aus ihre begenwart erkennen. Wie ein weizer Dampfitrahl wird die Suft nom auftauḑenden wal unter lautem faudzen hod emporgejtoßjen. Darauf folgt eine rajde Einatmung und erreutes Tauḑen, aber nur für einen Augenblick, denn jogleiđ tauđ̧t er wieder auf, von neuem, aber ¡đjwähyer blajend und von neuem ein= atmend. Das gejđieht nun mehrmals nađheinander, beim pottmal logar 60 bis $70 \mathrm{mal}$, bevor es zu einem neuen längeren Untertauden kommt. Die Suft in der Eunge wird aljo ausgiebig erneuert. Jedesmal kommen zuerit die Najenlöḑer, die ja hod auf dem Kopf liegen, an 
die (Dberflädc, und danađ, beim Wiederuntertauđen, nod cin Teil

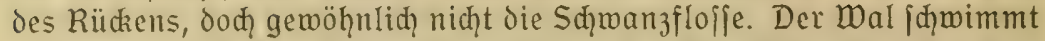
aljo in einer flachen Wellenlinic diḑt an der Dberfläḩe ḩin. Dor dem erneuten tieferen und längeren Tauḑen findet dann eine bejonders lange uno tiefe Finatmung itatt, es folgt eine jtärkere Bewegung, bei der der körper oft beträあ̨tliđ meḩr aus dem Wafjer hernortritt als fonit, bei der die Delphine fogar ganz aus dem Wafier hervoripringen und bei der mehrere der großen Walarten die Sḑwanzflofle zeigen. Danach veriđ̧windet das Tier wieder für längere Jeit.

Was an allen diejen Dorgängen Walfifdfänger und Naturforjąer von jeher am meiften intereffiert hat, ijt der hod emporjąiejende

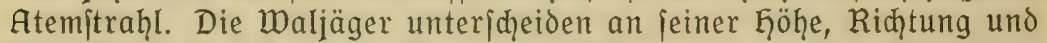
(5ejtalt die veridiedenen Arten von Walen mit großjer Siđjerheit.

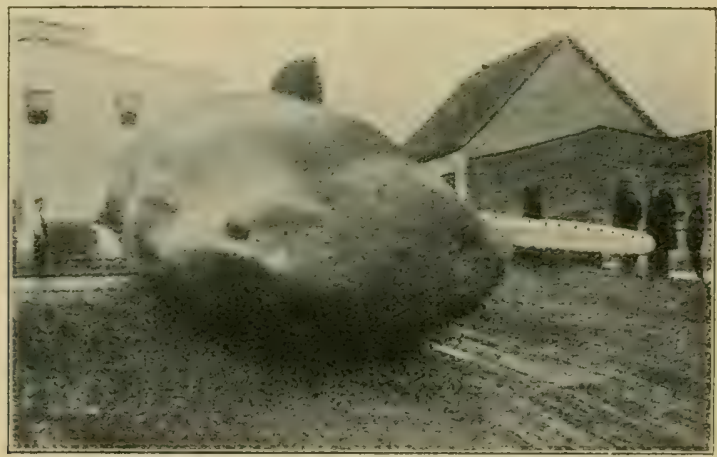

Abb. 28. Pottwalkopf, von der Stirnjeite gejeḩen. Dorn links das Blasloch, hinten unks ote Rüdkenflofie, oben die linke Bru, r= flofie, rechts der Unterkiefer. (Aufnahme des Derfafiers.)

Während er bei den großzen Bartenwalen der nordifđen Meere mehr oder meniger \{enkreḑt in die hö̈he jteigt, riḑtet er fid beim pottmal iḑräg nadi vorn, inoem er einen Winkel von ungeräḩr $55^{\circ}$ mit der Ilceeresoberfläḑe biloet. Da der pottmal nur ein einziges, linksfeitig gelegenes Kajenlod hat (Abb.28), muß der Atemjtraḩ einfad jein. Aber audh bei den großzen furdhenwalen, dem Blaumal, finnwal, Budielmal

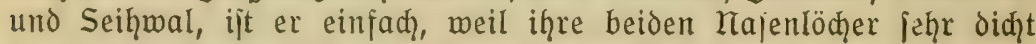
beieinander liegen. Dagegen ijt er bei den (blattwalen, dem (brönland= wal, dem Biscaner u[w., doppelt, was man allerdings nur bei der Anjiḑt bon vorn erkennen kann. Beim Sübwal gehen die beiden Atem= itrahlen jąräg auseinander. Seine Ģöhe ijt unter Umjtänden jeḩr be= deutend; fie erreiđ̨t beim Biskaner oder Kordkaper $5 \mathrm{~m}$, beim Blaumal angeblich bis $15 \mathrm{~m}$ bei der erjten, ftärkjten Ausatmung. Beim pottwal ift er kurz und breit.

Diel umitritten ijt die frage, woraus der Atemjtrah̨l bejteh̆t. Man hat die Lajenlöd)er der Wale lange als "Spriglödher" bezeidynet, weil man glaubte, fie fpien Waffer daraus herbor. So bildete man denn 


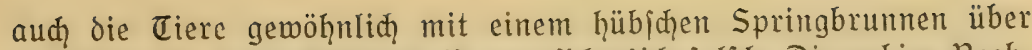
ber Taje ab. Dieje Meinung ijt nun fiderlith falfd. Die ruhige Beob= aḑtung Iäßst deutlid das Bild eines Dampfitrahls erkemen, der fid in eine leiđhte Wolke auflöjt. Nur für den pottwal fđ̆eint die Sađhe nod etwas zweifelhaft; fein Atemjtraḩl ähntelt, wie iđ aus eigener Beobadtung weißs, in hohem Grade einem Wafferftrahl, der in Tropfen zeritäubt wird, aber es ift anatomifd und phyjiologifd unveritänolid?, wie es möglid fein joll, dá̧ er wirklid wajper enthält. Daß̉ der Atemitrahl aller groben Wale fiđhtbar ijt, erklärt man daraus, dá bie mit grober heftigkeit ausgejtokene marme und wajferdampfreide Euft

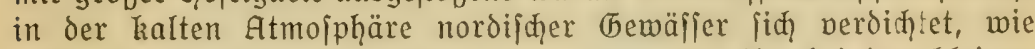
unjer Ģaud an kalten Wintertagen. Dá̉ man ih̨n bei den kleinen Delphinen niḑt jieḩt, mag an der Sđ̧wäđ̧e ihrer Atmung lisgen. Aber wie es kommt, daßj man iḩn bei den groken walen aud in den tropifđ̧en (bewäffern vortrefflid erkennen kann, iit nod niđt befrie= digend erklärt. - Bei den übrigen Meeresjäugetieren wiro ein Atem= itrahl niđht beobaḑtet, dođ zeigt im übrigen dic Atmung manḑc ähnliḑ̧keit mit dem, was hicr von den Walen gejagt wurde.

wie iłhon erwähnt, wird bei dem heftigen Ausitopen des Atems bei den Walen ein lautes fauđgen hörbar. Bei manḑen Arten ift zu= weilen eine deutlide Stimme damit verbunden. Der Budielwal läßst öfter in der Angit ein Sđ̧reien oder heulen verneḩmen. Der Weifzmal joll eine jehr helle und hlangwolle Stimme haben. Es miifien dabei irgendweldye Teile der Euftwege in Sḑwingung geraten, denn Stimm= bänder, wie fie fonjt zur Erzeugung bon Tönen dienen, bafigen die wale niḑt. Den Sirenen feḩlt eine Stimme, dagegen kömnen manḑe Robben laute đöne von jiđ̆ geben. Wenn im nörolidgen polargebiet nebel über dem Meere liegen, erkennen die Sdiffer in der tiefen Stille, weldye in jenen (begenden herriḑt, auf weite Entfermungen die Walrofie an ihrer Stimme. Es ift ein lautes bebrüll, das fie, zumal wenn ein Sçub fie aus der Ruhe auf einer Sḑolle auffinredzt, mit großer Geftigkeit hervorjtoken. Aud beim Sdywimmen uner wajfer

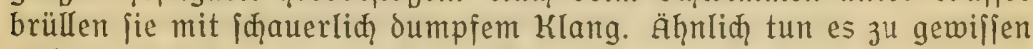
Jaḩreszeiten die groß̉en Bartrobben. Junge See=Elefanten iđgreien wie ein Pfau. Eine der antarktijđ̧en Robben, Roß̉' Seeḩund, hat eine Stimme, die mit dem (Jurren der Tauben und dem Gadkern einer Gente

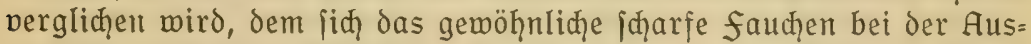
atmung anjळhliebt. Wie jđ̧on oben erwähnt murde, ijt der Kehllkopf des Tieres zur Erzeugung diejer Stimme in merkwüroiger weije um=

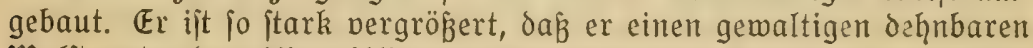
Wulit unter dem Kinn bildet, an dem man dieje Robba auf den erjten Blida erkennt. Aud die Dhrenrobben fąreien oder bellen mit weitḩin iđ̆allenden Kehltönen oder lajfen ein dumpfes бebrüll ḩören. Eine দ̧erde von Stelleriḑen Seelömen erzeugt ein Getöle, wie ein Sturm im winterlidien Walde, bei dem man auf 60-70 m Entfernung dis menja)= liḑe stimme nid̨̧t mehr veriteh̆t. 
Wenll man jid cinmal übarlegt, was woḩ die erite Deranlafiung jenes grofen Wandels in der Eebensweife gewejen jein mag, den bie Seefäugetiere bei i̧̧rem übergange zum wajierleben ourdgemaḑt

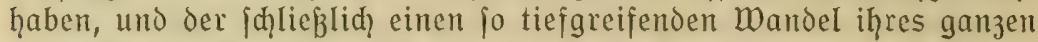
Körperbaues zur folge gehabt hat, fo wird man kaum eine andzre Urjaḑe dafür anneḩmen können, als die Entdechutg neuer Ma hrungs= quelfen im Meere. Man kann fid denken, daß̧ Weidzitzre die von der Ebbe blokggelegten Seepflanzen, vielleidgt noth früher die an den Strand geipülten abjterbenden (bewäḑje zu frefjen begannen, allmäh=

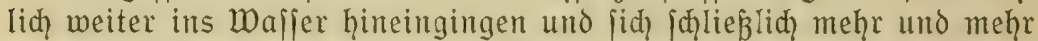
dem fejten Eande entfrembeten. Man Kann fich denken, daß̧ fleifh= freffende Eiere MujheIn, Krebje und Würmer am Strande aufiajen,

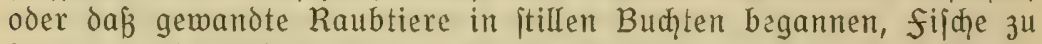
fangen. Jedenfalls wird man nur in der Taḩrungsjuđhe die Urjađgen eines foldhen überganges jehen können. Das neer ift pon einem un=

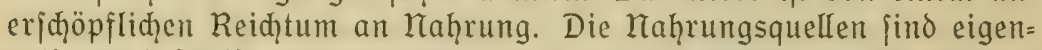
artig, und fo ift es notwendig, daß aud die Whittel der Ernäḩrung zuweilen eigenartige, auf dem Eande ganz unbekannte find. Auf dem sande ift alles, was Tieren zur Kaḩrung dienen Kann, Pflaızen fo= wohl wie andere Tiere, an den feiten Boden gebunden. Aud̆ wenn es fïd davon zu entfernen vermag, muß es dod nad kurzer zeit zur Eroe 3urüd. Aud im meere gibt es Bodenpflanzen und Bodentiere, abar fie Ipielen in der Bevölkerung der $\mathbb{W}_{3}$ eane eine ganz untergeordnete Rolle. Die großje Maffe des Eebendigen bildet hier das Shiwimmende und Stlwebende, das dem Boden fein Leben lang mehro oder weniger fremo bleibt. Es hat fiø feit längerer Jeit cine Unterfheidung von orei Ģauptarten von Eebensgemeinjąaften im Meere eingebürgert: Das, was in irgendeiner beife an den Boden gebunden ift, bzzeidynet man als Bentḩos, das, was fid frei und pelbitändig fđ̆wimmend fern vom

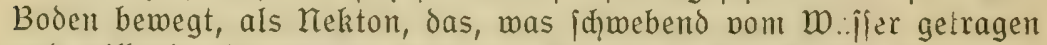
und willenlos fortgeführt wird, als plankton. Diefen orei Arten von Eebensgemeinfahaften entipriđ̧t meḩr oder weniger die Ernäḩrungs= weife der Seejäugetiere, entipreḑen oft fę̧r deutlid die Anpajfungen, melthe iḩre Eebensweife und iḩr Körperbau im Eaufe !anger zeit zu= gunften der befonderen Ernährungsweife erworben ḩaben.

Seeküḩe ḩaben mit Eandkühen niđ̧t eben viel gemein. Aber das ift ihnen doch gemeinjam, daß̧ fie beide weidend ihre pflanglithe Hah= rung fuđhen. Die heute nur nod in den Tropen libandan Sirenen hatten bekanntlid, nod bor 200 Jaḩren einen groß̉en Derwandten in den Kalten Gewäffern des Beḩringsmeeres. Das war deshalb mög= Iid, weil in jenem Gebiet meitausgedeḩnte 『anggründs mit den gro $\hat{B}=$ blättrigen Eaminarien bemadjen jind, die aud die nordifden Kuijten Europas und felbjt die Injeln des Eismeeres in diḑten rraffen um=

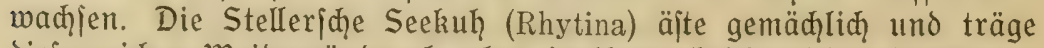
dieje reiḑen weidegründe $a b$, oh̆te in iņrem bejđ̧auliḑen Seben viel von feinden und fonjtigen (befahren geftört zu merden, bis der Menid] 
kam unto fie verniđhtete. Die möglidgkeit ihres Eebens in Meere gründete fiđ alfo auf den benthonifd̨en Dflanzenwud)s, und niđ̧t anders it es mit ihren lebenden Dermanden, den Eamantinen der atlantifḑen Küjten und der an iḩnen mündenden flüffe und den Dugongs des Indijhen (1)zeans. Bei den Dugongs ijt an der Küjte Allitraliens dic Art des frefiens etwas genauer bekant geworden. Sie meiden niđ̧̣t etwa Sḑritt für Sḑritt Iangjam die Seegräjer, von denen jie leben, $a b$, jondarn jie fahren jąwimmend iḑnell darüber hin, reißen mit einem eigentümliḑen zungenartig hervorragenden

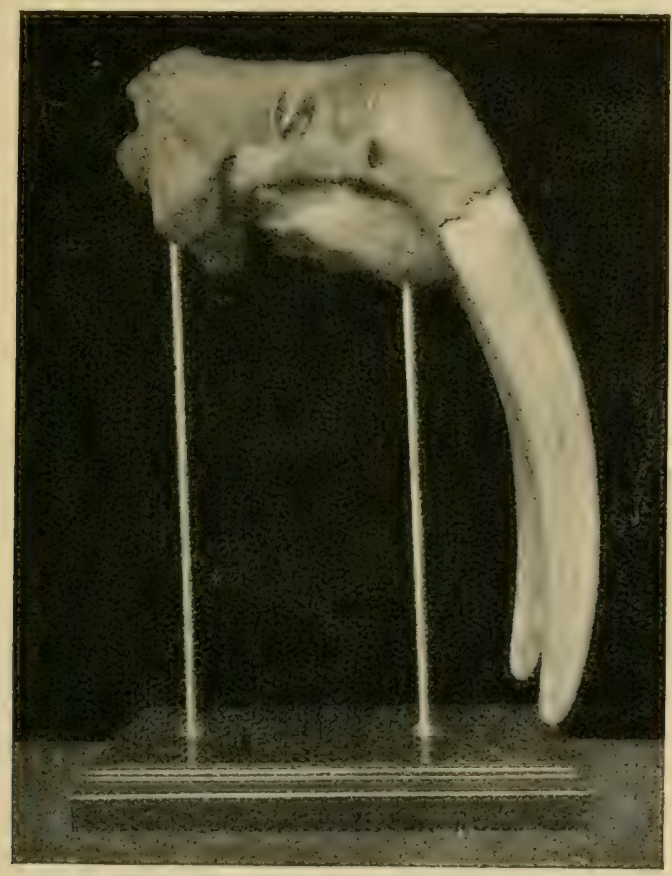

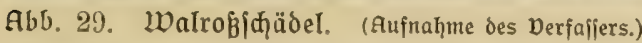

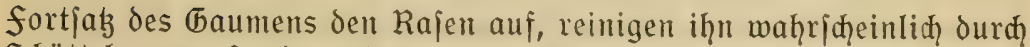
Sḑütteln vom Sande und zerreiben iḩn dann zwijhen ihren Kiefern. Alle anderen Säugetiere der Meere find in der hauptjadye Tier= freffer, aber pflanzennahrung kommit bod gelegentlid bei mandien

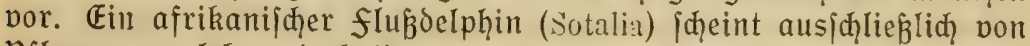
pflanzen zu leben, dod ijt er nod zu menig bekannt, als dap man dies mit Bejtimmtheit behaupten kömnte. Bei einigen arktijhen Robben und bei Walrofien findet man gelegentlid 『ange im Magen. Bei den See=Elefanten der kalten nicere des Südens ineinen fie jogar einen wejentliḑen Teil der Naḩruny zu bilden. Man wird jiđ im ganzen voritellen müfien, daß̧ gerabe diejenigen Tiere, weldie ihre 


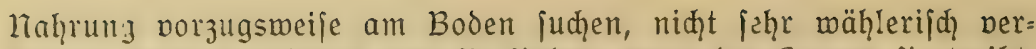
fahten, fondern nehinen, was fie finden, menn der Gqunger fie treibt.

So jheint es 3. B. bei den Walrofien zu fein, daren Mageninḩalt oft unterfucht worden ift und jid als jehr mannigfaltig herausgejtell hat. Es kommt da alles mögliḑe von Bodentieren, darunter Mujheln be= jonders häufig, por, es finden fid aber gelegentlid aud fijd)e oder Rejte von Scchunden. Selbjt junge Weikmale follen jie erlegen können und ein Eismeerfahrer beobaḑtete, wie ein Walroß einen fđ̧wim= menden Sturmoogel megid̨nappte. Auß̧erdem wird bahauptet, daß fie planktonifd̨e 区iere frefien. Das Merkwürdigite an ihrer Ernährungs= weije ijt das freffen der Mujd̨eln. Es handelt jid da bajonders um zwei Arten (Mya uno Saxicava), die in großen Mengen beifammen im und an Boden fejtifgen. Waḩridgeinfid wühlen die Walroffe mit iḩren Gauern (Abb. 29) den (brund an polḑen Stellen auf und ergreifen dann die muicheln mit den didien Eippen. Fïdjit fonderbar i, daran nur eines: Mran hat im Magen der Walrojfe niđht jelten die Mujḑeln in grober Jahl, aber ohne eine Spur von Sdyalen gefunden. Wie die Tiere dic Sḍalen öffnen, wie fie den Weiłhkörper herausḩolen, fo jauber, als wäre er von menjąlichen Ģänden herausgejđ̧ält, das ijt völlig unbekannt. Der einzige Anḩalt zur Erklärung diejes merk=

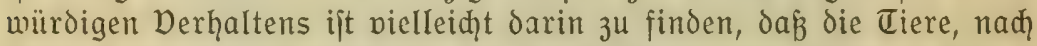

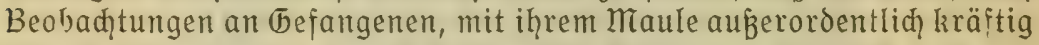
faugen könmen, aber eine bejriedigende Erlilärung läßst jid) au币 auf Gruito diejer fähigkeit einjtweilen niđ̆t geben.

Eine große Anzahl pon Seejäugetieren lebt von nektonifđer rahrung, das heipt von fijhen und Tintenfijdzen. Es find da bejon= ders fajt alle Jahnmale und eine großze Jaḩ non Robban ju tenmen. Aber aud zwei Bartenwale, der zwergwal und der finnmal, freffen

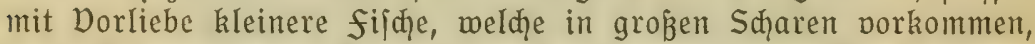
nämlidদ̆ heringe und Polaritinte (Mallotus villosus). Die Seeḩunde

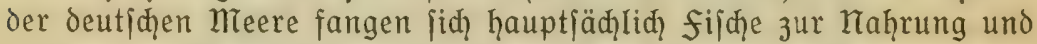
freffen fie niđ̧t jelten den fijhern aus den reben und von den fingeln meg. Es ift vorgekommen, daß man fie an den für Dorjd̨e ausgelegten Eangleinen gefangen hat. Sie jhäbigen zuweilen die fijherei be=

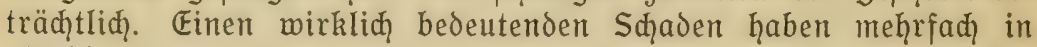
"Robbenjahren" die grönländijąen Seehunde angeriḑtet, wenn fie, von Spibbergen oder dem "Diteife" kommend die Murmanküite und die des nördlichen Kormegens entlang zogen, an denen die fijh̨erei unter allen Wirtið̧aftszweigen die bedeutendite Rolle ipielt. Als fif thjäger find ja aud die Delphine bekannt, die mit ihrer rajh̨en themandtheit es felbjt den fąnelliten Sđ̧wimmern an (bejdywindigkeit gleiḑtun mögen. überḩaupt frefien alle Jahnmale, von den kleinjten bis zu

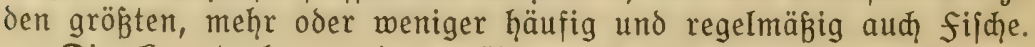

Die Gauptnaḩrung der größeren Jahnnale bejteht aber aus Tintenfijḑen. Man kann das daran nadweifen, dá̧ der Magen= und Darminḩalt gewöhnlid in großzer Jaḩl die Kiefer diejer weid)= 
tiere enthält, braune, hornige Gebilde, die lebhąt an einen papagıi= id̨nabel erinnern. Sie find das einzige, was von dem weichen körper der Tintenfijhe bei der Deroauung zurüdkbleibt. Es gibt unter iḩnen kleinere, fąlank gebaute, vorzüglid jd̨wimmende Arten (Abb. 30), welđ̧e zumeilen in ähnlicher weije in riejigen Sḑaren in die nähe dex Küjten kommen, wie manḑe fijd̨e, Ģeringe, Stinte, Doriḑe ujw. Sie werden von den walen verfolgt, wie denn überhaupt bei vielen Seejäugetieren das Mafienvorkommen ihrer Beute= tiere von wejentlider Bedeutung für iḩre ganze Eebensweije ijt. Es gibt aber aud großje uno zum Teil riejenhafte cintenfijḑe, denen nur die Riejen unter den walen nod gewadjen find. fajt jagenhaft waren lange 3eit june ungehzueren Kraken, deren Eeib eine Eänge von viec Iretern oder dariiber erreidit, und deren arme 11 meter Iang werden können, fo dak das Cier im ausge= ftreckten 3ujtande naḩezu die Eänge eines groß̉en wales hat. Man kennt aud heute nur wenige von diejen Ungeheuern der Cieffee, die zumzilen gejtrandet aufgefunden worden find. Dieje groken Kraken werden von den pottwalen angegrifien uno von įnen überwunden. Ģarpunierte pott= wale ppeien oft im Codeskampf den Inḩalt ihres rragens aus und man hat dann unter den Mah̆= rungsrejten Stüke von den gewaltigen Armen der Cintenfijळhe ḩerumiḑwimmend gefunden. Fin Jeiḑen von den Kämpfen, welð̧e dieje beiden Giganten des $0_{z}$ zeans miteinander ausfechten, fino eigentümliḑe kreisrunde Stellen auf der haut der Pottwale, etwa jo groß wie ein fünfmark= ftück, die von den Saugnäpfen ḩerjtammen, welḑe die Arme der Tintenfijąe bededken. Die großjen, einfaḑen Jähne, weldhe im Unterkiefer des pott= wals jtehen, find fiḑerlidy wohl geeignet, den glatten, meidhen Körper der 区intenfifiche zu packen, den danad die gewaltigen Kiefer zerquetjhen. übrigens fribt diejer Rieje nid̨t nur Riejen. Er begnügt jiḑ aud mit den kleineren Arten und dadurḑ leijtet er hice und Ja der Joologie wejent=

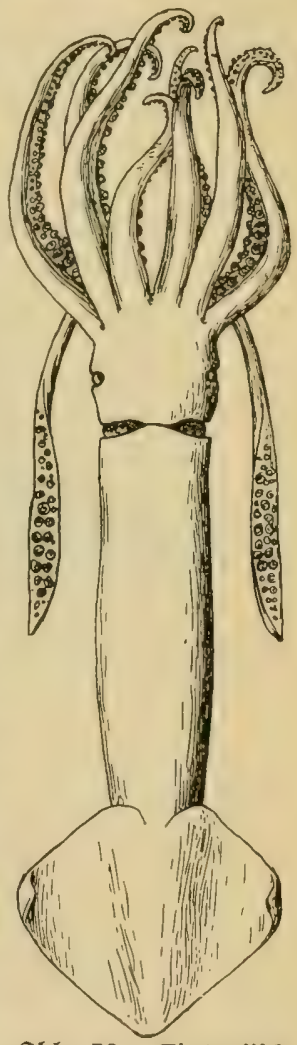

Abb. 30. Tintenfifd (Illex illecebrosus.) Eänge $25 \mathrm{~cm}$.

(3eid̨nung des Derfaffers.) lid̨̧e Dienjte. Denn da er bis in jeḩr groß̉e एiefen hinabtaud̨t, bringt er von dort gar mandies herauf, was unjere Kege nur jelten erlangen. So hat 3.B. der fürit von monaco auf jeinen forjqungsreijen bei den Azoren aus den Mägen von pottwalen perjđitedene merkwürdige Arten zubor unbekannter dieffeetintenfiç̧e zutage gefördert.

Wic die pottwale, ourd Kampf und (bewalt ihre Beute über= windend, zeitweije zu eigentliden Raubtieren werden, fo gibt es 
aud) ein wirkliḑes Raubtier unter den Jahnwalen, ausgeftattet mit zahlreiḑen jd̨arfen und kräftigen Jähnen, ftark, gemandt und mutig, einen Derfolger warmblütiger Ticre, nämliḍ den Sđ̧wertwal, den dic Engländer "Itorowal" (Killer=whale) nemen. Man fieḩt dieje in form und färbung lehr iḑönen एiere $(A b b .31)$ in allen Meeren, zu= mal in dent kälteren, niđht jelten, wie fie in kleinen "Sdulen" fđjwim= mend dahinziehen. Sie gehen aud alle zujammen auf Raub aus und iđ̧euen (iđ) niđht, den größten wal anzugreifen, den jie mit ihren

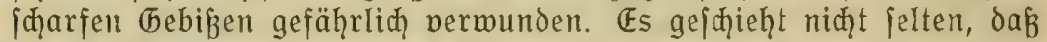

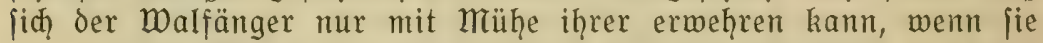
den erlegten wal gierig umjđ̨wärmen und iḩm den Sped in segen vom Eeibe reiben. Don groken walen freflen fie mit Dorliebe die Junge. (Dft jagen fie den Müttern iḩre Jungen $a b$. Sie verjąlingen aber aud kleinere Delphine und Robben. Fin Beriđteritatter, an

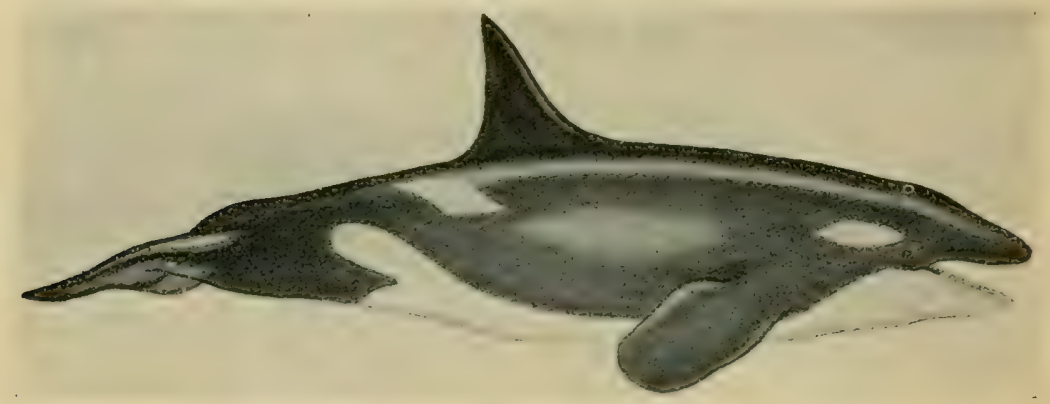

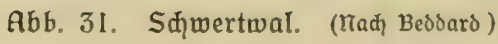

deffen Waḩrḩaftigkeit niđht gezmeifelt merden kam, fđ̧reibt, dak̉ er im Magen eines Sdqwertwals 14 Seehunde und 13 Braunfiphe ge= funden habe. Das Tier war $7 \frac{1}{2}$ Meter Iang.

Unter den Robben kennen wir ebenfalls ein eḍtes Raubtier, das auक einell Raubtiernamen trägt. Es ift der Seeleopard, der, wie auf den neueren antarktifchen Expeditionen feitgeitellt worden ijt, mit

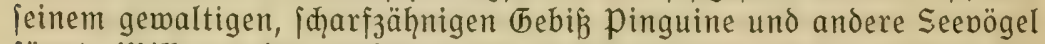
fängt. Will man den Eisbär zu den Seefäugetieren reḑnen, fo ijt er na= türliđ̧̧ hier por allen anderen mit zu erwähnnen. Bei iḩm ijt es ja geradz die Taḩrung, der fang der Seehunde, was ihn unbedingt an das Meer bindet.

Am merkwüroigiten in bezug auf die Ernährung fino unter allen meeresfäugetieren die, welḑe von planktonifक̣en Brganismen

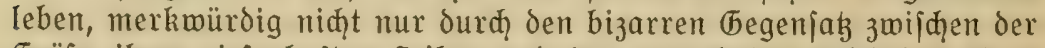
Größe iḩrer riefenḩaften Seiber und der zwerghaften Kleinheit ihrer nährtierđ̧en, fondern auळ, und nođ viel meḩr, wegen der innigen Beziehung zwifhen iḩrem Körperbau und jener ganz eigenen Art der Eebensgejtaltung, die für das ganze Eeben der Dzeane von grund= legender Bedeutung ift, und die wir eben als plankton bezeidinen. 
übrigens leben niḑt mur die großen Bartenwale von planktonifher Nahrung. Wenn man in den Eismeeren, wo jenes kileinfte Sđypebe= leben zu jeiner reidjten Entwidklung kommt, Robben unterjud,t, fo findet man in vielen ausið̨ließ̧liđ plankitontiere. Es gibt mehrere Arten, die zeitweife nur von den grö̈eren formen des Dberflächen= planktons, zumal allerḩand kleinen Krebjen leben, die das kalte wajper zwijhen dem Treibeife und am fub der Fisberge hernorbringt. Sie fangen dieje bis zu ein paar Jentimetern groben Tierdien meift einzelı und können dođ bei iদ̧rem reiđ̧liḑen Dorkommen genügend dabon zujammenbringen, um jiḑ damit zu jättigen. Daß̧ bei einer antarktif̧̧en! Robbe, dem meiken Seehund, cin Mafjenfang itatt=

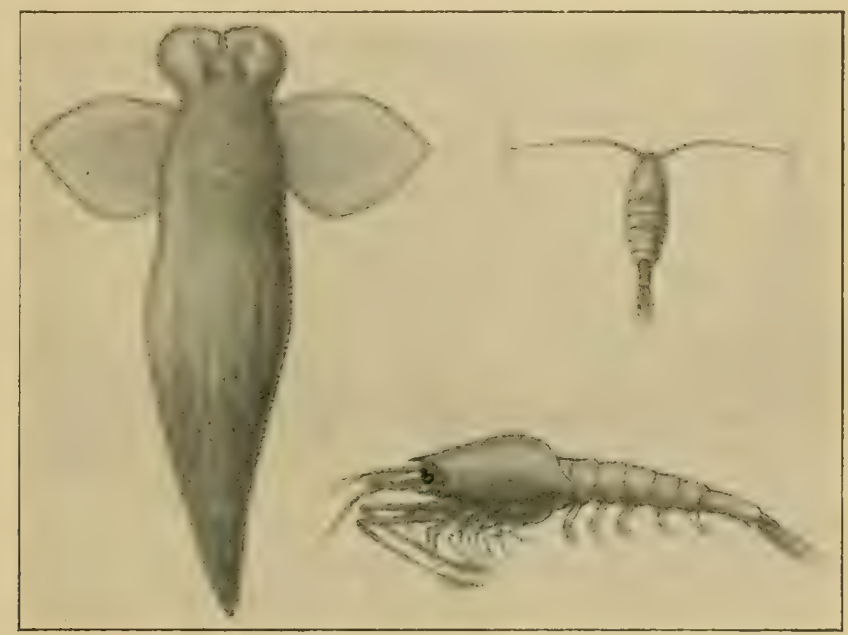

Abb. 32. Arktifage Plantitontiere, itt anderthalbfacher (bröke. Sinfis Clione limacina, reçts oben Calanus finmarchicus, rechts unten Rhoda inermis. (3eidnung des Derfaffers)

finden joll, habe id fḑon oben bei der Bejpreḑung der (bebifie er: wäḩnt. Es mag das übrigens unter günitigen Umitänden bei allen Arten gejdehen.

Don den groken Bartenwalen war, was dan merkwürdigen plank= tonfangapparat angeht, dem fie ihren Kamen verdanken, jhon aus= führlid die Rede. Es wird genïgen, wenn id hier nod von diefer Iaḩrungsquelle jelbjt und von dem Derḩalten der Wale zu iḩr einiges Wenige hinzufüge. Die Unterjuđ̧ung des Mageninhalts cines Blau= wals hat einmal ergeben, daßz er mit meḩr als 1000 Sitern Kaḩrung vollgepfropft war, die aus kleinen Spaltfukkrebjen (Rhoda inermis, Aъb. 32) beitand, weldje $m u r ~ 3 \mathrm{~cm}$ Iang werden. Dies Beifpiel zeigt, wie aukerordentliđ groß der Bedarf an planktonijđ̧er ITaḩrung bei

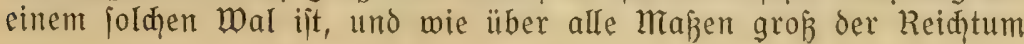




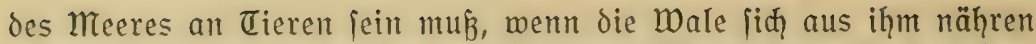
follen. Der Planktonreidhtum veridjiedener meeresteile ift in hohem Grade verjwieden, auळ die Jujammenjegung des planktons mechielt jehrr. Die nordif̧̧en (5emäfier jind, zumal in den (5ebieten, wo kalte Strömungen aus dem polargebiet mit warmen Strömungen - bei uns dem (5olfitrom - zujammentreffen, von einer aukerordentliçen produktionskraft. ferner find die küiten und Bänke bejonders reiđ an plankton und ziehen darum die Bartenwale mehre an, als die hohe See. Seit alter zeit ift den norwegifinen fifhern das plankton aus der Aniḑauung bekannt, und jie haben den veriḑiedenen formen bejondern Tamen, 3. B. "Eodde" und "Krill", gegeben. Es pflegen nämliđ einzelne एierformen in groß̧en Sđ̧wärmen aufzutreten und das ganze prankton am betreffende Drte io jehr zu beherriḑen, daßs fie dent Waffer ein ganz bejtimmtes Ausfehen verleihen.

Id nannte von foldien Tieren iḑon die fijhe, die ja allerdings niđ̧t zum eigentlichen plankton gehören, deren kleinere Arten aber dod von den Bartenmalen gefrefien werden. So bejonders der kleine polaritint, der von den Morwegern Eodde genannt wird. Die Gaupt= rolle ipielen Krebie. An die obenermähnte Art iकlieken fid mehrere andere eng an, dic oberfläđ̧liđ an unjere - viel grögeren - бar=

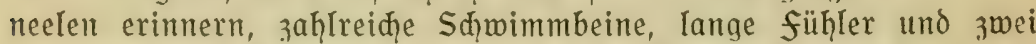

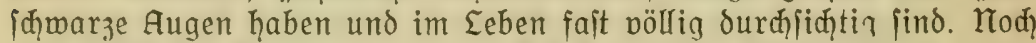

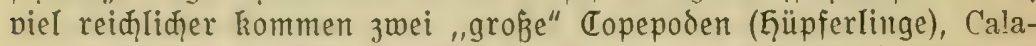
nus finmarchicus ( $(\mathrm{bb} .32$ ) und C. hyperboreus, vor, die fraum $1 \mathrm{~cm}$ lang werden. Sie haben einen länglid ovalen seib mit einem ¡đ̆malen Sđqwanzanhang und zwei groken Ruberantennen am Kopf, die an iḩren Enden äuserit zierlidhe leuḑtend rote fiederchen tragen. Diele andere Krebje fpielen eine geringere Rolle, weil jie niḑt fo mafien= haft auftreten. für den (Frönlandmal kommt bejonders nod das "Walfifđ̧aas", die Clio borealis (riḑtiger Clione limacina, Аbb. 32) in betrađ̧t, eine zarte, teils durḑiintige, teils lebhaft gefärbte flüael= fąnecke, die bis zu $4 \mathrm{~cm}$ lang, aljo ziemlich groß wird und vielfach aud) in gemaltigen mafien auftritt. Sie hat einen iḑnedrenartigen Ecib, der im wajfer jenkrecht iteḩt, und jeitmärts daran zmei rebhaft iđlagende flügel.

Da das Dorkommen der Planktonmale von der Derteilung des planktons abhängig ift, fo miuffen jie auf die in diejer Ginjiḑt be= jteḩenden jaḩreszeitriḑen und örtlinen Unterjhiede durd wande= rungen reagieren. Seit alter zeit find den Walfänqern foldhe Wande= rungen bekannt. Die alten Basken, jene berüḩmten Walfänger der älteiten 3eit, wusten reḑt gut, wann der Biskanerwal im Golf von Biskana, mann er bei Island, mann bei Keufundland auftrat. Die nordif̧en Walfänger, welđ̧e den Grönlandwal jagten. hatten längit

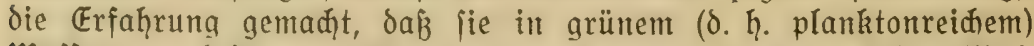
wafier am eheiten auf Wale ređnen konnten. Aud die beiten Wal= grüne der Tegenwart, wie das norwegijh, Nordmeer, der Eabrador= 
ftrom, der "Kodiak=(бrund" im nördiḑen Stillen (Bzean werden be= jonders zur zeit reidjiter planktonentwicklung von den walen bejuß̧t.

Die Uriađ̧e für die Wanderungen der wale iit aber niđ̧̧ allein das Auffuden der Kahrung; aud das (bejhledtsleben ipielt dabei eine groß̧e Rolle. für den Budrelmal find im normegijdzen nteer die Monate februar und März und Juni und Juli die Gquptfangzeit.

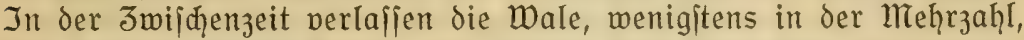
das nahrungsreiđge (bebiet und ziehen nadh Sübmeiten, waḩrihein= Iid, teils über die Azoren und Bermudas nađ den Antillen, teils nad den Kapwerdij̧̨en Injeln. Ihre Mägen werden dann meijt leer ge= funden. Der Anlaj zu der Wanderung, deren Beginn jđon vorher durch eine großze Unruhe der tiere angekündigt wird, liegt cinerjeits in der herannahenden (beburt der Jungen, die in den wärmerent (be= wäffern des Südens abgejegt merden, andererfeits wohl in der bevor= iteḩenden Begattung, die dort bejonders häufig beobađ̧tet worden ift.

Wir wiffen im ganzen reçt wenig über die fortpflanzung der Wale. Die Dauer der đräđ)tigkeit dürfte bei den großzen Arten durd)= (đ)̣ittliđ cin Jaḩr betragen. Sie gebären im allgemeinen nur ein Junges, das bei Bartenwalen mehr als ein Diertel, bei manḑen Jahnn= walen jogar meḩr als ein Drittel von der Eänge der Multer meffen Fann. über das Säugen ift aus Beobađitungen Kaum ctwas bekannt,

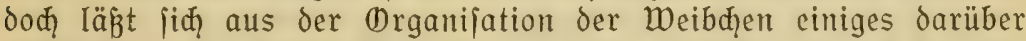
erjhließzen. Die beiden zigen liegen ređ̧ts und links neben der be= [d] leđ̧tsöffnung und find in je einer Gqutfalte verborgen, die ver= möge kräftiger Derjhluß̧muskeln ihnnen Sđqub gemährt. Das Junge hat eine etwas jđhnabelartig gebildete Sdinauze, die es in dieje falte hineindrängt. Es [đ̧eint aber niđht eigentlid, zu jaugen, jondern, wie aus dent Dorhandenjein gemiffer Muskeln zu jølließen ijt, wird iḩm die Mild) von der Mutter ins Maul geiprigt. Dieje Mild ijt ganz wie bei anderen Säugetieren beiđ̧affen. 1-2 Jaḩre Iang iđ̧eint das Junge noch die mutter zu begleiten, die es in diejer Jeit mit grofer Sorg= falt behütet.

Bei denjenigen Säugetieren des Meeres, welche niđht jo vollkommen zun Eeben im Waffer übergegangen find, wie die Wale, ijt es die fortpflanzung, die fie länger und entjhiedener an den jejten Boden bindet, als irgend etwas anderes. Die Robben haben dies mit den

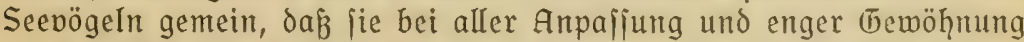
an das Meer doch durch den fortpflanzungstrieb alljähnrlid wieder aufs Eand oder aufs fejte Eis zurüdzgetrieben merden. Gerad mie

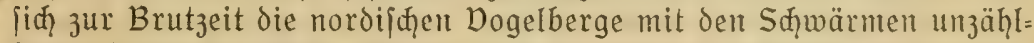
barer Summen, Alken, möwen und Sturmö̈gel bededien, fo fammeln

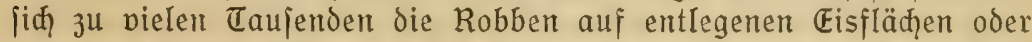
einfamen feljeneilanden an, um ił̧re Jungen zu gebären und, ganł wie es von den walen erzäh̨lt wurde, fid bald danady aufs neue zu be= gatten. Mäßhtig ergreift jie im eriten früḩling der 区rieb zur fort= pflanjung und ein tief eingewurzelter Injtinkt weijt if̧nen die wege 
3u jenen oft weit entlegenen Deriammlungsplägen, wo fiđg das nur menigen meniden aus eigener Anjḩaunng bakante überaus groß́= artige Sçaupiel ihres Gattungslebens vollzię̧t.

Man kennt dieje Derhältniffe befonders von den beiden wirt= [đ̧aftlid) wid̨tigiten Robbenarten, dem grönländifđ̧en Seehumb oder der Sattelrobbe (Phoca groenlandica) und dem Seebären odar der Bärenrobbc (Arctocephalus ursinus); ifre fortpflanzungsmeije mag in Kürze gefđilldert werdan. Die grönländijđ̨en Seehunde haben drei Gauptgebiete für die fortpflanzung im arktijhen 区eile des Eismeeres, nämlią, an der Kü̈te von Eabrador, in der Gegend von Jan Manen und im Weiken Meer. Im frühling kommen fie dort zujammen und lagern fid auf den weiten, nod fejtliegenden Eisfeldern in Sđ̧aren von vielen Taujenden. Bei Jan Manen merden dann in Jer zweiten দ̧älfte des März die Jungen geboren, etwas früher bei Eabrador und im Weiken Meer. Dieje Jungen haben einen vollkommenen weiken, feinwolligen $\mathrm{PeI}_{3}$, der nađ einigen Tagen gelblid und nad) einigen woḑen grau wird. Bejonders um diejes feinen Pelzes der eriten Tage willen ziehen, wie jđyon ermähnt wurde, die Robbenjळläger von Keu= fundland, Normegen und Rußland auf den Jurgieehundfang. Die fau= genden Jungen find leid̨t zu fangen, da fie fid, bevor fie das Gaar gemedifelt haben, jđ̧euen, ins Wajfer zu gehen. Aud Alte werden gleid: zeitig viele erlegt. Nid̨t lange danad findet die Begattung itatt. Balo nad diejer Iöjen fid? die Derjammlungen auf und gehen mit dem aufbreḑenden Eije nađ̆ verjhiedenen Riḑtungen auseinander.

Noch viel merkwürdiger find dieje Derhältniffe bai den Seebären, den "fur=Seals", bei denen fie ebenfalls megen des Iughertes diejer

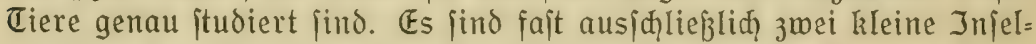
gruppen des Beringsmeeres, die pribnloffinieln im Diten und $\delta: e$ Kommodorskinjeln in Weiten, auf denen fid fämtliḑe 『iere diejer Art in frühling vereinigen, um dort die fortpflanzungszeit zu ver: bringen. Thegen Ende April eriḑeinen zuerit Kundiḑafter, die äuberit vorjidtig Umiḑau auf den Injeln halten. Damn folgen immer mehr alte Männḑen, unt non den Küjten Bejig zu nehmen. Ein jeder mäḩIt (id) feinen Plaz̧ für den Sommer. run cridgeinen in Scharen die Weibhen und jedes Männḑen bildet fid cinen Garem von durd\}= \{ạnittliđ\} etwa 15 bis 20 Weibd\}en. Die jüngeren Männd̨en, die "Iunggejellen", werden gemaltjam zurüdigetrieben. Sie b!eiben länger im Meer und fuđ̧en päter einjame oder weiter nađ̆ innen gelegene Teile der Inieln auf, wo fie von den Alten nidht behelligt werden und den Sommer in großen Sḑaren verbringen. Teils durd, Eiebenswürdig=

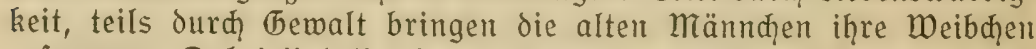
3ujammen. Dabei find Raub und Kampf unabläffig im (5ange. Durd) Kraft und Wađjamkeit mub jedes Männḩen feine Weibḑan zujammen= halten, um fie niđ̧t an jeine Kađ̧barn zu verlieren, und oxs sie ganze 3eit der fortpflanzung hindurd. Anfang Juli gebären die Weibdenen, und bald darauf findet aufs neue die Begattung itatt. Ijt deren Jeit 
vorüber, fo gehen die alten Männđ̧en meḩx und meḩr ins L $\mathfrak{D}$ affer zurüd. Sic find fdwad und abgemagert, da fie die ganze jeit ïber auf dem sande geblieben find und nur von ihrem eigenen fett gezehrt haben, während die fäugenden Weibçen öfter ins Meer gehen, um

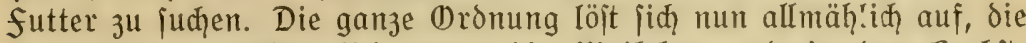

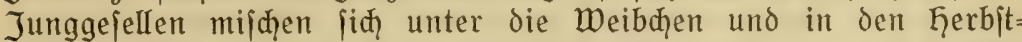
monaten drängt alles wieder zum Aufbrud. Auđ̄ die Jungen find inzwifhen genügend herangewađj]en, 1 m an den weiten Wanderungen nad Siiden teilnehmen zu können, fie haben ihr Gaar gemedjelt und Sdywimmen gelernt. Ende Dratober jind die Injeln im mejentlichen wieder vou den Robben verlafien.

Es würde jid nođ viel aus der fortpflanzungsgefchiḑte der Meeresjäugetiere erzählen laffen, dođ bieten dieje Dinge nshen dem, was ich gejagt habe, niḑt meḩr viel neues, gerade für die Figenart des Eebens im Meere Bezeiḑnendes und können deswegen hier über= gangen werden.

Es mag aber noch darauf hingemiefen merden, was gerade die zulegt erwähnten Erjd̨einungen über das Sinnes= und (beijtesleben diejer Tiere auszujagen vermögen. (5erade das fortpilanzungsleben pflegt bei allen Tieren mehre von den pindiif̧̧en Dorgängen in ihnen aufzudecken, als die übrigen Eebensfunktionen. Es zeigt aud hier, und ganz bejonders in dem hodhentwidielten (battungsleben der Bären= robben, daß jind. Man wird in jeinem Urteil über die geiftigen fähigkeiten eines

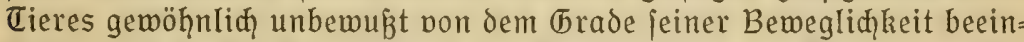
flukt, und da die Bewegungen der Seefäugetiere im Waffer ziemlid

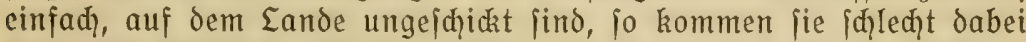
weg. Dic Sirenen allerdings bieten in bezug auf iḩr Seelenleben, fomeit fiđ das aus der Eebensführung beurteilen läß̧t, für ein Säuge= tier nur redt wenig. Aber wer einmal Delphine beobad)tet hat, wird

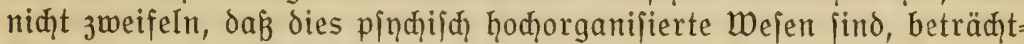
lią̧ den jo ähnlidien fijß̨en überlegen.

Daß̧ die Robben entlegener, äuzerit jelten von Menjdien bejuçter Gebiete dic Gefaḩr, welḑ̧e ihnen von diejen droḩt, oft niḑt erkennen und daher dumm eriđheinen, liegt wohl nur daran, dak fie Erfahrungen in diejer Beziehung niḑt maḑen konnten. In bewohnten begenden pflegen fie jđ̧eu und vorjid̨tig zu jein. Sie lafjen fid aber täujđien

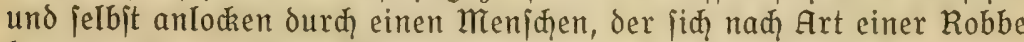
bemegt. Jene großken Wanderungen, won denen iळ geiprođ̧en ḩabe, bemeifen das Dorḩandenfein hod entwidkelten Drtsinnes, der dem der Jugrögel niđ̧ts nađgibt. Aud an die Abriळhtbarkeit der floffen= füber, befonders der Whrenrobben, mag in diejem Jufammenhange nod eimmal erinnert fein. Die Biloung von "Sd,ulen" und zumeilen gewaltigen herden offenbart die gefelligen Initinkte bei Robben und waten. Auf Jagofahrten hat man oft den Eindrud bekommen, dáz

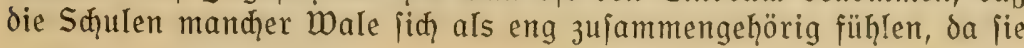


bei cinem iterbenden Gefährten verweilen, folange er nod lebt. God̨= entwidielt find jallebliळ die mütterlidien Initinkte. Die Muttertiere

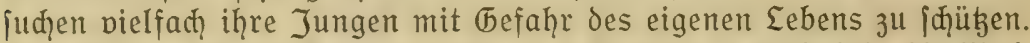
Wir wiffen, wie die Grönlandmale iḩre Dorjiḑt in Kühnhheit, die Wal= rolfe ihre Garmlofigkeit in Wut verwandeln, fobald ingre Jungen angegriffen oder getötet werden. Bei den Pottwalen foll die Mutter jogar nod nad dent Tode des Jungen längere Jeit einen wütenden Kampf gegen die Walfänger füh̨ren.

wir würden ficherlich zu dem hier behandelten (begenitande nođ manhes Eigentümliche aufzuführen ḩaben, wenn wir über die phn= fiologie, bejonders die der Wale, beffer unterriatet wären. Es ver= bergen fid da vielieiđt nođ manđe merkmürdigen Dorgänge unjerem Auge. Denn muß̧ man niđ̧t annehmen, daß̧ die funktion der Eungen eines wales wejentliđ veridjieden ijt von der eines Eandjäugetieres? Sollte man nidht vermuten, dakj der BIutkreislauf in irgendeiner weije auf den ungeheuren Drud in grozen Meerestiefen iid abjtimmt? Müffen niąt notwendig die Sinnesorgane für das Auffuchen der Kah= rung in der finiternis der Tiefe bejonders geartet jein? - Es iteht alfo aud hier, wie bei allen wiffenidhaftliden Gegenitänden, eine lange Reihe von fragezeiđhen hinter dem wenigen, was wir wiffen.

\section{Kapitel.}

\section{Dorgeichichte der Seejäugetiere.}

Wie geidickte hände ein Kunjtmerk geitalten, jo hat das Meer an einer Anzahl von Säugetieren eine wunderbare Arbeit geleiftet. Als ein Künitler, ein feiner, geiftreiđher (bejtaIter und Umgeitalter bietet es uns dieje jeltfamen Tierbilder dar. Sein Eigentum ift die Figenart der Eebensweife, noh mehr die Eigenart des Körperbaues diejer (be=

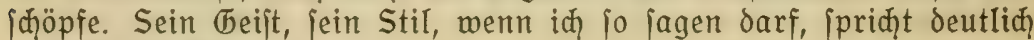
aus innen allen.

Wir fragen uns mit Dermunderung: Wie war das möglich? Wie ijt es dahin gekommen? Wie hat der großje Shyöpfer Meer dies alles geiḑaffen?

Darüber miffen mir nun rectit menig. Dunkel ift der $\mathfrak{w e g}$, den der zu gehen hat, welđher dieje Arbeit von Jahrtaujend zu Jaḩrtaujend

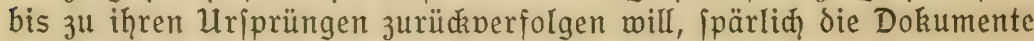
der (bejd̨iđte des Sebens; nur Andeutungen find uns von dem gegeben, was wir zu wiffen wünihen. Wir wollen das Wenige zujammenitellen, mas als "(beiḑiđ̆te der Meeresiäugetiere" einen allzu itolzen Mamen

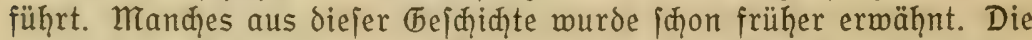
anatomijhe Dergleidiung der Tiere und das Studium ihrer Entwidie= lung geben oft bentlidhe Ģinmeife auf die Organifation ihrer Dor= 


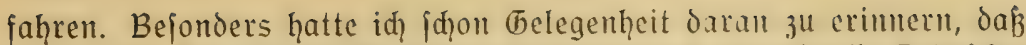
nađ̆ einem (brundgeję der Eebensentitehung die individuelle Entwidie= lung (Ontogeneje) in vielen Zügen die Stammesentmidzelung (Pḩn̨lo= genefe) nađ̧ahmt und dadurd vieles zu iḩrer wiffenjd̨aftlid̨en wieder= herjtellung an die hand gibt. Fier foll nor allem nod cine dritte Gruppe der Jeugniffe herbeigezogen werden, die Jeugniffe der längit Deritorbenen, deren Gebeine uns die Erorinde - und die mujeen aufbewahrt haben.

Denn wir mit freier phantajie an das anatomijhe und biologif̧̧e Material herangehen, weldyes früher beiproḑen murde, fo können wir eine formenreihe der meeresfäugetiere aufitellen, die uns zwar nidht jagt, wie die Mecresiäugetiere entitanden find, wohl aber, wie das Meeresjäugetier, wie der Inpus eines foldhen Tieres entitanden ift. Id will in Kürze ein Bild von diejem ideellen Dorgange entwerfen. Der Eisbär - wenn wir ihn wieder einmal mitreden laffen wollen jteh̆t ant eriten Anfange diejer Reihe. Sein Körperbau bietet niḑ̧ts pon augenifheinlichen Anpafiungen an das Eeben im Meere, dagegen verdient er in Anbetraḑt jeiner Eebensweife mit gutem Reḑte hier ieinen Plas. Als vortreffliḑer Sḑwimmer und Cauḑer ijt er jeinen Derwandten in der Beherriḑung des Waffers weit überlegen. Ihm würde iiđ der Seeotter zunäđjit aniḑließzen. Dies tier hat mit den fijđottern des jüßen Waifers die malzenförmige Körpergejtalt und die Ausbildung von Sđlwimmhäuten zwijhen den 3eḩen gemeinjam, es ift aber injofern weiterentwidzelt, als die zu flofien umgebildeten Ginterbeine ganz bedeutend gröger gemorden find und in viel voll= Eommenerer Weife zum Rudern dienen können, als bei jeinen Der= mandter in den Binnengewäfern. Welch großer fortidritt dem Eis= bären gegenüber in bezug auf das Sḑwimmen und Tauţen hier erzielt iit, wurbe oben fīon beiprodien.

Dejentlich weiter gehen dann die Robben. Die Körpergejtalt ift in dem Grade verändert, daß̧ iḩre Bewequng auf dem Eande nur meḩr oder weniger unbeholfen fein kann. Während beim Seeotter die Ginter= beine jo gut zum Eaufen wie zum Sdiwimmen geeignet jind, herrið̧t in den GTiedmaken der Robben Bau und funktion des Sđhwimm= organs meientlidh vor. Seidlid gut vermögen fid nod die (Dhrenrobben auf feitent Grunde zu bewegen, weniger die Walroffe, am menigiten die Seehunde. In gleiđer Riđhtung liegen die Umbildungen der Körper= aejtalt, der słpwund der äuß̉eren Dhren, die zumeilen mangelhafte Ausbildung des Gaarkleides, die Rükkbildung des Gebifles.

Die Seekühe haben dann den grökten Sdpritt in dem ganzen Ent= midalungsgange bereits getan. Sie haben das Eeben auf dem Eande vollitändig aufgegeben. Unter den vielen und ticfgreifenden Umbil= bungen, die damit zujammenhängen, brauḑen nur die bedeutenditen now einmal erwähnt zu werden: Die Dorderaliedmaken find flofien, die Gintergliedmaß̉en feḩlen, eine Sḑwanzflofje ift neu entitanden, die

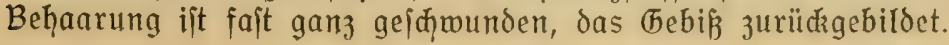


Don den Sirenen zu den Walen, mit denen fie früher zujammen=

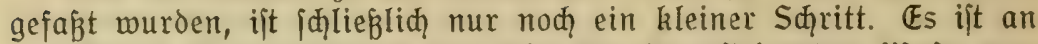
ben walen im wejentlichen nur alles das in geiteigertem Maße vor= handen, was bei den Seekühen vorbereitet oder angedeutet war. Die Gejtalt ift noch fifḑähnliḑer, die floffenbildung nod vollkommener,

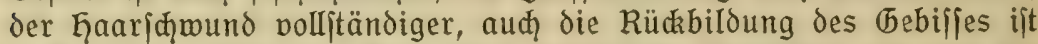
noch weiter geiteigert. Eine legte mejentliche Keuerung, die uns die betreffenden wale als die volfendeiten aller Seejäugetiere erjąeinen läßst, iłt die Ausbildung der Barten. Mit diejen körperliđ̧en Umgejtal= tungen geht die hödjitgradige Anpajfung aller funktionen des Körpers an das Eeben im Meere Gand in Gand.

Derfolgt man in diejer Weife jozujagen den "Plan" des Seejäuge= tieres, wie es fid, von Stufe zu Stufe weiter entwidkelt hat, fo darf man niḑt vergeffen, daß̉ man nur künitliđ etwas zujammenfügt, was

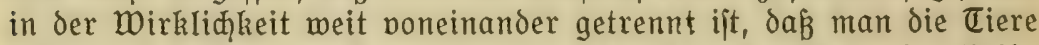
millkürlid nad einem (5rundjage der Dernollkommnung in cine Reihe ordnet, in die fie niđht geḩören. Als geiḑiđhtlid kann man diejen (bedankengang allerdings aud bezeidhnen, er ftellt aber mur die (be=

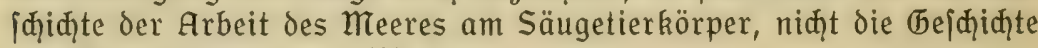
der Meeresfäugetiere jelbjt bar.

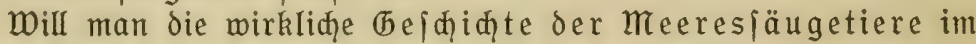
einzelnen verfolgen, fo muß man vor allem fid deffen bewust jein,

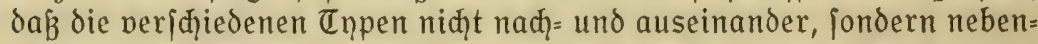
cinander entitanden find. Es unterliegt mohl keinem zweifel, dak Eisbär, Secotter und Robben drei jelbitändige Inpen daritellen, ebenjo

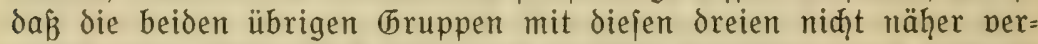
wandt jind. Dá̉ jedođ wale und Seekühe einander fremo jind, ijt erit ipät erkannt morden. Nunmehr aber wiffen wir, dak die Wale zu allen anderen Säugetieren der See mejentliळ näḩere Beziehungen haben, als zu den Sirenen, die iḩrerjeits eine ganz jelbjtändige Stellung einnehmen.

Bären und (Dttern find bekannte Raubtiere. Was die Robben be= trifft, fo geben uns weder Deriteinerungen noch die Embrnologie mejent=

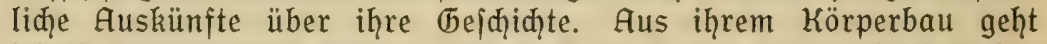
jedod unzmeifelhaft hervor, dẩ aud jie in die Derwandthaft der Raubtiere gehören. Man pflegt geradezu die Raubtiere in zwei groß̧e (5ruppen, die Eandraubtiere (Carnivora fissipedia) und die floffenfüßer (C. pinnipedia) zu teilen. Ja man würde, wenn jie niđ̧t fo ganz auberordentlið, umgebildet mären, die Robben als cine mit den (5ruppen der kagenartigen, hundeartigen, marderartigen ujw. gleiđ̧wertige Abteilung der Raubtiere betraḑten müfien. Den anato=

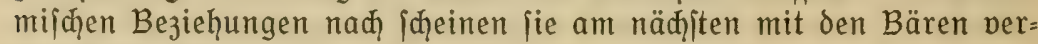
wandt zu jein.

Um vieles beffer find wir nun, bejonders ourd foffile funde der neueiten zeit, über die Dorfahren der beiden ḩöchiten đnpen, am bejten über die der Sirenen unterrid̨tet. Daß̧ uns die Erde Sirenen= 
gebeine bejonders freigebig fpendet, hat darin feinelt (5rund, dá̧ dieje Tiere von altersher nur in das flaḑe wajjer nahe den küjten gegangen find, hat in legter Sinie feinen Grund darin, dak fie Weide= tiere find, die weder in der एiefe noḍ im offenen $D_{j}$ ean Kaḩrung finden. Im fladen, ufernahen waffer wurden die fterbenden Dor= fahren der Seekühe jąnell pon Sand und Sd̨lick überdedat und liegen nun, nađ̧dem der Meeresboden fiđ nur wenig gehoben hat, an ge=

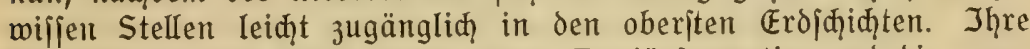
Entwicklung läßt fiø durc die ganze Tertiärformation und die quar= tären Ablagerungen bis heute verfolgen.

Dabei ijt es merkmüroig, dak die Rejte, fomeit jie bis heute be= kannt find, in ganz anderen cändern liegen, als wo heute Sirenen leben. Die ältejten funde - aus dem Eozän - geḩören dem Mittel= meer an. Dort ijt augenicheinlich die Urheimat der Seekühe, in einem Gebiete aljo, wo jie heute vollitändig fehlen. Don dort haben fie fich naw veridiedenen Seiten weiterberbreitet, aber eben die mediterranen funde verbinden die heutigen Derbreitungsgebiete und maḑen die Catjaḑe, daß̧ heute Sirenen in jo meit voneinander getrennten (bebieten vorkommen, verjtändich. Jüngere formen jind aud̆ aus den nörd= lichen Eändern Europas bekannt. Das Eand aber, wo die ältejten, wid̄tigiten formen gefunden wurden, ijt Ägypten. Erit vor einem Jaḩrzeḩnt find im fajum und in den Mokkatambergen bei Kairo jene berühmtel Ausgrabungen gemađ̨t worden, die über die Uriprünge einiger der widitigiten Säugetiergruppen bedeutende Aufid̨lüfie ge= gebent haben.

Auber den Dorfahren der Sirenen find es bejonders nod die der Elefanten, welḑe man dabei kennen gelernt hat. Und merkwürdiger= meife - dies ijt einer der bedeutenditen Erfolge der Unterjuđung hat jiđ gezeigt, daß̧ dieje beiden Tierformen auf diejelben Dorfaḩren zurüđzgehen. Man kann geradezu jagen, daß̧ die Sirenen von clefanten= artigen Dickhäutern abitammen.

Don den Rejten diejer Dorfahren find bejonders die Gebijfe und

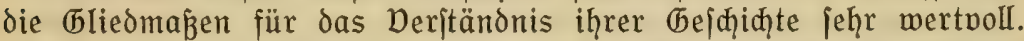
Bei den ältejten Seekühen (Protosiren) jteḩt die Bezahnung nođ̆ auf einer wejentlid, höh̆eren Stufe als heute. Es Iafjen fid Sd̨neidezähnne, Edizähne, eḍte und faliḑe Badzzähne deutlid unteriąeiden, und die

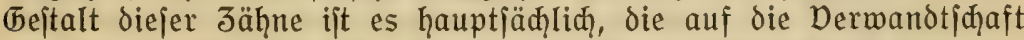
mit den ältejten Elefanten hinweift. Später treten Dereinfađung des (bebilfes und Sdymund von zähnen ein, die iḑließ̧lid, bei der Steller= ihen Seekuh (Rhytina) zum völligen fehlen der Bezaḩnung gefüh̨rt haben (Abb. 13). Merkwüroig ijt es, daß̉ der Jahnneedjel ber Eaman= tine (Manatus), die heute an den Küjten des Atlantijhen (Dzeans leben, mit dem der Elefanten eine großße ähnlidi̧keit hat. Wie bei diejen fällt jedesmal der vorderite $3 a h ̧ n$ aus, wenn er abgenught ift, und die hinteren jhieben iid langiam nad. Es befinden fï aber, im Unter= faciede von den Elefanten, im Kiefer der Eamantine zmijhien den ein= 


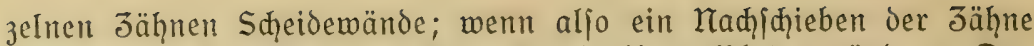
ftattfinden foll, müffen aud diefe wände ihren Plą̧ perändern. Das gejdieht in jeḩ merkmüroiger Weife: Jede Sḑeidemand mähịt naḑ vorn immer weiter, indem jie fortwährend neue knoḑenjuhidgten an= legt, an der Finterjeite aber löit fid gleiđhzeitig und im felben Maß̧e die Knoḑenmaffe Sdyritt für Sḑritt auf.

గod viel bedeutjamer jind die überbleibjel, welche von den (b Iied = maken jener Urjirene bekannt gemorden find. Es wurde oben er=

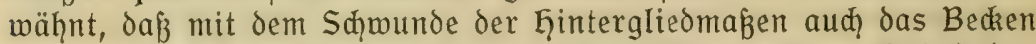
зu zwei einfaçen Knoḑenitäben zurüđagebildet wurde, und daß das

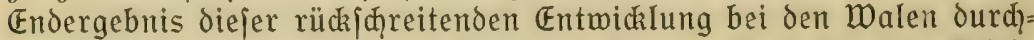
aus dasielbe ift wie bei den Sirenen. Da zur Gejđithte der Glied= maken der wale menig brauđbare foffile funde porliegen, jo ijt es unt fo millkommener, dak uns die der Sirenen klar vor Augen jteht
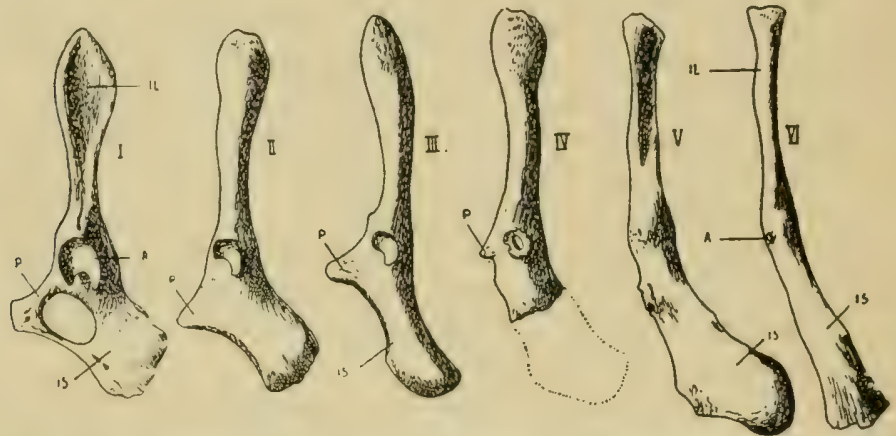

Аьb. 33. Linke Beffenţäliften ${ }^{-}$von Seekühen. I Eotherium (unteres Mittel= eocän). II Eosiren (oberes Mitteleocän), III Halitherium (Pliocäı), IV Metaxytiierium (Mincäri), V unto VI Dugong. (Man Abel.)

(Abb. 33). Die äItejte bekannte Seekuh ägnptens (Eotherium) hatte

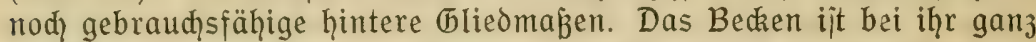
ähnlid wie bei anderen Säugetieren gebaut; es läßt die orei Knoḑen, Darmbein, Shambein und Siģbein, und zwijhen iḩnen das meite hü̈ft= Iod deutlid erkennen. Die Gelenkgrube für den Dberiḑenkel ift wohl entwidielt. Je höh̆er man in den Erdjđiḑ̨ten hinaufgeht, um jo einfacher wird dies Bedien; das Ģüftlod verkümmert meḩr und meḩr die Knodien werden formlojer und verjąmelzen inniger miteinander, die Gelenkgrube bildet jiđ meḩr und meḩr zurük. Die Gliedmaß̉en find gleid)zeitig perjd̨wunden, nur beim amerikanifḑen Eamantin findet fid, wie jđ̧on oben erwäḩnt murde, now ein Rejt des Dber= fhenkels, wie es ja aud bei walen now hier und da der fall ift.

In bezug auf die wale reiđ̧en unjere Kenntniffe pon den Glied= maß̧en, wie gejagt, niळ̨t fo weit zurüdz. Die ältejten formen haben vorn iđgon wohl entwidzelte flofjen und über iḩre hinteren (bliedmaß̧en ift niḑts bekannt. Dagegen haben die Paläontologen zur Entwicklung iḩres Sdïäels 
und (bebifjes ziemliø vollitändige Reihen von funden zufammengebrađ̧t. Danach war der enpus des pottmals, wie er heute nod lebt, finon im oberen Miozän vollkommen ausgebildet, er hat jiđ̆ feitdem kaum mehr verändert. Aber in den legt vorḩergehenden, verhältnismäß̈ig kurzen

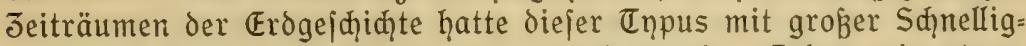
keit ganz bedeutende wandlungen ourchgemant. Tehen wir etwas über dic Uriprungszeit der eigentliđįen pottwale (Physeter), die nur im Unterkiefer lauter gleiḑ̧artige, jeḩr einfađ̧e jähnne ḩaben, jurüd, fo itokelt wir auf eine form, bei der in der Jugend der Dberkiefer noळ Jähnne trägt, die aber bald ausfallen. Unter den noळ älteren formen ragen die Sheldemale (Scaldicetus) der (நegend von Ant= werpen bejonders hervor, die nod ein vollitändiges (bebiß bejigen. Bei ihner find aber zugleiđ altertümliçe Jüge an den einzelnen

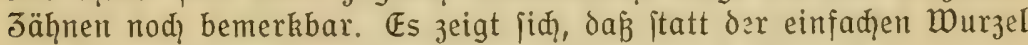
der pottwalzähne, uriprünglid zwei Wurzeln vorḩanden waren, es

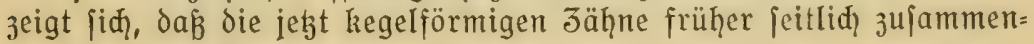

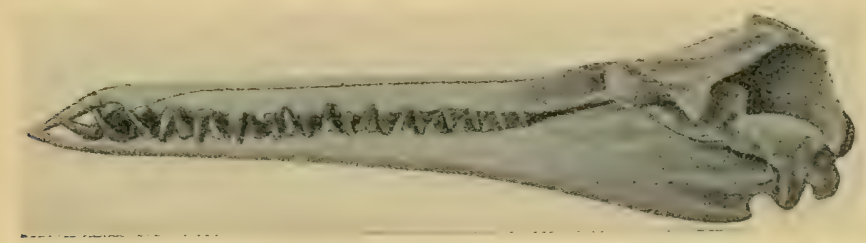

Аьъ. 34. Sđiädel eines Gaijaḩnmals (Squalodon).

(rad v. Stromer aus Abel.)

gedrüđat gemejen find und daß̉ die Sđ̆neidezähne feingejägte Kanten hatten.

Ein nod tiefere Stufe nehmen die Gaizahnmale (Squalodon, Abb. 34) ein. Sie laffen (dion deutlid erkennen, was bei den Schelde= walen nod, wenig herwortritt, daßj das eintönige (bebiß ber pottmale aus einem mannigfaltigen бebiß nom gemöhnliđ̨en Säugetiertnpus abzuleiten ift. Jwwar jehen die vorderen उähne nod cinigermaß̧en denen der pottwale ähnnliđ, aber die Backenzähnne, zumal die hinteren, find peitlid zujammengedrüdit, haben zwei, felbjt orei wurzeln und find am oberen Rande, obwohl eine Spize vorherridt, etwas gezackt. Auळ̆ dieje Wale lebten nod in der Miozänzeit. Die ganze Umbiloung nom Gaizahnmal bis zum pottwal hat aljo in diejer einen kurzen periode der Erogeiđ̧iđ̧te itattgefunden.

weiter rüđwärts befigen wir aus diefer Tierreiḩe mi ipärliḑe Rejte. Was uns hier feḩlt mird aber in ganz befriedigender Weije ourh eine andere formenreihe erjegt, die neben den Anfängen der eben bejprođienen einhergegangenen, aber jđ̆on im oberen Eozän

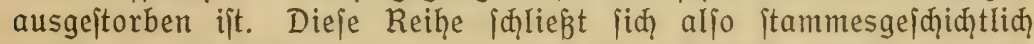
nidịt an die haizahnwale an, fie bildet einen anderen zmeig aus der= 
jelben familie, aber jie maḑt die mangelhaft bekannte Urgejḑiḑte

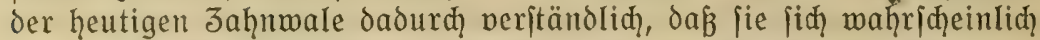
analog zu deren Dorfahren entwidkelt hat. Es ift das die Reihe der 3euglodontiden.

Die Urwale der (battung Zeuglodon (Abb. 35) hatten einen wenig

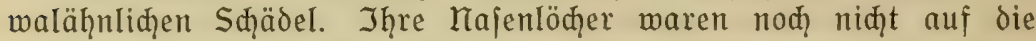
Gïhe des Kopfes hinaufgerüd, ihre Badenzähne waren viel ftärker gezacit, als die der Gaizahnmale. Die Jahl der Jähne war in jeder Kieferḩälfte 11, fie hatten aljo im ganzen 44 3ähnne, während bei den

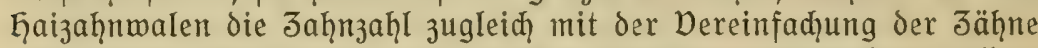
auf 56-64 gejtiegen war und jie beim pottwal im Unterkiefer allein über 50 betragen kann. In der dqarakterijtijđen Jadkung des Dber= randes der Jähne erinnern dieje wale an manḑe der heut lebenden Robben, von deren Ђebiß früher die Rede gemejen ijt. Man könnte

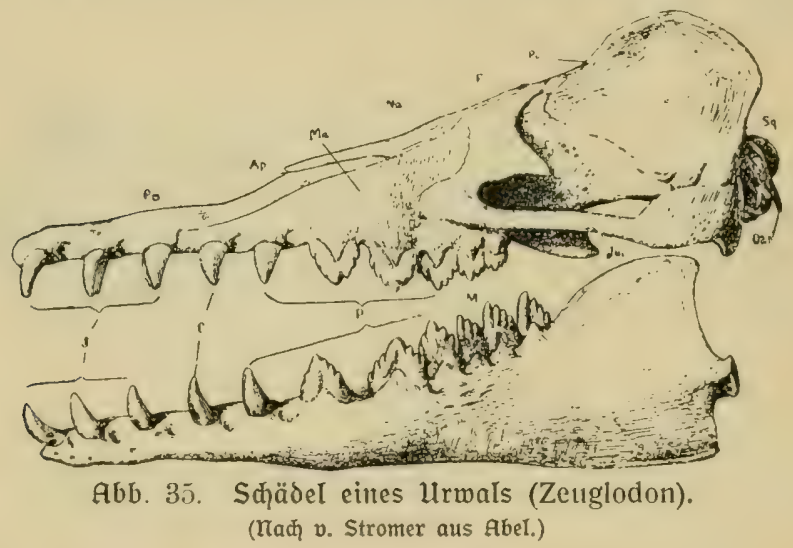

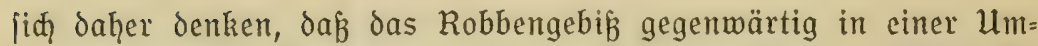
bildung begriffen ijt, welḑe vor vielen Jahrtaujenden vom Gebiß ber wale durḑlaufen wurde. In anderen Merkmalen ähnelt alleroings

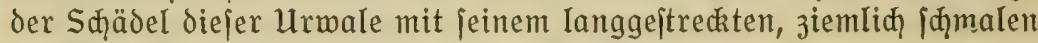
(bejiđţtsteil durḑaus niđht dem der Robben.

In einem weiteren, jehr wejentlidien punkte findet aber wieder eine übereinjtimmung mit diejen 区ieren jtatt. Die Robben jind, wie gejagt, ił̧rem anatomijh̨en Bau nađ̆ auf Raubtiere zurüçzuführen. Die Sḑädel der Urwale führen ebenfalls von Stufe zu Stufe auf die ältejten Eandraubtiere zurück. Das (bebißz mit der zahnzaḩl 44, uno zwar mit drei Sd̨neidezähnnen, einem Edzzahn, vier faliḑen und orei eđ̧ten Badzenzähnnen, ift das tnpijḩe (bebiß̧ der ältejten Raubtiere. Diejes

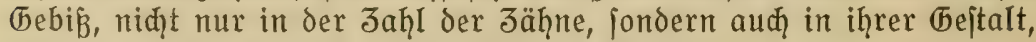
finden wir bei den ältejten bekannten Walen (Protocetus, Eocetus) wieder. Aud die form des Sçädels, der übrigens jđ̧on die verḩält= nismäßig bedeutende (bröß̉e von $60-90 \mathrm{~cm}$ erlangt hatte, entipriçt 
vielmehr einem Raubtier als einem Wal. Unjere lebenden Riejen= zahnwale itammen aljo von Raubtieren $a b$.

was die heutige Joologie gewöhnliđ unter dem Kamen 3ahn= male (Odontoceti) зujammenfaßst, die Gejamtheit der Waltiere mit Gusnahme der wenigen Bartenwale, erweijt fiđ nađ den paläontologi= jh̨en forjhungen als aus mehreren getrenten Stämmen herbor= gegangen, von denen aber die meiften auf die Б̧aizahnnale zurüds= führen. Keben den pottwalen jind die Entenmale, find Karwal und weiṕwal und find noc andere, zum Teil bereits wieder ausgejtorbene Gruppen, jelbjändig entitanden. Einer von diejen Ausgejtorbenen jei hier noch erwähnt, weil er in einer bejtimmten Entwidklungsriḑtung

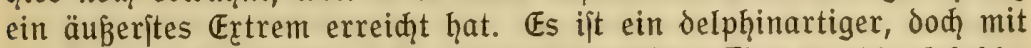
den heutigen Delphinen niđht näher verwandtes đier, Eurhinodelphis, das mit fo vielen anderen in der Gegend von Antwerpen entoeckt wurde. Die Äḩnliđ̧reit mit den Delphinen beruht auf der Eänge der Schnauze, in der aber Unter = und Dberkiefer verjđieden lang find. Die Eänge des Dberkiefers mit dem 3mijhenkiefer beträgt neun Elftel der Sdädellänge und mehr als ein Diertel der tbejamtlänge des Tieres. Eine \{đ̧nabelartige Derlängerung ber Sḑnauze hat öfter in ber Erogejđiđhte bei den großen Wirbeltieren des Meeres jtattgefun= den, ijt aber niemals fo weit gegangen wie hier.

über die Abjtammung der heutigen Delpḩine wiffen wir bisher nur reḑt wenig, aber dies wenige ijt zum Teil jehr merkwüroig. Es

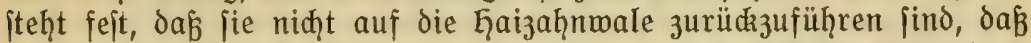
fie aljo den anderen Jaḩnwalen gegenüber eine felbjtändigere Stellung einnehmen. Schon früher war von einer Eriheinung die Rede, die gerade bei den Delphinen beobaḑtet worden ift, und die auf die Ge=

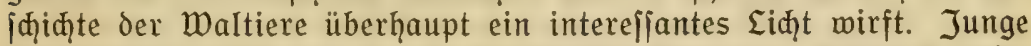
Delphinembrnonen zeigen am F̧interleibe beiderjeits äußerliø fiąt= bare Doriprünge, die als Anlagen hinterer (bliedmaßen zu seuten find. In der weiteren Entwiklung jḑwinden dieje Anlagen bald wieder, und ihr Auftreten im Embrnonalleben ift nur als eine vererbte Figen= tümliąkeit zu verịteḩen, die auf Dorf̧aḩren zurückdeutet, welḑe nod, ähnliç wie die foffil bekannten Dorfaḩren der Sirenen, gebrauḑs= fähige hintere Glieomaß̧en bejaß̧en.

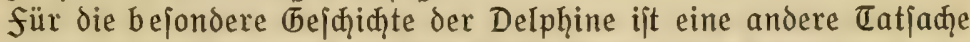
des Embrnonallebens bon groß̉er Wid̨tigkeit. Die Embrnonen ge= wiffer Delphine (Neomeris) zeigen den ganzen Rü đ̌en entlang kleine, knöherne, in der haut gelegene plätthen. Aưh beim erwađjenen Tier find nod Reite davon vorhanden, und bei mandien anderen, 3. B. bei dent Braunfij und jeinen Derwandten (Phocaena) finden jid ebenfalls nod im ermadjenen 3ujtande Kleine hornige plätţ̧en an den Dorderrändern der floffen oder menigitens der Rückenflofie allein. was hier embrnologifक und anatomij hnklar angedeutet wird, erhebt

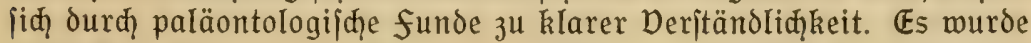
nämIiđ in Kroatien ein kleiner ausgejtorbener Delphin (Delphinopsis) 
entdedat, defien Dorderflofje mit einem panzer von Knoḑenplättđ̧en bededat ijt. Auf drei verfhiedenen Wegen werden wir fomit ju der überzeltgung geführt, daß̧ die Dorfaḩren der Delphine, diejer fo be= jonders glatthäutigen Seęäugetiere, mit einer meḩr oder weniger

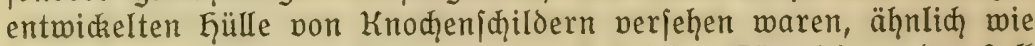
das unter del lebenden Säugetieren nod, bei den Gürteltieren der fall ift. So kennen wir aus der Stammgejdidhte der Delphine wenigitens eine-redit bemerkenswerte Tatjaḑe.

Auch in bezug auf die Bartenwale find unjere hijtorifhen Kennt= nifje jehr bejđ̨ränkt. Die paläontologie ḩat nur ergeben, dá̉ jie fich

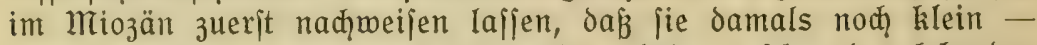
etwa $6 \mathrm{~m}$ lang - waren, dak jie aber übrigens jđon den lebenden furḑenwalen ähnelten. Dazu ḩaben wir aber aud hier eine reḑt

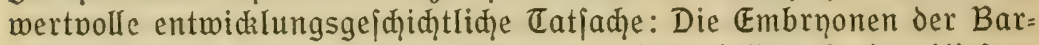
tenmale haben, bevor fiø die Barten bei innen bilden, in den Kiefern wohlentwidzelte Anlagen von Jähnen. Sie zeigen aljo nod heute in frühejter Jugend deutliđ, daß̧ jie von bezahnten Dorfahren abjtammen. Andererjeits beweijen jedod pergleichende Anatomie und Entwidke=

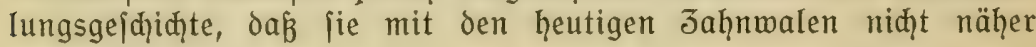
perwandt jino.

Manḑe Erjd̨einungen, welḑe im Doritehenden als bejonders merk= würdig hervorgeḩoben wurden, find für ein gewöḩ̧liḑes Säugetier

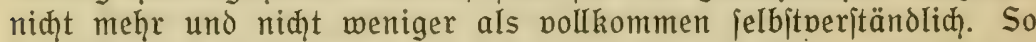
die Anlage von Jähnen in den Kiefern eines Embrnos, die Anlage von (bliedmaken am embrnonalen hinterleibe, das Dorkommen von Gintergliedmaken bei den fofjil erḩaltenen Dorfaḩren, die Derichie= denartigkeit der zähne im (bebib ausgejtorbener Arten. Und dod) mirken jie hier als etwas ḩöhịt Auffallendes, wirken mit dem eigen= tümliçen Reiz des Unerwarteten und überrajd̨enden. Wenn man jid, diejer Empfindung einmal reflektierend gegenüberjtellt, wenn man

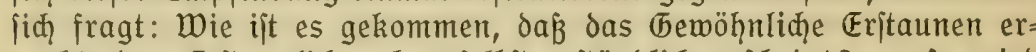

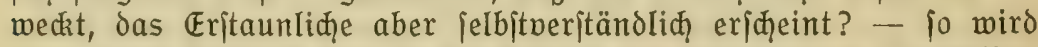
man einen Einblid tun in die Gründe des eigenartigen Interefles,

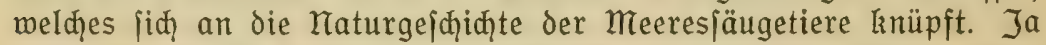

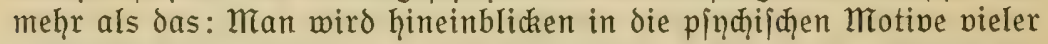

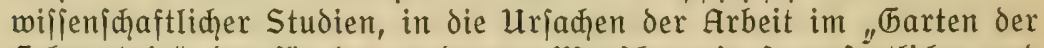
Erkenntnis", der für den modernen Menjळen ein jo wejentlidger und wertboller Teil feiner Umgebung geworden ift. Die Betraḑtung der Meeresfäugetiere führt zu einer eigentümliđenen Deränderung des Stand= punktes den übrigen Säugetieren gegenüber. Fine fülle bekannter Ericheinungsformen zeigt fich in neuem Eiḑte. In diefem immer neuen (5ewinnen bejonderer (befichtspunkte, in diefem immer wieder anderen, immer durdigeiftigteren Sehen der Dinge liegt aber der eigene er=

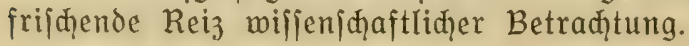


3oologifd betrađ̧tet iteḩt die Erde heute im 3eitalter der Säuge= tiere. Sic find, auc wenn mir bon der ganz einjigartigen Stellung des Menjhen unter den heutigen Eebewejen abjehen, in veriḑiedener Ginjiḑt als die Beherrjher der Erde zu bezeidinnen. Sie dehnen iḩre herrjąaft aud auf das Meer aus, dem jie jøon feit den eriten An= fängen der Heuzeit der Erde, der känozoifđen periode, fiđ anvertraut haben. Dor dem Jeitalter der Säugetiere liegt das der Reptilien. Sie beherriø̧ten im Mittelalter der Erde, in der mejozoijhen zeit, das Eand, die Euft und das Meer. Und wie heute bei den Säugetieren das Beherrichen des meeres zugleidy in einem anderen Sinne ein Beherrjळ̨t= werden durd das Meer ift, jo war es aud bei den Reptilien. Gewalt=

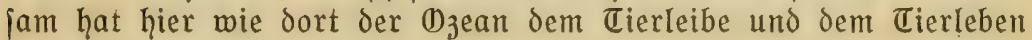
jeine Eigenart aufgeprägt.

Es wird niđ̨t unerwünjđ̨t jein, wenn wir für einen Augenblidz diejen Tieren unjere Aufmerkjamkeit jđenken, denn der Dergleiø mit ihnen wird die Katur der Säugetiere des Meeres nod einmal in be=

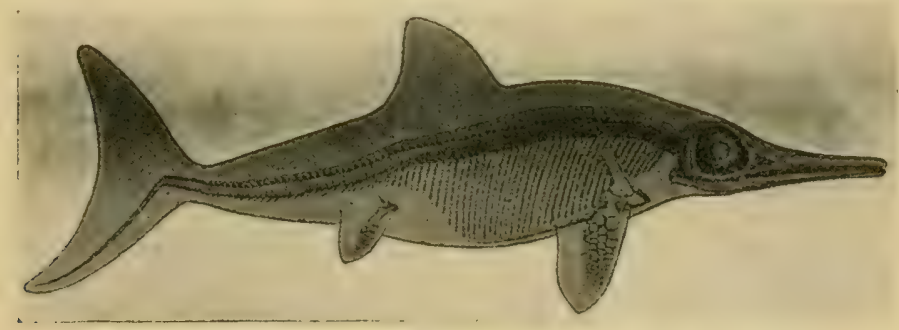

Abb. 36.J Ichthyosaurus. (Mac, Đ. Jaekel aus AbeI.)

jonderer weije beleuhten. Es finden fich ja aud bei den wenigen lebenden Meeresreptilien, den Meerjhllangen und Meerjụildkröten - ebenjo wie bei den Seevögeln - manḑe Eigentümliđ̧̧keiten, welḑe die Dorgänge der Umbildung an zum wajierleben übergegangenen Eandwirbeltieren deutlid] zeigen. Aber fie bieten bei meitem niđ̨t das, was die groken ausgejtorbenen Reptilien uns in diejer Beziehung leiften können. Die parallele zu den Säugetieren ijt bei diejen in ber Tat in jeder Riđhtung eine vollkommene.

Auch unter jenen alten Reptilien gab es formen, welḑe, äḩnlid] wie die Robben, fowohl auf dem Eande wie im Wajfer jidf gut zu bewegen vermoditen (Nothosaurus), es gab formen, walche den plum= pen Körper mit vier grofen floffen durd das wajfer ruderten (Plesiosaurus), es gab lange, iąlanke, ebenfalls mit zmei paaren von floffen und mit einer Sţwangfoffe verfehene formen, wie die "Maas= ed\};en" (Mosasaurus), die über $12 \mathrm{~m}$ lang wurden, es gab lieerkroko= dile, Meeri̧̧ildkröten ujw., es gab aljo eine fauna, die nod mannig= faltiger war als die der heutigen Seejäugetiere. Als die intereffantejten unter if̧nen follen hier nur die herausgehoben werden, welḑe am 
pollkommeniten dem Eeben im Meere angepaß̧t waren und am voll= kommeniten von Meeresfäugetieren "nađhgeaḩmt" werden, nämliđ̆ die Idthyofaurier.

Maul hat jie mit Reḑt als die Delphine des Mittelalters der Erde bezeidnnet; jowohl in ihrer Körpergeftalt wie in iḩrer sebensweije waren fie für die mejozoifhen Meere das, was heute die Delphine und kleineren Jahnnmale find. Ein folḑer Ichthyosaurus (Abb. 36) war ein vollkommen fijđ̧artiges Reptil. Der ipindelförmige Körper, deffen hals veriḑwunden ift, endet in einer jenkrectit jtehenden Sdymanzfloffe und bejigt ein paar Bruftfloffen, ein paar Baudfilofien und eine fkelettlofe Rückenflofie. Die aus Beinen entjtandenen floffen, zumal die der Brujt, offenbaren eine weitgehende Deränderlichkeit in bezug auf iḩr Knoḑengerüit. Die Jah̆l der finger kann größzer als 5 werden, dic Jaḩ der fingerglieder kann außkerordentlid, zuneḩmen, die einzelnen fingerknodien können in bezug auf Eage, Gejtalt und gegenfeitige Derbindung innerḩalb ber flofje itark von den gewohnten Derhältniffen abweiđ̧en. Der Sđ̧ädel endet in einer langgejtreckten delphinartigen, mit vielen zähnen beję̧ten Sḑnauze. Bei manḑen ipäteren formen tritt in ähnlicher weije, wie bei mandien Walen, ein Sdyminden der zähnne ein. Ebenjo können jiđh die Bauđ̆floffen zurüđbilden.

über die Eebensweife diejer Tiere läßt jid manhes aus ihrem Körperbau, aus der Art, wie und wo jie gefunden merden, aus den Rejten ihrer Nahrung in der Magengegend und den Skeletten pon bei den Mütterli gefundenen Jungen erichlię̧en. Sie atmeten augenichein=

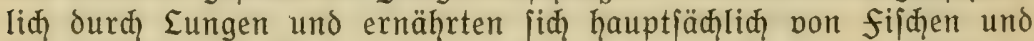

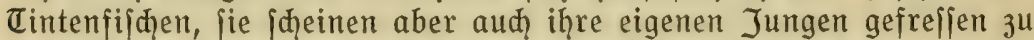
haben. Dic Jungen wurden wahridgeinlich lebendig geboren. Die Jąhthnofaurier bewohnten die Ģodjee und lebten nadi Art vieler DeI= phine in Sdiaren beieinander.

Die ähnlidkkeit, welke in allen diejen Dingen zwijhen diejen meeresreptilien und Waltieren bejteht, ijt fo hodigradig, jo vieljeitig und $j_{0}$ in die Augen jpringend, daj jede weitere Erörterung darüber überflüjlig fein würde. Man jieht, es gibt aud in diejem falle niđ̧ts Meues unter der Sonne. Dder, um es wiffenidiaftlid auszuorüdken, es gibt eine fülle von "Konvergenzerjheinungen" zwijḩen den mejo=

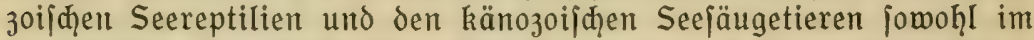
allgemeinen, wie zwifhen den Idthnofauriern und Cetaceen im bejon= deren. Die Betrađ̧tung jeder pon beiden Tiergruppen ift in hohem Grade geeignet, das Deritändnis auđ für die andere zu fördern.

Die (bejđidhte jener alten Meeresteptilien ijt jeit langer 3eit $a b=$ gefळ]lofien, nur aus einem Jweige der Sđ̧ildkröten haben wir in ber Sederjđ̧ildkröte (Dermatochelys) noch einen leģten überlebenden. Dieje alte Reptilienfauna des Meeres erreiđ̧te in den Intḩnojauriern ihre দ̧ödijte Entwidkelung, und diejelbe Ģöhe ijt nun wieder bei den Walen erreidt worden. Wird es aud hier eine legte höhe jein? - Das 
fortbejtehen dex großzen Walarten ift durd) den Menjąen gefähroet, das der kleineren formen, zumal der Delphine, zunähị woḩ kaum. Es wäre gerade bei jo how entwidkelten, jo vollendet ihren bejonderen Sebensverḩältniffen angepaß̧ten Tieren wie den Į̇tḩnofauriern von großßen Intereffe, zu wiffen, was iḩ Ausiterben veranlaß̧t hat. Wir haben aber darüber nid̨t einmal begründete Dermutungen. Undenkbar wäre es niđht, daß̧ die Entwikkelung der Waltiere noch weiterginge; es hat fid in der (bejhidhte des Eebens auf der Erde jo oft gezeigt, daß̧ das Unmöglichite möglich werden kann. Und es gibt für die An= paffung der Landwirbeltiere an das Eeben im Meere ein problem, nor dem bisher nod alle itehengeblieben find, das ijt das der Atmung. Alle, die wir kennen, find an die Suft gebunden geblieben. Bei aller

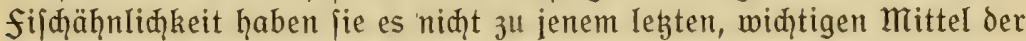
Beherridqung des Meeres, zu der Gewinnung des Saueritoffs aus dem waffer gebraḑt. Unter den niederen đieren der (bewäffer, wenig= fters des jüpen wafjers, gibt es eine ganze Anzahl, bejonders unter den Sđinecken und Injekten, welḑe beim übergange vom Eandleben zum wajferleben aud diejen Sđ̧ritt getan haben. Dielleiđ̧t wird

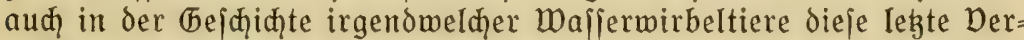
vollkommung nod einmal eintreten.

\section{Kapitel,}

\section{Die Seejäugetiere und der Meniø.}

Die (bejhidhte der meeresjäugetiere hat nod ein legtes, einiger= maken tragifhes Kapitel. Es handelt von ihrem Kampie mit den Menjđ̧en. Diejer gewaltiame Derniđ̧tungskrieg, den ber weit über= legene feind jeit einer Reiḩe von Jaḩrḩunderten gegen fie führt, hat in vielen fällen zu auß̧erordentliḑer Derringerung ił̧er Jaḩl, in einem jelbit zu ihrem völligen Untergange geführt.

Die nubbaren stoffe, um derentwillen auf alle arten von meeresjäugetieren Jagd gemađt wird, jind jehr mannigfaltig und zum Teil jehr kojtbar. Fette und öle bilden die ḩauptmaffe unter ihnen. Aus dem Sped der Wale wird Eran gekoḑt, der früher allgemein zur Beleuđtung gebrannt wurde und nod jegt mannigfaḑe Derwendung findet. Das ö[ im Kopfe des Pottwals (audh des Döglings) liefert das Walrat. Das fett der Robben und Walroffe wird ausgekodit und zu verinhicdenen bejonderen 3wecken benugt. Wertwoller als das fett find die Barten der Wale, die das fijbbein liefern. Am wertbolliten find die des Grönlandwals, weil fie die aukerordentliđ̧e Eänge von $3 \mathrm{~m}$, manḑ̧mal jogar 4,5 m erreichen. Die 3ähne nom Pottmal, Narmal

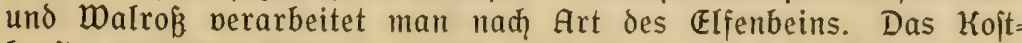
barjte, was von Walen geliefert wird, ijt die Ambra. Diefer Stoff, 
den man frïher nur als einen Auswurf des Meeres an den Küiten auf= 3ufammeln pflegte, und über defien Uriprung viel gefabelt wurde, ijt cin mahrif̧einlid Krankhaftes Erzeugnis im Endoarm des pottmals.

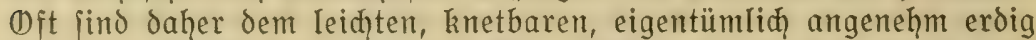
riechenden Stoffe die Kiefer von đintenfijhen eingebadzen, welçe dem mal zur Kaḩrung gedient haben. Ambra wird bekanntlid bei der Feritellunn von parfüms vermendet. Keuerdings benugt man von den Walen, menigitens wo man fic zur Derarbeitung an die Küjte id̨leppt, alle Teile des Körpers. Die Knođ̧en werden in Knođ̧enmüḩlen ver= mertet, aus dem fleijd wird ein futtermehl für das Dieh oder der fog. "Walguano" zum Düngen der ädier hergeitellt. Walfleifd iit aud ébar uno wird bei den malfaktoreien viel verzehrt. Das fleifh des (brindmals foll redit mohlidhmedrend fein; herz, Eeber und Nieren diejes Wals gelten aIs Eeckerbiffen. Es find mehrfađ Derjuđe gemađịt morden, das fleifळ im großzen als lahrungsmittel auszunugen, dod bisher mit geringem Erfolg. In neuejter Jeit foll es gelungen fein, den Tran für die Feritellung einer Margarine zu verwenden. Das fleifक der Dugongs wird von den Eingeborenen der Sübjeeinjeln gern gegefien, ebenjo wie das der Seehunde von den Eskimos. Don den Robben vermendet man auker dem fett noch das fell, teils zur Ger= ftellung won Eeder, teils als pelzmerk. Das jtarke Eeder der Walrofie ift jeḥr hod gejđäğt und dient bejonders zur Anfertigung von Treib= riemen. Unter den Robbenfellen find, wie iđon früher ermähnt wurde, von hohem werte die weiken felle der ganz jungen Sattel= robben oder grönländijen Seehunde. Nod viel teurer werden die unter dem ramen "Sealikin" bekannten pelze der Bärenrobben be= zaḩIt. fait die ḩöhiten preije unter allen Rauḑwaren erreiḑen die felle der Secottern, die jest, da jie jehr jelten gemorden find, im werte bis zu 8000 mark iteigen können.

Es ift bei diejer vielfältigen nubbarkeit aller diejer Tiere, die um io größer ijt, da es jī̄ teils um riejenhafte wejen, teils um joldhe handelt, die in Maffen erlegt werden können, veritändliđ, daß̧ die

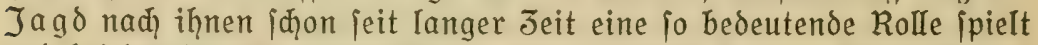
und bei den feefaḩrenden Dölkern eigene Berufe für ihre ErTegung und Derarbeituna hervorgebrađ̧t ḩat. Dieje Jago verlanate zumal in früheren Jahrḩunderten, verlangt aber zum đeil nod jeght kühne Entiकlofienheit und einen itarken Unternehmungsgeift. Sie ijt oft als eine vortreffliçe Sçule der Secleute gerïhmt worden. Das Aben=

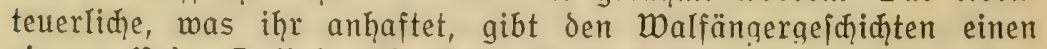
eigenen Reis. Es find auक oft mit Walfifhfana und Robbenjagd Ent= dedungsreifen in den Polargebieten eng verbunden gewejen. über

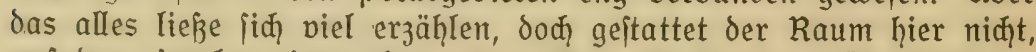
auf das einzelne einzugehen. Es muß genügen, einen überbliç der geidid̦tlidien Entwidkelung diejer Jagofahrten und der Art und Weife, wie fie in der চbegenmart ausgeführt nerden, z" geben. Einiges bavon wurde ja jayon früher angedeutet. 
Dic eriten, weldhe, foweit wir wiffen, walfifdfang regelmäbig ausübten, gehörten 3 u einem jest fajt verfhwmundenen Dolke oben in den Pprenäen, an der (brenze von Spanien und frankreid, nämlid) den Basken. Shon vor dem 10. Jahrhundert betrieben fie den fang im Golf von Biskana, der damals noch regelmäßig von jenem Wal bejuकt wurde, weldier nad iந̧m feinen Namen bekommen hat. An den Abhängen der pprenäen, nahe der Küite, ftanden Cürme, von denen aus das Teer übermadit und wale, die in den (bejichtskreis traten, gemeldet wurden. Diejer Küjtenfang ijt damals jeḩr ertragreid gemeien und hat im Eeben diejes Dorkes eine grobe Bedeutung gehabt. Nod bis in unfere Jeit haben fich Erinnerungen daran in theitalt von Malereien, Stadt= und familienmappen, Namen uim. bei den Basken erḩalten. Aber der fang verniđhtete mit der Jeit den Walreiđ̧̧tum des (bolfs von Biskana, die kühnner gewordenen Walfänger jahen fid

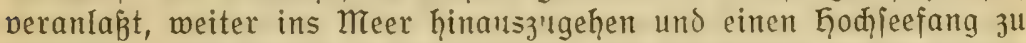
betreiben. Sie kamen in den nädjiter Jahrehunderten an die küiten von Irland, von Island und bis himüber nud Keufundland, wo man nod jegt einen Grabitein in baskijøer Spradie aus jenten 3eiten zeigt. Im Jahre 1372 hatten fid zum eriten Male baskifde Seefahrer der Teufundlandbank genähert und dort viele Wale gefunden. Im Jaḩre 1578 zäḩIte man bei Neufundland fait 300 Walfängeriđịffe, darunter

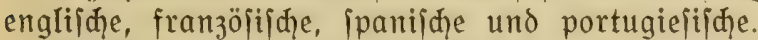

Au历̆ im norwegijđen Nordmeer war in jener Jeit derfelbe Wal, der dort Nordkaper genannt murde, eine regelmäßige Erjheinung. Im 9. Jahrḩundert wuß̧te man bereits, wie weit bei ihren alljährliḑen wanderungen der Küjte entlang die Wale nach Torden gingen. Aud dort wurde fhon früh diefer wal geiagt und auक dort führte diefe Jagd im Eaufe der Jeit au einem Derfapinden der mertwollen Beute, die wegen ihrer Iangen Barten und ihrer leidgten Erlegbarkeit allein für den damaligen Walfifdfang in Betradht kam. Durd? den jahr= ḩundertelangen fang murden fo die Dalfifđfänger immer meḩr nađ dem Norden geführt. Sie kamen in die Täḩe des ewigen Eijes und trafen dort mit einem anderen Wal zujammen, der für weitere Jahr $=$ ḩunderte, für die 3eit der hï̋jiten Blüte des Walfifhfanges zum Gaupt= gegenitand der Jagd werden follte, mit dem (5rönlandmal. Somoh̆ im AtIantijळhen wie im Stillen Dzean bejtand eine bejtimmte Grenze für diefe beiden Wale, die einander in ihrem Dorkommen ausidloffen.

Die eriten Grönlandwale murden im Anfange des 16. Jaḩrḩun= derts erlegt, aber die großze Jeit fïr ihren fang begann erit im Jahre 1611. Kur zuvor, in den Ieģten Jahren des 16. Jaḩrḩunderts waren

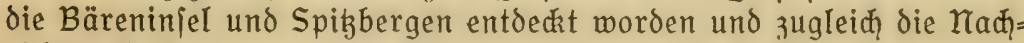
riat nađ Furopa gekommen, daß̧ das Eismeer in der Utmgebung diejer Injeln reid an walen iei. Es kamen zuerit enalifhe Sdiffe, dann

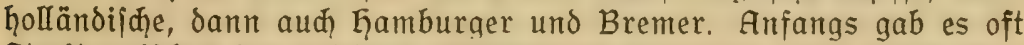
Streit zwifhen den fifßern veriđiedener Tationen, 1617 nahm man eine Gebietsteilung an der Küite von Spib̧bergen vor, an die nod 
jegt Namen wie Amiterdam=Iniel und Gamburger=Ban erinnern. Im Jahre 1630 foll holland 300 bis 400 Sḑiffe mit 20000 Mann nađ̆ Spigbergen entiandt haben. Man nannte das Eand die Goldmine des Nordens. Es gab damals iin Sommerleben in Spigbergen, das weit über das hinausging, mas wir heute dort jehen. An den ந̧äfen der Walfänger waren Dörfer entitanden, in de:ten den Sommer über eine

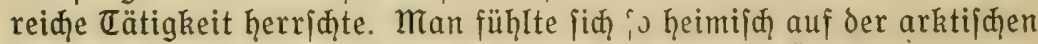
Injel, daß̧ man jogar Kirmes dort feierte. Auch überwinterungen murden verjuđ̧t.

Int Anfang des 18. Jaḩrḩunsert: naḩm die fangtätigkeit bei Spijbergett $a b$ zuguniten eitres neuen Jagdgrundes, der in der Davis= itraß̉e und Baffinsbay entdeckt worden war, und der für ein weiteres Jahrḩundert zum ḩauptgebiet des Walfanges wurde. Im Jaḩre 1721 zäh̨lte man in der Davisftraß̉e 533 Schiffe, darunter 251 Golländer, 55 Kamburger, 24 Bremer, 5 Kormigar, 28 Basken. Diejer fang hat fich in ganz geringem Umfange bis heute erhalten, wo nod einige wenige inottijhe Shiffe alfïhrlich ju diejem 3weck ins Eis= meer hinaufgehen. Gauptiäḑliđ finiet aber die Jago auf den im atlantijđ̆en Teile des Eismeeres fait ausgerotteten (Grönlandwal nod im Beringsmeer und dem nördlich der Beringsitraßze yelegenen Teil des Eismeeres jtatt.

Die Art und Weife, wie der alte Walfang ausgeübt wurde, ift ja bekannt. Man warf mit der Gand vom Boot aus die Garpune aus unmittelbarer Nähe auf den Wal. Er pflegte dann mit rafender (be= ¡đ̧windigkeit zu tauchen. Sobald iḩn das Atembedürnnis wieder an

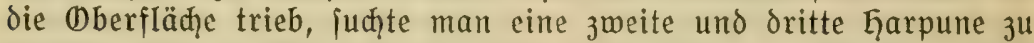

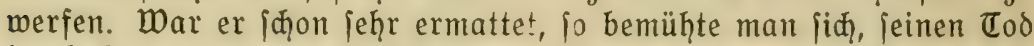
ourd Eanzenitiçe zu bej̧leunigen. Wenn man mun, wie in Spis= bergen, den Wal an eine Küjte jđlleppen konnte, wo Tranjiedereien vorḩandel waren, fo wurde der Sped an Brt und Stelle ausgekod̨t, andernfalls verpadite man ihn cbanfo wie die Barten in fäffer und bradte if̧n 10 in die Geimat. Jur Jeit des Gauptfanges in der Baffinsban befanden fid zum Beifpiel an der Unterelbe zaḩlreiळhe Traniliedereien.

Die 3aḩ der erlegten wale war in der älteren Jeit cine jeḩr bedeutende. Im Jaḩre 1697 töteten 54 Gamburger Sdjiffe 515, und 15 Bremer 119 Wale. Tod im Jahre 1873 erlegte der britifde Eis= meefahrer "Arctic" 28 GrönIandmale, 119 rarvale, 20 Robben und 12 Eisbären.

Aud in anderen Meeren wurde fónon in älteren Zeiten Jxys auf die großen Wale gemaht. An den Küjten von Japan, wo dor dem Norbkaper nahe vermandte Japantermal - auker den groken furđ̧en= walen - vorkommt, benugte man itarke rege, um diejen wal zu fangen, den man dann mit Eanzen eritađ. An den Küjten non Kali=

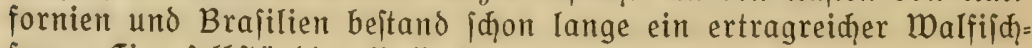
fang. Fine felbitändige Rolle pielte von jeher der bejonders gefähr 


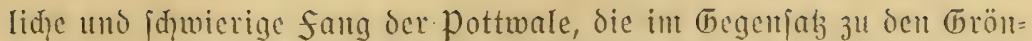
landwalen äuperit mild und angriffslujtig find. Sie wurden teils, wie nod heute bei den Azoren, in der nähe der kiijte crlegt und an Eande verarbeitet, teils von Sdiffen aus gejagt, dic die ganze Eroc umiegelten und an Bord Einriḑtungen zum Auskodyen des Spedis bejaßen. Bejonders anterikanijhe Schiffe bejuḑtel in diejer beije nacheinander eine Reihe bekannter fangplähe für pottwale, wie die Lap Derdijden Injeln, die "Carrol"=(5rïnde in Sübatlantijdgen (i)zean, die Straße von Mozambique, die Strabe volt Malakka, das (bebiet im Südojten von Japan urd den tropificen Stillen (I) zean. Im nor=

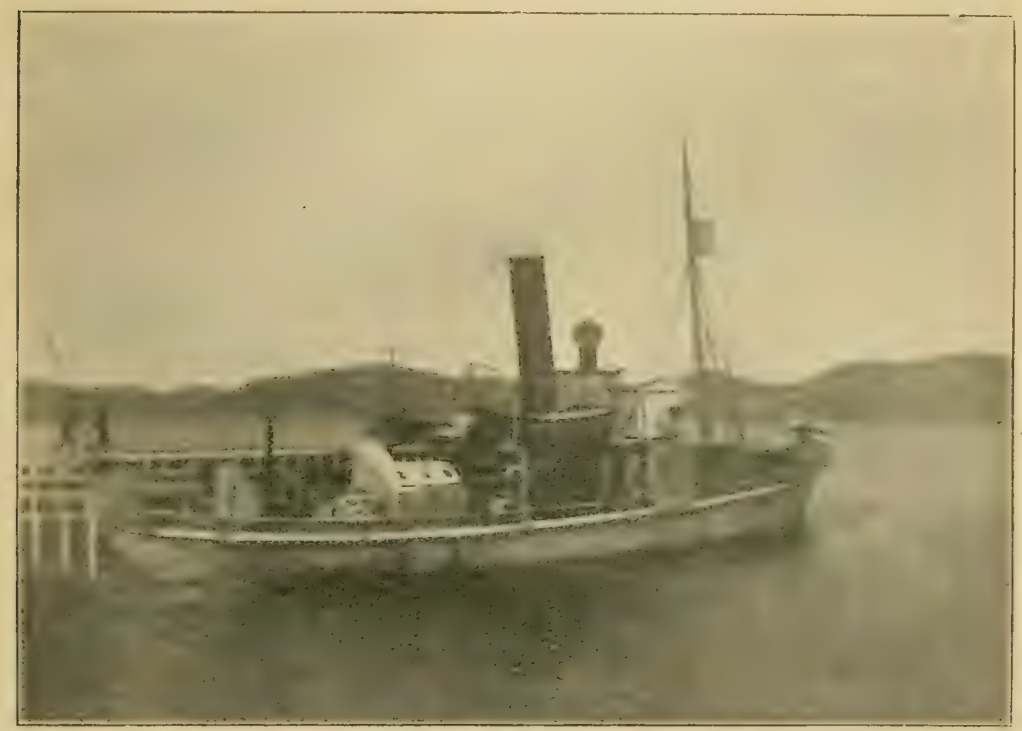

Abb. 37. Mroderner Waldampfer. Reḑts vorn die Lgorpunentianone, am 2hait die Tonne. (Aufnahme des Derfafiers.)

wegifden Loromeer ift neuerdings aud die Jago des Enienmals (Dög= lings) von ciner nid̨t geringen Bedeutung (Abb. 40). Bei den färöeru wire feit alter zeit der brinomal in der Weife gafangen, daj cine in der ITähe der Küite jiđ̧tbar gemordene Gerde diejer Wale von viclen Booten unzingelt und allmählid in das fladye Laffer ciner Budft getrieben wird, mo man die Tiere bann vom Boot aus critidht*). Dic Weißjmale fängt man in Spibbergen uno (5rönland mit Kegen, aud? mit der Garpune. An mandzen Küften werden aud Delphine regel= mäpig gefangen, 3. B. der Braunfifक nođ heute in Dänemark.

Seit den fiebziger Jaḩren des vorigen Jaḩrhnutderts iit $\delta: x$ WaI fijąfang zu neuer Blüte gekommen uns hat in der begenwart wieder

*) Dergl. Katur IV, Geft 15.

ந̧entidyeI, meeresjäugetiere. 
eine großje Bedeutung erlangt. Der normegijḩe Kapitän svend fọn konitruierte damals eine jhwere eijerne Garpane mit mänizizen anker= artigen widerhaken und mit einer aufgejđrobenen Sprenggranate als Spije (Aъb. 38). Die Garpune wird von einer Kleinen Kanone abgejḑofien, die am Dorderende eines Kleinen, jeḩr leiḑt bemegliḑen Dampfers (Abb. 37) angebrad)t ift. Diefe Erfindung, die übrigens in= zwifhen in mannigfaḑer Deife umgearbeitet worden ijt, beherricht heute die Walfifhjagd auf der ganzen Erde. Und die Kormeger find mit diejem neuen fangapparat in eigentümlicher weije in Derbin= oung geblieben; auf der ganzen Erbe find normegifhe Walfanggejell=

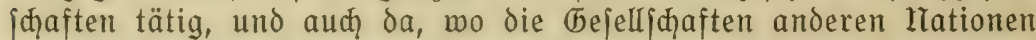

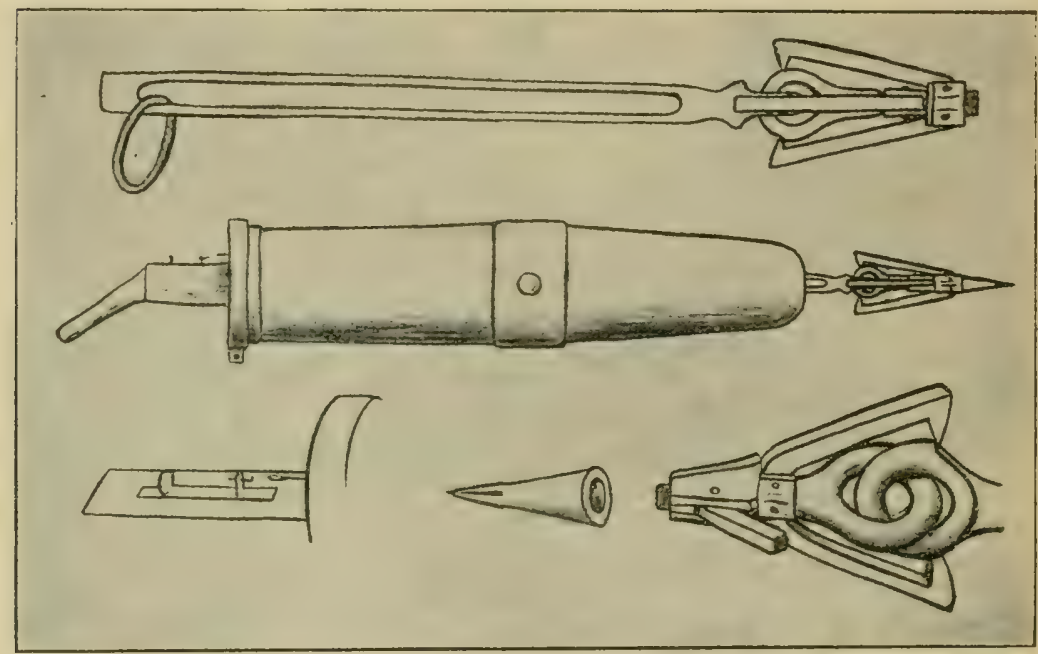

Abb. 38. Garpune und Garpunenkanone. (1) ben die Garpune ohne Spige. In oler mitte die Kanone mit eingejegter Garpune. Unten links der Ent= Iader der Konone, ređts der Kopf der Garpune mit abgejđrobener Spize. (Jeiđ̄nung des Derfaffers.)

angehören, werden meijt Norweger für den fang angeworben, die ihn

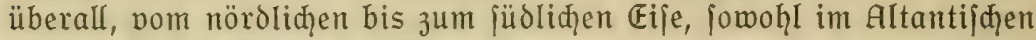
wie im Stillen $\mathbb{B}_{z e a n}$ ausüben.

Der thegenjtand des fanges find vorwiegend die furchenwale, Blaumal, finnmal und Budielmal, aud der kleine Seiḩmal, jomie dann in gewiffen Gegenden der Pottwal, in den jüdlidhen Meeren der dem Biskaner entiprechende Sübmal und an der Weitküfte Tordamerikas der (braumal (Rhachianectes). An den normegijđgen Küjten und an der Murmanküjte, pon wo diejer fang uriprünglia ausging, ijt er jeit einer Reihe von Jahren im angeblidien Interelfe der fijḑerei verboten. Die Walfaktoreien jind infolgedefien naw Spifbergen, den färöern, den Gebriden und Island perlegt morden. Ein bedeutender walfang bejteht ferner in Keufundland und Eabrador. Da jegt bes 
reits wieder die nordifden fanggebiete im Allantijdyen (1) zean jtark ausgenugt find, hat jid der Gauptbetrieb des Walfifdffanges nad, den reiden Walgründen der füblichen Meere gezogen, wo cine Reihe bedeutender Unterneḩmungen in Süofhetlano, Südorknen, den jüo= liđ̧̨en Sandmiđ̧infeln, Südgeorgien, den falklandinfeln, Südafrika, den Kerguelen u[w. iņren Sib haben. Aud deutid̨es Kapital iit an diejem Sübfang wieder beteiligt. Die Derarbeitung gejd̨ieḩt meijtens in faktoreien am Eande (Abb. 39), feltener auf fogenannten Kods= ¡đjiffen, welḑe die Jagbdampfer begleiten, aber keine jo vollitändige Ausnub̧ung der wale geitatten, wie die faktoreien. Don ber Alus= dę̧nung und den Erfolgen diejer fangtätigkeit mögen einige Jaḩlen aus der neuejten zeit einen Begriff geben. Die Ausbeute der norwegi=

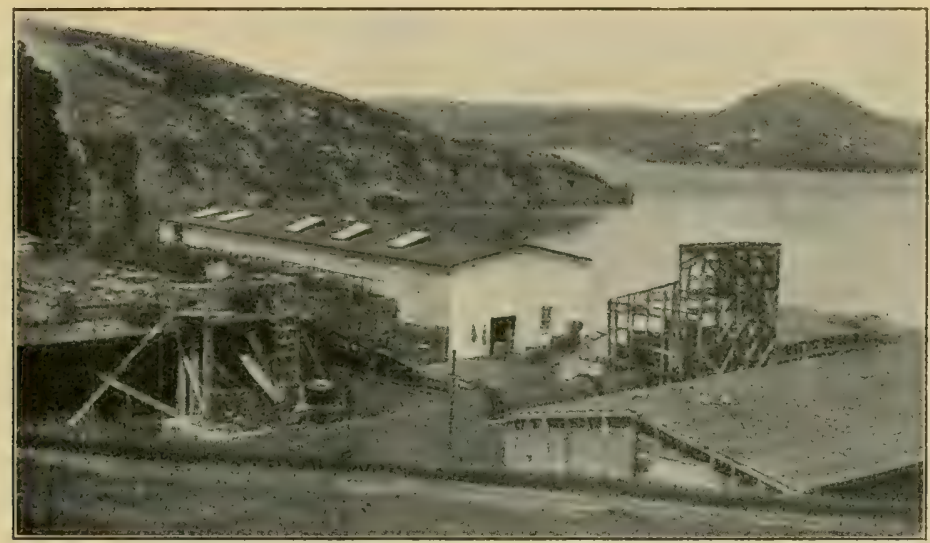

Abb. 39. Walfaktorei bei đrinith in Meufunsland. Im Dordergrunde die

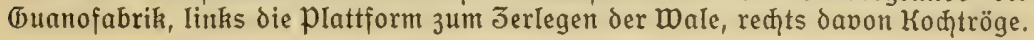
(Aufnahme des Derfaifers.)

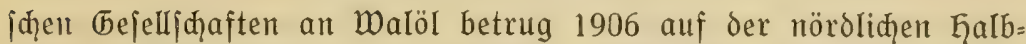
kugel $47200 \mathrm{fa} \hat{\beta}$, auf der jüdliţen $4200 \mathrm{fa} \dot{a}$, dagegen $1911 \mathrm{im}$ Torden 38000, im Süden 306000 faßj. An der Küjte von Tatal wurden in den Jahren 1908-1910 im ganzen 569 wale erlegt, fajt ausidgließlid Buckelwale. Was den wert eines einzelnen Wals betrifft, jo mag beifpielsweije angefüh̨rt jein, daßj der neuerdings wieder meḩrfach gefangene jeḩr mertwolle Tordkaper auf 6000 bis 11000 Mark gejųäbt wird.

Wie man fieḩt, ḩat die nunmeḩr ein Iaḩrtaujend Iang fortgejeģte Jagd auf die groß̉en Wale einen tiefen, verderbliḑen Einfluß auf ihre Gäufigkeit und Derbreitung gehabt. Wir kenten zwar keinen

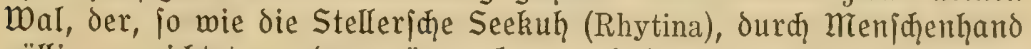
völlig verniđgtet worden wäre, aber zwei Arten find jeḩr jelten ge= worden und andere bedeutend an baḩ perringert. Die neue fidhere und gefährliḑe Waffe, welḑe nunmeḩr jeit ein paar Jaḩrzeḩnten, 
Into das in inmer größeren Lunfantuc, jux Verniḑtung ber Wale an= gewendet mird, bejhlleunigt den Gang des Derderbens fïr dieje praḑt= vollen Riejen der $D_{3}$ eane. Db es zu einem vollitändigen Untergang cinzelner oder aller Arten kommen wird, ijt fḑwer zu jagen. Einer der bejten Kemer der Derhältniffe, der Korweger Prof. (5uldberg,

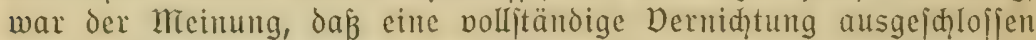
fei, da jid, wenn die jagobaren Wale allzujelten geworden find, dex fang niḑt mehr Iohnen würde. In der Tat trifft das ja für die (blatt= wale zu. Es find neuerdings Konferenzen abgehalten worden, um cinen Sduty der Wale in die Wege zu leiten, die praktijąen Stzwierig= keiten diejes jo notmendigen Unternehmens jüb aber natürlich außzer= ordentlid grope.

Eine ebenjo grope Bedeutung, wie der fang der Wale, hat für die ganze "Meerwirtjhaft" der feefahrenden Dölker der fang oer Rob= ben gehabt und hat fie nod heute. Er verbindet fich im europäijąen Eismeer jeit alter Jeit zum teil mit dem Walfang, wird aber vor= wiegeno von eigens dazu ausgerüfteten Sdiffen ausgefüḩrt. Aud? dieje Jagojahrten haben teilmeife die Tiere an den Rand des Der= derbens gebraḑt. Der See=Elefant der Wejtküjte von Amerika ijt jo

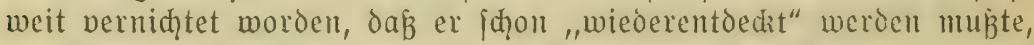
die Walroffe find im europäif̧̧en Fismeer nur nod in unzugäng= liḑeren Teilen zu finden, die wertwollen Pelzrobben des Beringmeeres

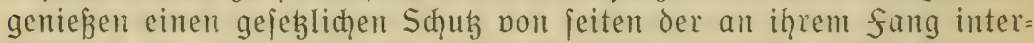
effierten Regierungen, meil fie fonjt bald zugrunde gehen würden. Andere Robbenarten finden fid nod immer in grobin inaffan, und obwoh̨l int nöroliḑen Eismeer alljährliđ fạt eine halbe miílion getötet wird, läbt fiфh dod eine Abrahme nidht bemerken.

Wie iđ fđ̧on früher ermähnte, ijt die Sattelrobbe, dar grönländijd]e Seehund, der hauptgegenjtand des Fismeerfangs, daneben aud die Klappmüge und die übrigen Arten. Die Sdifife der Robbenihläger juchen int eriten früḩling die pläze auf, wo die Sattelrobben iḩre Jungen abjegen, wie das $F_{i s}$ in der Umgegend von Jan Mạnen, das Weike Meer und an der amerikanijhen Seite die kiüte von Eabrador, um die Jungen im weißjen Pelz zu erjd̨lagen. Diejer in glüdalid̨en fällen äuß̧erjt ertragreid̨e fang braḑ̧te 3. B. im Jahre 1910 über 350000 junge Seehunde von Eabrador nad Keufundand. Die Robbenfhläger töten die Tiere ourch einen S丸llag auf den Kopf, jiehen iḩnen an Ort und Stelle das fell $a b$ und jajaben ipäter an Bord des Schiffes oder daheim das fett vom fell. Später, in dell Sommer= monaten, wird die Jagd mit der Büdge im ganzen Eismeer ausgeführt. Beide Jagoweifen liönnen jehr verjdiedenen Erfolg haben, je nađ̧dem ob die Shiffe auf großze Robbenherden treffen oder nidht. Bei den groben Wanderungen, welḑe die Robben ausführen, werden niḑt immer diejelben Wege eingehalten, und die Eisverhältnifje ändern fidh von Jaḩr zu Jaḩr. Jumeilen findet man in foript reidhen Gebieten mur ganz vercinzelte Tiere. Nit der Robbenjagd verbindet jia dic 
Jago anf Eisbären und Walroffe. Die Bären merden anf dent Eife oder im Wajfer jiemlid, mühelos geidjofjen, ihre Jungen oft lebend

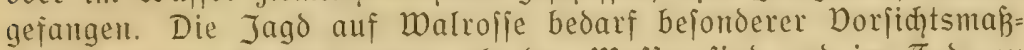
regeln, oa die Tiere jhwerer als das Waffer find und im Tode zu jinken pflegen. Kann man fie niḑ̨t auf dent Eije duth cinen Sḑuß̧ töten, fo berfolgt man fie in bejonders eingeriḑteten Booten mit cinem

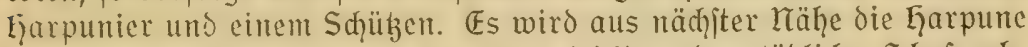

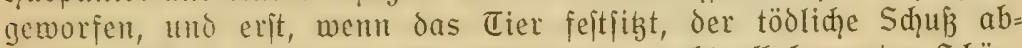
gegeben Dieie Jago ijt nicht jelten bon praḑtooll bemegter Sḑön= heit. Di: Derfolgung der taudhenden Walrofje in der fonnenjtrahlen=

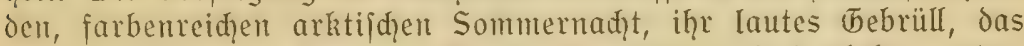
die tiefe Stifle der See= und Gletidherlandjđ̧aft fajt furḑtbar unter= brid̨t, der itarke, gewandte Garpunenmurf des fangmants, der Kampf des getroffenen Tieres mit dem mähtig bewegter Boote, dem es oft mit orohend exhobenen hauern entgegeniḑwimmt, der fd̨wierige Sdup, der das mädntige एier zur Ruhe bringt - das alles zujammen= mirkend bringt Eindrüdie hervor, die zu den großzartigiten gehören,

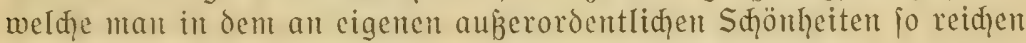
Eismeer empfängt.

(Б) Bärenrobben, der "Sealfkin"=Robben auf den pribn̨loff= und Kont= modorski=Injeln. In habe die eigentümlinge Eebensweife diejer Tiere mit ihren groken Sommernerfammlungen auf den Injeln jut fort= pflanzungszeit oben gejdildert. Die Jagd ijt ganz diefen Eebensver= häItniffen angepaßzt. Wenn die eriten alten Mämndhen, die Kundjđafter, sut den felskïjten der InjeIn erjđeinen, zichen jiđ die Bewohner zu

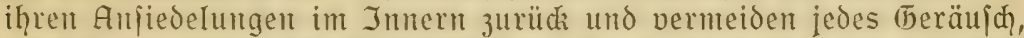
un sie heranziehenden Robben niḑt zu itören. Sogar die feuer löihen jic aus, uni nidht am aufiteigenden Rauक bemerkt 3 w werden. So kummen allmählid die Sḑaren der Seebären ans Eand, wäḩlen iḩre plähe und verfammeln die weibđen um fid, die bald darauf iḩre Jungen gebären. Indeffen juḑen die "Junggejellen" abjeits gelegene …hepläge auf, wo ie in groken Sdiaren den Sommer verbringen. Diç: : "ngen Männđen find allein Gegenitand der Jagd. Die aleuti=

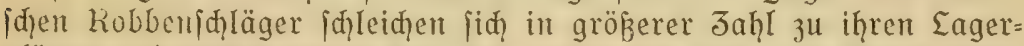

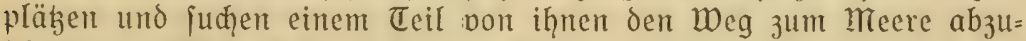
jąneiden. Dieje Robben treiben fie dann langlam ins Innere der Injel hinein. Alle paar Mimuten maden fie eine paule, um den Tieren Erholung zu gönmen. Endrid rommen fie auf dieje Weije in ein $a b=$ gelegentes đal, mo fie über die Robben herfallen und fie erfịlagen.

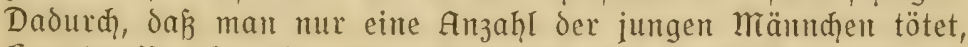
die Gauntmafle aber, die alten Männdien mit ihren Weibnen, un= geitört läßjt, ift die Dauer diejer wertwollen Seebärenjagd cinigermaß̧en gefichert. Wenn iłgr Ertrag, wie der Bejtand an diejen Sealikinrobben iiberhaupt, dentod feit cinter Reiḩen von Jahren ftark jurüds= gegangen ift, fo liegt das daran, daß̉ diejelben Robbenherden aud 
nod in einer anderen Weije verfolgt merden, die Keine Rüdsjid̨t auf trähţtige Weibhen und jaugende Junge nimmt. Es ijt das der $0=$ genannte "pelagifdie" fang, ber bon Sdyonern aus im offenen Meere hetrieben wird. Die Sḑiffe, weld̨e pon den periḑiedenen dem Berings= meer nahe wohnenden Tationen ausgerüitet werden, perfolgen die zichenden Robbeniḑaren und die Bejałung jđieß̧t die एiere waḩllos in großzer zaḩl. Diele finken unter und gehen verloren. Am gefäḩr= lichjten für den Bejtand der Robbenherden war dieje pelagijųe Jagd in unntittelbarer nähe der InjeIn, weil iḩr dort aud die jäugenden Weibdien zum Opfer fielen und infolgedeffen die Jungen am Eande perhungerten. Man hat im Jahn 1905 auf den pribnloff =Injeln 30000 verhungerte Junge gezählt. Die betei'igten Regierungen, die ameri=

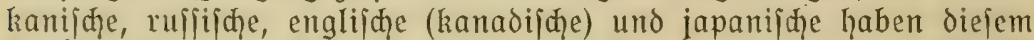
Treiben mit allen Mitteln entgegenzuwirken gejudt, teils durd $\mathrm{Ab}=$ maḑungen auf internationalen Konferenzen, teils mit den härtejten (bewaltmakregeln, aber exit in der neuejten zeit ideinen diefe $\mathrm{Be}=$ müḩungen Erfolg 3u veriprechen. Im Jaḩre 1911 ift ein neuer Der= trag auf 15 Jahre gejhloffen worden. Aus diejem geht u. a. hervor, daß̧ man auf eine jährliche Ausbeute von wenigitens 100000 fellen auf amterikanifher und 18000 auf ruffifher Seite redinet.

Auber den genannten beiden Injelgruppen liefert nod die japanijąe "Robbeninjel" im Süden von Kamtjąatka, jomie ver: jđiedene Infeln an den jüdamerikanifhen Küjten und einige InjeIn

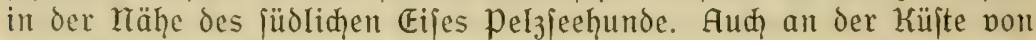
Deutjh:Sübmejtafrika werden welche gefangen. Dieje alle find jedod? bon geringerent Wert als die der pribnloff = und Kommodorski=Infeln.

Der nördiche Stille (Dzean ift bekanntliक aud die Geimat des Sccotters. Früher gab es dieje diere non Kalifornien bis Japan in groken Maffen, aber die unaufhörliđ̧en Derfolgungen, durch die gewaltigen preisiteigerungen der felle nur noळ mehr gefördert, haben dic Seeottern immer jeltener und jeltener merden lajien. Geute werden die wenigen, welḑe bei Kamtiḑatka nod leben, von der ruffifकृen Regierung durd, Jagdverbote geiḑübt; aud auf der Berings= infel jteht die Jago unter Auffiḑt der Regierung. Die meipten der etwa 300-400 Stück, melđ̧e jährlich in den Gandel kommen, ftammen von Alaska und den Aleuten. An den Küjten von Dancouper im Diten und クeffo im wejten werden kaum nod welḑe angetroffen. früher gingen die felle diejer Tiere, die von den Thinejen "Seedrachen" ge=

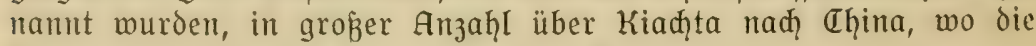
Mandarinen pelzjacken aus Seeotterfell trugen.

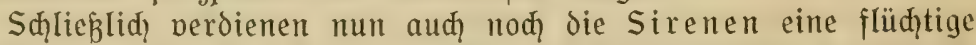

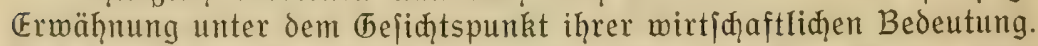
Daß̉ die Stellerj̧e Seekuh (Rhytina) einmal, wenn auch nur etwa 40 Jaḩre lang, eifrig und bis zu iḩrer völligen Derniđ̧tung gejagt

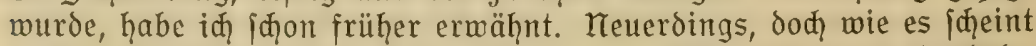
auch nux vorïbergehend, hat der Dugong in Aujtralien einen Ģandels= 
wert bekommen. Eine (bejellidhaft in QueensIand unternaḩm es, die Tiere aı den aujtralijøen küjten zu erlegen, die Ђäute zu Eeder zu verarbeiten, das fett 3 uermerten und das mohlidimediende fleijh zu Konjervieren. Die Erträge des Unternehmens follen aber in den legten Jaḩren jeḩr zurüdrgegangen jein. Don den Eingeborenen der malaiifकृen und melanefijd̨en Injeln wird feit alter Jeit der Dugong teils mit regen, teils mit ḩarpunen erlegt und jein fleijd gegejien. An der Torresitraß̧e liefert auß̉er den Sđ̧ildzröten der Dugong die

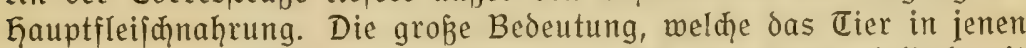

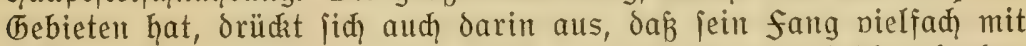
jeltjamen zeremonien umgeben wird, und daß̧ fid allerlei Aberglauben und Mnthen mit ingm verbinden.

man fieht aus dem, was hier zujammengejtellt wurde, das fajt alle

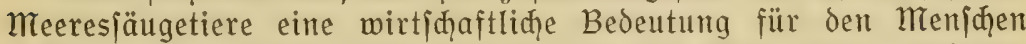
haben, und es würde leid,t mögliđ fein, mit hilfe einiger weiterer

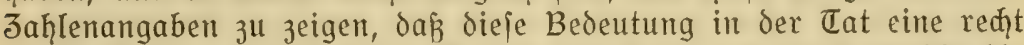
groß̉e iit. Im ganzen habe iđh nur von fang und Jagd, weldhe die Kulturvölker ausgeübt ḩaben oder ausüben, geiproḑen. Es mag aber hier nod eines nadigetragen merden, als ein Beipiel der engiten und vielieitigiten Beziehungen zwijhen Menid und Meeresjäugetieren, nämliă das Derhältnis der Eskimos zu den Seeḩunden. Es ift ja

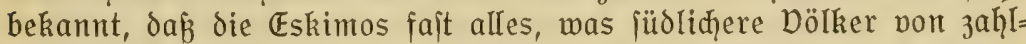
reidien Tieren und pflanzen entnehmen, fajt alles, was jie zur Lahrung, KTeidung, Wohnung, was fie an Werkzeugen und zur Jaad gebrauhen, von den Seehunden des Eismeers geminnen. Das fleifh bildet į̧re haupţäđ̆liđ̧e Kahrung, aus Blut und Teilen der Fingeweide ver= jtehell jie eine jđmadihafte Suppe zu bereiten, das fett wird zur $\mathbb{E r}=$ nährung, Beleuḑtung, feuerung und anderen 3medien gebrauḑt, die Knođen zu allerlei Gerätiđaften, die Sehnen dienen als fäden, die felle finden ihre wiḑtigite Dermendung zur Kleidung, zum 3eltbau und zun Bau der Boote, der jogenannten Kajaks. Das leiḑte fellboot dient vor allem der Jago auf die Seehunde. Der Eskimo nähert fid darin, durd ein meines ausqeipanntes uㅐ den Eindrudi eines [dwim= menden Eisblodss portäuihend, der Robbe lautlos und mit kaum merklidher Bemequng. (helingt es ihm, nahe heranzurommen, jo jđ̧ieß̧t er und mirft, iळnell herbeirudernd, gleidh danad die Garpune. Am Ende der Garpunenleine, die aus dem fell einer Bartrobbe geidnitten ijt, befindet iid eine BIaje aus Seehundsfell, meldye das Unteriinken der Robbe verhindert und, wenn fie nod lebt, anzeigt, wohin jie ¡đwimmt. Kommt fie wieder hervor, fo wirft der Eskimto die Eanze naḑ ihr, die fie vermundet, aber, da jie keine Widerḩadren hat, aus dem Körper wieder herausgleitet und fhwimmen bleibt. Durh jolđhe

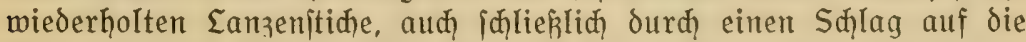
Naje wird das Tier getötet und dann mit einer Blaje verbunden an

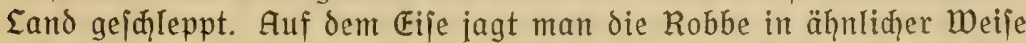
mit Filfe eines Sdilittens ftatt der Kajaks. - Die Bedeutung der Sec 


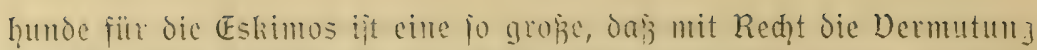
ausgejprodgen worden ift, des Dolli wüde zugrunde gehan, wam c's reine Sechunoc mehr fäıde. Einen der merkmürdigiten Ausorïdie hat

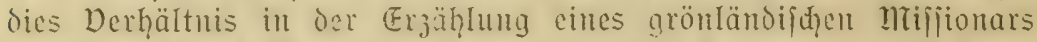
gefunden. Diejer Menm iprad den heionifden Eskimoz von der herr= Iidhleit oes finmuls. Sie hörten ihm zu, aber als er fọmieg fragten fie logleidh: "(bibt es Seehund: im Limmel?" "lein," jagte der miffionar. Da hatte der Fimmel feinen Reiz für die Eskimos verloren.

fang uno Jagd der Secpängetiere find jehr alt, abse dic kenntnis non biefen Ticren blicb im allgencinen auf dic Küftenbevölkerung und auf ungebildete Meirihen befhräulit. Die Erträge der Jagden wan= berten jeit der älteiten zeit ourd? alle Dölker, aber man wuß̉te in vielen fällen gar niḑt, moher dieje Stoffe eigentlid kamen und wie fie gemonnen murden. So murde über die langen Stoßzähne der larmale, denen man einé munderbare Geillraft zufdrieb, viel merk= mürdiges öug gefabelt. Sie follten von dem jagenhaften afrikanifhen Einhorn itammen. Uno als man ipäter in Erfahrung gebraḑt hatte, dak fie cinem. "fifd" angehörten, bildete ein gelehrter Sdhriftiteller dicien fifd? mit cinem mie das forn eines hashoms aufredititehenden Stohzahn ab. Es murde ja gewib viel fabelhaftes den Dingen, malḑe die Secfahcer nad) Gauje braḑten, wois ihn felbjt mit auf den Mia gegeben Dieles, mas fie nur flï ḩtig gefeh:n hatten, verband fid in ihrer phantajie mit abergläubijden Doritellungen. So entitanden jente zah̆lreiden Sagen und märdien, in denen Meeresfäugetiere eine munderlid phantajtifąe Rolle fpielen und die wieder das Material

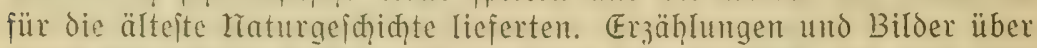
diejen (begenitand wirken auf uns ḩeute jehr ergögliđ. Sie jind aber

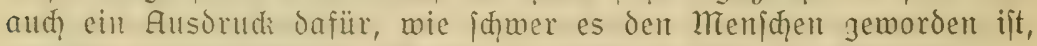
von den Säugetieren des Miecres ein riđ̧tiges Bild zu gewinnen.

Wesu dic alten KuIturvölker am mittelmeer, zumal die mit dent neere jo nahe vertrauten (briechen, von wunderbaren Seegeid̨öpfen

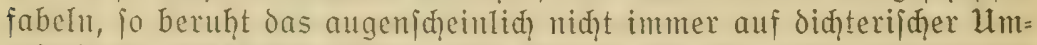
geitaltung wirkliḑer Tiere. Fin Wefen mie der ewig mandelbare proteus, der in der Mittagsitille von Robbenidaren umIagert it

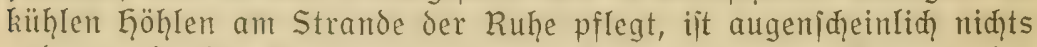
anderes als cine Dermeniḑlichung einer Eigeniḑaft des Meeres, eine reine Erdid̨uturg der Mnthologie. Danteben glaubt man, daß̧ Sagen vou niecrmenjhen aus dem Diten, in Legter Einte von den indifhen Küiten her in dic (beijteswelt des (5rieđhentums eingedrungen feien. Die Dugongs des Indifhen (1)zeans haben oft, niđjt mur in jener alten 3eit, megen der

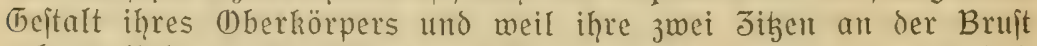
gelegen find, zux Doritellung von Neermännern, Seejungfrauen u. ogl. gefïhrt. Andere (bejđöpfe des neeres mögen auf die aud im Mittel=

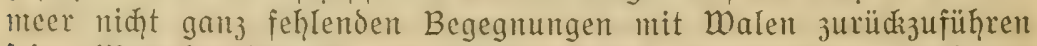
peir. Uan hat dies für die Andromedajage angenommen. Aud zur 
Sḑöpfung des Eeviathans der Bibel fheinen - wenigitens jum Teil Wale das Material geliefert zu haben. Ob in der Jonasjage mit dem groken fifd wirklich ein walfif gemeint mar, ijt angezmeifelt morden.

Am meiften ungaben natïrlid die (briedpen mit Sagen und aber= gläubijdzen Doritellungen die Säugetiere, welḑe ihnen aus eigener Anjhauung mohlbekannt waren, die Delphine und dic damals in den Gewäifern des Ägäijhen meeres nod zahlreiḑen Mönḑsrobben. In den Mnthen von poleidon als dem (5otte des Meeres und Apollon als dem Gotte der Sonne kommen die Seehunde öfter zur Erwäh= mung, als Begleiter des proteus merden ite im vierten Gejange d:

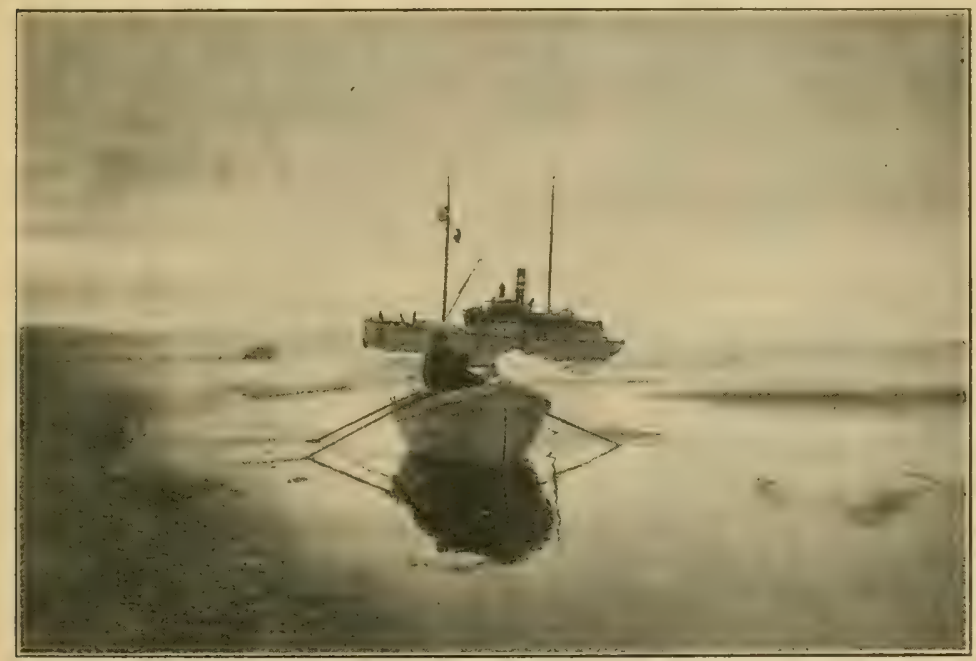

Ab6.40. Korwegifđ̧er Dampfer für den Döglingsfang. (Aufnaḩme des Derfaffers.)

(1) dnffee anjळ̧aulid vorgeführt. Manđ̧erlei geheimnisvolle Kräfte wurden ifnen zugejhrieben, bon der Keilkraft gegen das podagra bis zum Shube gegen den Blibidilag. Eine Suge von phokios, dem See= hundsmanne, wird als did̨terijd ausgebildete Erinnerung an Robben:

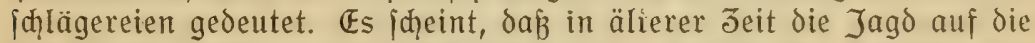

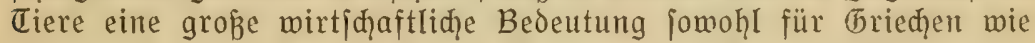
phönizier hatte, und dẩ der Reiđhtum an Robben in manthen (begenden ein jeḩr beträḑttiḑer war. So mag es 3. B. bei der alten äolif̧̧en Stadt phokaia (o. h. Robbenjtadt) gemejen jein, non dec man eine Münze mit dem Bilde einer Robbe kentrt.

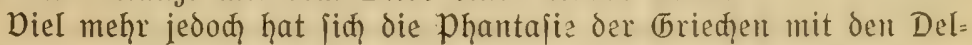

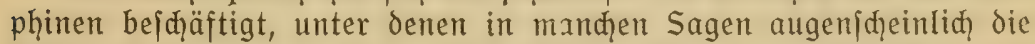
Tümmler (Tursiops) mitzuveritehen find. Die ganze Keiterkeit des Südens mit allem was am meere freundidy und wohltuend für den 
Menjđen ift, dic ganze liđ̨tduidjitrömte Sḑönheit des Mittelmeers fand für das griechijhe Auge und den griedijį̧en Diđ̧tergeift iḩren

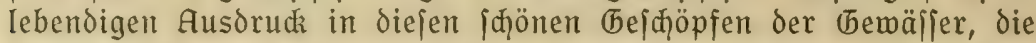
(brieḑenland und die griechijhe Injelmelt umfluten. freundid, und glüdiverheikend waren die Delphine den Seefaḩrern, wenn fie in lebhaft jagenden, ipielenden, ipringenden Sḩaren das Schiff be= gleiteter. freundid aud den fijhern, denen jie bei der arbeit hilf= reiđ waren, indem fie ihnen meeräphen in die Kege trieben. Sie wurden den Ertrinkenden zu Rettern, den Derfolgten zu Befreiern. Die Sage non dem Knaben, den ein Delpḩin auf jeinem Rüdken reitend über das Meer trägt, wurde oft und in vielfach veriḑiedener form wiederholt. Sie fand ihren bödiften und bekanntejten Gusdrud in der (befđiḑte des göttliḑen Sängers Arion, der, pon Seeräubern ins Meer geitürzt, von einem Delphin fiḑer ans Ufer getragen wurde. Dabei fpiclte die Eiebe der Delphine zur Mujik bedeutjam mit in die Sage hinein. Dft ift der auf dem Delphin reitende Knabe Eros, wie denn überhaupt im Kreife der Sagen um die aus dem Meere er= itandene Aphrodite Delphine immer wiederkehren. Sie begleiten die auf einer jhmimmenden Muideliçale ruhende Göttin. Sie werden zu cinem Snmbol der Eiebe. Sie kehren überall in der bildiąen Dar= itellung wieder, bejonders auf (6rabmälern, wo jie das in eine Muiḑel= idgale eingelaffene Bilonis einer geliebten frau einrahmen, oder überhaupt als freundliḑe (beleiter, welḑe die Deritorbenen jur Unter= melt führen, aufzufafien find. Don diejem reiđhen Sagenkreis, der das idïne đier umgibt, ift vieles aud hinübergenommen in die shriftliḑe Eegende. Auf den đrifitliden (brabmälern der Katakomben finden fid nod dic Delphinbilder mieder. In Daritellungen, welø̨e iid auf die Seefaḩt beziehen, Kommen naturgemäß ebenfalls Delphine überall vor. ferner findet man jie an Rennbahnen und Jirkusbauten, wo fie als Simbild der Schnelligkeit neben dem Bilde des Adlers angebrah̨t waren.

Don den kindiḑ̧en Sagen, melḑe die Südjeeinfulaner nom Dugong erzäḩlen, bis zu dem reiḑen und präç̧tigen muthengemande, mit dem die (⿹)riedien den Delphin umgeben haben, ift ein weiter Weg. Was alles zwijhien diejen Enopunkten liegt, muß hier im mejentlichen über=

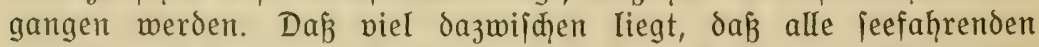
und Seejagd treibenden Dölker aud in ihrer meife die Seefäugetiere iłrent geiftigen Eigentume eingefügt haben, verjteht fid von jelbit. Und es ijt begreiflid, daß̧ die Figenart eines jeden Dolkes, now mehr die Eigenart der Meere, welde es befuhr, darin jeinen Ausdrud findet.

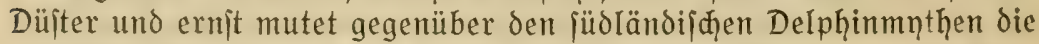
nordifh] Sage an. Sturm, rebel und finiternis jheinen im Minthen= gewebe der Kordländer als unholde weien lebendig geworden zu fein, in benen man Wale und Robben meḩr oder weniger deutlid wieder= erkennt. Alle feindliđen (bewalten des Meeres wurden hier zu böjen Tieren, die den Menjđgen hajfen und ihn zu verderben juçen. Tod? 
heute klingt das alles in den Märḑen der Eofotenfifđ̧er naḑ, mit denen fie die lange winternaḑt zu hauje am ftillen Ferde jigend verkürzen.

Einigermaken peinliđ, wenn man es nidht lähherliđ finden will, wirken diejer jđ̈̈nen welt der Märḑen gegenüber die mittelalter= liḑen Darjtellungen von Meeresfäugetieren, welđhe fid als Wiffen. jđaft gebärden. Wir jehen die großen Gelehrten, Albertus Magnus, Dlaus Magnus und wie jie weiter heiken, iḩre didzen folianten

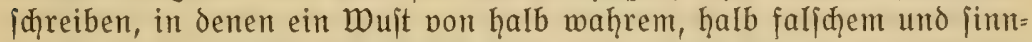
lojem Stoff zufammengetragen und mit einem kaum begreiflichen Grade von Kritiklojer Willkür toll phantaitifh ilfujtriert wird. Die Bilder in diejen Bühern find augenjheinliđ oft nad dem bloken Namen des Tieres erfunden. Das Seepferd hat einen pferdekopf und cinen fijd; đ̧wanz, der Seehund und der Seebär jind nad demielben plane gebaut, dazwilhen ipuken die Seejungfrau und der Meermann, und als eine der ergöglidgiten Ericheinungen der Meermönd mit Tonfur und Kutte. Ungeheuerliḑe Walfifhfraben treten auf, an denen man vielfach ređt deutlid fehen kann, wie fiđ riđhtige Beobađłung mit plattem Unjinn innig verband. Der Tert entipriđ̧t den Bildern. Don der (bröße der Walfifice wird viel tolles zeug gefabelt. Fin englifher Walforjher Eritifierte cinmal das Derfahren diejer Dar=

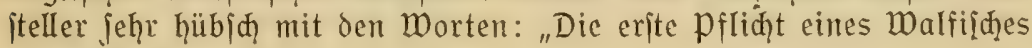
iit, großs zu jein."

Daßz der wiffenfđaftliḑen Erforfdung der Meeresfäugetiere in vieler Beziehung ganz bejonders groke Sḑwierigkeiten entgegen= ftehen und nod meḩr in früheren Jaḩrḩunderten entgegenjtanden, liegt auf der Gand. Bei den groken Walen ift das im hödiften (5rade der fall. Thre ungeheure Größze, die Unmögliđ̧̧eit, fie zu konjervieren, die Sdwierigkeit, aud nur Skelette zur genaueren Unterfuळ̧ung 3u gewinnen, find jø̨mere Ginderniffe für iḩr Studium, jelbjt heute nod, wo zur Unterjuđ̆ung der Tiere auf den Walfaktoreien perḩältnismäßig günjtige Bedingungen vorhanden find. Iod ihwieriger ift das Studium iḩrer Eebensmeije, denn jelbit, menn ein gejdiulter Katurforjher ben walfifhfänger begleitet, hat ex dod immer nur recht wenig belegen= heit, Beobaḑ̧tungen zu mađ̧en, weil die Jeit zwijđen dem Eripähen eines Wals und feiner Erlegung jehr kurz ijt, und weil überḩaupt auber den Sḑwimm= und Atembewegungen unter gewöhntid̨en Der= hältniffen niळht viel zu jehen ift. Unjere bejten Iaḑriḑten über die Eehansweife berdanken wir zum groken Teil den menigen Walfild = fängern von Beruf, melḑe Intereffe und fähigkeit zu wiffenjđ̧aft= liđ̧̧er Beobađ̧̧tung bejaß̧en.

Während die jađlid unvollkommenen, diđ̧terifd aber sigenartigen und zum Teil vortrefflichen Daritellungen von Meeresiäugetieren aus früherer Jeit ein hiiftorifines und pinḑologijd̨es Interefie für uns

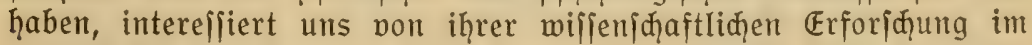
wejentliḑen nur das, was dabei herausgekommen ijt. Dieje Rejultate 
itt härze zufammenzufafen ift in oiejer Salrift verjuḑt ivorden. Dabei wurde das cigentlid biologijhe problem, die frage nad der wedhis = wirkung zwifhen dem Organismus und feiner Umgebung fo viel wie möglich zum! leitenden Бedanken genommen, denn diejer Jujammen= hang ift es ja, den jozujagen die ratur in diejen Cieren als an einem bejonders anjḑauliḑen Beifpiel fo ungemöhnlid deutlich zur Dar= ftellung gebrađt hat. frühere Dölker haben vor allem das Seltiame und Wunderbare an diefen neeresgefööpen gejehen und in ihrer Weife verarbeitet. Wir Menfden von heute jehen vielleiḑt meḩ Wumberbares an ihnen als irgendeine frïhate Jeit, aber mir jehen es auf eine ganz andere Weije, jehen es mit ganz neuten Augen an: Wir haber vor jeder Dergangenheit die hohe Befriedigung noraus, daß wir im Wunderbaren niđht mehr das Willkürliđge, fondern die allbeherriḑende Gejezmäß̈igkeit erkennen. 


\section{Iamen $=$ umd Sacbregifter.}

श1bertus Miagnus 91 .

Ulten 45, 63 .

$21 \mathrm{mbra} 16,77 \mathrm{f}$.

2inoromedajage 88.

UInpafiurt $23 \mathrm{fi}$.

Ulphrodite 90.

Arctocephalus nosinus 12,64 .

Irion 90.

Minmmetrie 43.

Wtempauien $52 \mathrm{f}$.

2(temitrabl 54.

?Itmung 40,52 f., 77.

2lugen $43 \hat{f}$.

?tujtralijder 3 wergmal 39.

Bärenrobbe $12,31,64,78$, 85.

Baifalrobbert 8 .

Balaena glacialis 14.

Baläenidae 14 . mysticetus 14

Balaenoptera borealis 15 .

, $\quad$ musculus 15.

Balaenopteridae 14. physalus 15

Barten $38,40,43,7 \overrightarrow{7}$.

Bartenwale $16,41,53,61,74$.

Bartrobbe $7,43,55$.

Basten 79

Bedett 29, 70.

Beffenrubimente 29.

Begattuntg 63.

Bebaarung 31.

Beine 27, 47.

şenthos $56 \mathrm{f}$.

Bewegungen $47 \%$

Bezabmung 69.

Biber 23.

Bijamratte 23.

bistayerwal $14,54,62,79$, 82.

DIajen 53.

23laslöd)er $33,41,54$.

Blaumal 15, 53 f., 82 .

bortentier 21.

Braunfild) $18,30,42,60,73$, 81.

Budelmal 15, 16, 28, 51, 53 ff., 82.

Calanus $61 \mathrm{f}$.

Caitor 23.

Cetacea 13.

Chamifio 50 .

Chironectes 23.

Clio borealis 62 .

Clione limacina $61 \mathrm{f}$.

copepoden 62 .
Crossopus 23 .

Cystophora cristata 6 .

Delphinapterus leucas 17.

Delphine $13,34,36,45,58$, $65,73,89 \mathrm{f}$.

Delphinoptis 73 .

Delphinus delphis 18.

Dermatochelys 76 .

Dosmant 23.

₹ögling $17,36,53,77,81$.

Drucf Des 213aliers $44,66$.

Dugong (Dujong) 19 f., 49, $52,57,70,78,86 \mathrm{f} ., 90$.

Einlourn 88.

Eisbär 21 f., 60.

(Ele fanteil 6?.

(clfenbein $7 \%$

(Fmbruonett $27,7.3 \mathrm{f}$.

Enhydra jutris 21.

Entchual 17, 36, 73, 81.

Eocetus 72.

Eojiren 70.

Eotheritim 70 .

Ernäbrung $35,56 \mathrm{ff}$.

Estiml 0s 78, 87 .

Euchinodelphis 73 .

Erforjd)ung ?1.

Tatin 79 ff.

Fanggebietc 8:3.

folle 31,78

Fett 49,77 .

Jiber 23.

Jinntmal 15, 54, 82.

Fiji)bcin 39, 77.

Jifidje 37, 58, 62.

Jijdjotter $23,67$.

sleifd) 78 .

Flofien 27 if. $47,7(), 75$

frlofientiüice 6 , fis.

J̆lübelphinte 57.

Julspferd 23.

Jortpflanzung 63 \%

Fonn (Eveno froin) 81.

Jurd)enwale $14,26,39 \mathrm{f} ., 5.5$ Jur= Ecais 64.

(5)angesdelphit 19.

(5ebi/3 37, 71 .

(5)emeiner Delphiu 18.

(bemeinter Eceljunto 4.

(5erud) 43.

(5eidiled)tsleben 63 .

(5) eidmat 43.

(5e) d) windoigteit 51 .

(5iraffe 3 ?

(5) Inttuale 14,54 .
Gliedmabert $26,47,70$.

Globiocephalus melas 17 .

(5raumal 15, 82 .

(5ried)en 88 .

(5rintwal 17, 28, 78, s1.

(5rönlänoijd)er Seehuno $6 \mathrm{f}$. $50,58,78,84$.

(5rönlantowal 14, 27, 39, 53 f., $62,66,79$.

(i) irteltiere 74 .

Guloberg 84 .

5raare $31,33$.

5ämเapophn fert $26,29,36$.

5aizalmuvale $71 \mathrm{f}$.

Halichoerus grypus 8.

Halicore dujung 19, 49 .

Halitherium 70 .

5)aiswirbel 25.

5)arpumen $80 \mathrm{ff}$.

5ัnater 38.

5out 31 .

Sinterbcinc 30.

5interglieomajen 29, 73.

Hippopotamus 23.

5iipferlinge 62.

Hyperoodon rostratus 17

Ichthyosaurus $75 \mathrm{f}$.

Jllex 57.

Jnnere Drgane 34 fi.

Taģo 13 f., 78,81 f.

3apanerwal 11, 80.

Joltasjage 89.

Rت̈แquruh 43.

Saspifd)er Eeehumb 8.

Raucil 36, 40.

Sienelrobbe 8.

Sivilifurdjen 40 .

Sicbltopf $41 \mathrm{f} ., 55$

Killer-Whale 60.

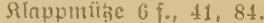

Sinod)en $49,78$.

Sitod)en[dilder $7 t$.

Sïrperform 25.

Sionvergcis 24,76 .

Sirabbenfreifer 10,37 .

Sirale1t 59.

Sirebje $37,61$.

sirill 62.

Lagenorhynchus acutus 18

Lcbensweife $45 \mathrm{ff}$.

Samantinc 19 f., $49,57,69$ f.

Yeier 78 .

LeDCridilotröte 70.

Leptonychotes wedideli 10. 
Qeviatbait 89.

Lobodon carcinophagus 10.

loode 62.

\&ummen 63.

\&ungett 40,66 .

Lutra 23.

Miaasedjen 75.

Macrochinus leonicus 11.

ख)ähnerrobbe 12.

y)är(f)en 88 .

Mlaget 40.

Mallotus villosus 58

Manatus $19,49,69$.

Meeräid)en 90.

刃ieerntänทter 91.

Meerntönd 91.

Mteeridumein 18

Megaptera boops 15 .

Mesoplodon 36

Metaxy therium 70 .

9)iild 63

Wittelalter 91 .

Mrönd)srobben 9, 89.

Monachus 9.

Monodon monoceros 17 .

Mosasaurus 75 .

Mu[đ)eln 58.

Mya 58.

Myogale 23.

Mystacoceti 16

Minthen 89.

9ahrung 56 if.

) Tal)rungsquellen 35,56 .

Jarwal $17,26,38,73,77,88$.

yrajenlöd)er 41 f., 54.

) letton 56,58 .

Neobalaena 39.

Neomeris 73 .

Ylorbifđer Delphin 18.

Ylorblaper $14,54,79 \mathrm{f}$.

Nothosaurus 75 .

Mubbare Stoffe 77.

Odontoceti 16.

Dle 77.

Ogmorhinus leptonyx 10.

Obrer 33,43

Obretrobben 12, 47, 55 .

Dlaus Magnus $y 1$.

Ommatophoca rossi 10.

Orca gladiator 17.

Drtsfinn 65.

Otaria jubata 12.

Otariidae 12

Dttern 68.

Dtteripikmaus 23.

Phoca barbata 7 . caspica 8.

Phocaena communis 18,73 .

Phoca foetida 7.

. groenlandica 6,64 .
Phoca sibirica 8.

;- vitulina 8 .

Phocidae 6,12 .

Phokaia 89.

Phokos 89.

Physeter macrocephalus 16,71 .

Pinguine $37,45,60$.

Pinnipedia 6,68 .

BIaniton 56, 60,62.

Platanista gangelica 19.

Plesiosaurus 75 .

Polaritint 58 .

Bolarmal 14.

Sotamogale 23.

Pettwal $16 \mathrm{f},, 26,32 \mathrm{f} ., 35$ $41,51,53,54,59,66,71 \mathrm{ff}$. , 77, $81 \mathrm{f}$.

Protocetus 72.

Protofiren 69.

Raubtiere $59 \mathrm{f}, 68,72 \mathrm{f}$.

Reptilien 45,75 .

Rhachianectes glaucus 15,82 .

Rhoda inermis 61 .

Rhytina stelleri $21,56,69,83,86$.

Ringeirobbe 7 .

Robben 6 ff., 67.

Robbenjago $5,78,84$.

Robbeniahre 58 .

Ro' ' Eeehuno $10,25,55$.

Rüdenfloije 30.

Rüifel $6,41$.

Sagen $88 \mathrm{ff}$.

Sattelrobbe $6,64,78,84$.

Saugen 63.

Saxicava 58

Scaldicetus 71 .

Sh)idewale 71.

Sđillofröten $45,76,87$.

Sđlund 43.

Schnauze 73.

Ednurrbart 43.

Echulen 60,65 .

Ex)wart3 26, 49, 51.

Ed)wanzfloife 30,49 .

Echwertwal 17, 60.

Edwimmen $49 \mathrm{ff}$.

Echimmbaut 27

Gealifin $12,47,78,85$.

Seebär $12,31,47,64,91$.

Seedrachen 86.

Gee=Elefant 11, 41, 48, 55 , $57,84$.

Geehunde 6 ff., 47 f., 52, 87 , $89,91$.

Seciungfrauen 88,91 .

Eeeleoparo $10,37,60$.

Eeelöwen $12,47$.

Scetúlhe 19,28 f., $52,56,67$, $69 \mathrm{f}$.

Geelenteben 65.

Geeotter $21,27,31,52,67,78$, 86.
Secpiers 91.

Geenögel 63.

Eeihwal 54, 82.

Ginnesleben 65.

Ginnesorgane 43.

Sirenen $19,26,37,55,65,68 f$. 86.

Sirenia 19.

Sotalia 57.

Epezififides (5ewid)t 32,34, 49

Epert $32,77$.

Epriglöळer 41, 54.

Equalooon 71.

Etelleriae Eeeful 20 [., 37. $56,69,83,86$.

Stelleridjer Geelöwe 55.

Etrmme 55.

Stobsähne $38,88$.

Eturmoogel 58, 63.

Sildwal 14, 53 f.; 82 :

Taîtempfinoungen 43 .

Iaudien 49,54

Iauditiefe 50

Thalassarctos maritimus 21 .

Tintenficice $58 \mathrm{f}$.

Irädtigteit 63.

Iran 77 .

Trichechidae 6, 12.

Trichechus rosmarus 7 .

Iümuler 19,89 .

Tursiops tursio 19,89 .

IIrmal 72 .

Bngelberge 63.

Worgejdidite $66 \mathrm{ff}$.

शBale 13,68

Walfattoreien $82 f$

Walfifduas 62.

Walfilidfang $78 \mathrm{ff}$

Walguano 78 .

Walrat $16,32,77$

Walro $37,12,38,43,55,57$. . $66,77,78,84 \mathrm{f}$.

Manderungent $50,62 f$.

Wajierorud 44,66 .

Majeriöd)er 47,53 .

Mafferipibmaus 23.

Mafierwiberitand 33

Meodelrobbe 10.

Weiper Geehuno $10,37,61$.

Weikmal 17, 25 f., 55, 58 , 73,81 .

3äbrte $35,71 \mathrm{f} ., 77$.

3ahnwale 16, 73 .

Заһ)rwed) fel 69.

Zalophus californianus 12 .

3euglodon 72 .

3iken 63.

3unge 40.

3 wergmal 15. 


\section{Brutpflege uno Elternfüriorge}

\section{Von Dr. R. Rojen}

Mit 46 Abbildungen. Brofhiert 1 mark, gebunden (1). 1.60

(für Mitglieder der D. 12. G. 75 Pfg., geb. M. 1.20

Das intereffante Gebiet der Brutpflege im Tierreich behandelt der lerfaffer in einer für den Caien fowohl als aud für den Sad)mann hö(hit ansiehenden form. Die Schift ift eine allerliebite Einfübrung in das zweifelsobne anfpredhendite Gebiet der Biologie. Text und reid)es Bildermaterial führen die doarakteriflifh f'en Beifpiele fo präzi:e vor Augen, daf̧ jedem Gebildeten dadurch die fähigkeit gegeben ift, andere nicht behandelte Tiere bei der Brutpflege mit Dutzen sur Bereid)erung der eigenen Fenntnis von der Biologie rid)tig beobadten 3 u können. Der foricher.

Theod. Thomas Verlag, Leipzig, Königitr. 3

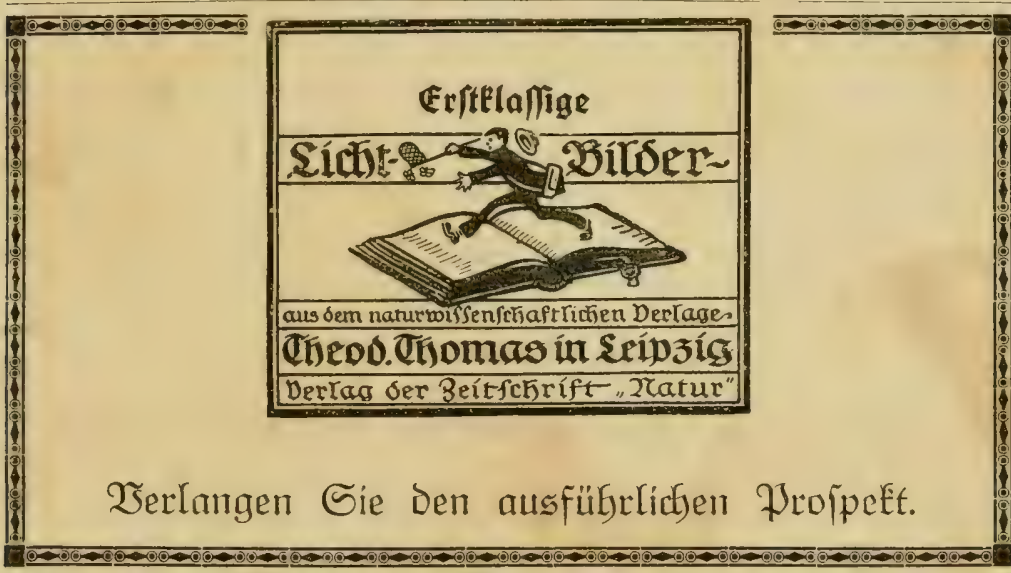

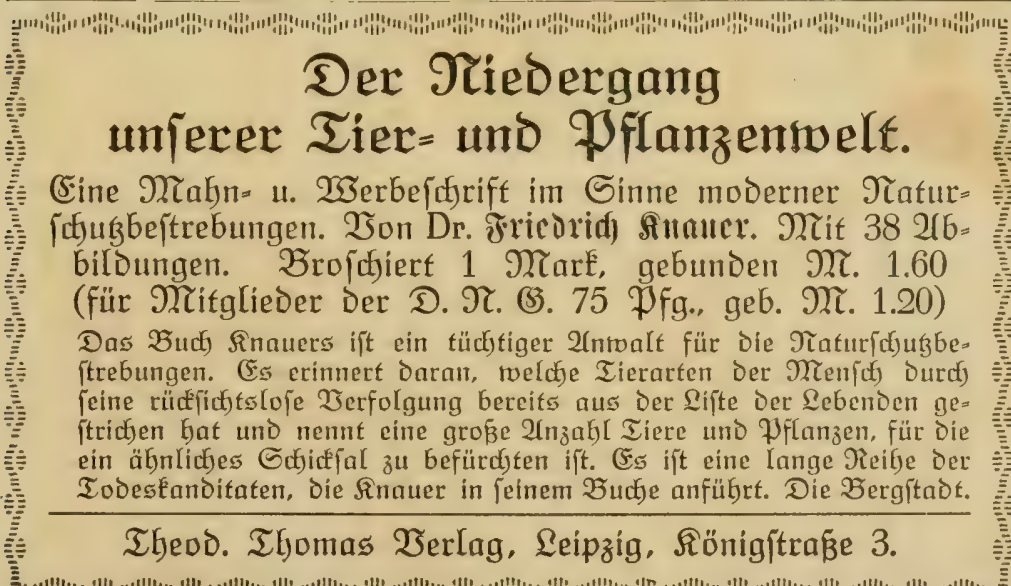




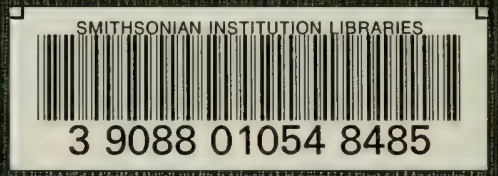





SMITHSONIAN INSTITUTION LIBRARIES

39088010548485 